Florida International University

FIU Digital Commons

FIU Electronic Theses and Dissertations

University Graduate School

$1-14-2010$

\title{
Development of Innovative Load Transfer Mechanism to Reduce Hurricane-Induced Failures in New and Existing Residential Construction
}

Sheikh Saad Ahmed

Florida International University, sahme005@fiu.edu

DOI: $10.25148 /$ etd.FI10041627

Follow this and additional works at: https://digitalcommons.fiu.edu/etd

Part of the Structural Engineering Commons

\section{Recommended Citation}

Ahmed, Sheikh Saad, "Development of Innovative Load Transfer Mechanism to Reduce Hurricane-Induced Failures in New and Existing Residential Construction" (2010). FIU Electronic Theses and Dissertations. 157.

https://digitalcommons.fiu.edu/etd/157 


\title{
FLORIDA INTERNATIONAL UNIVERSITY
}

Miami, Florida

\section{DEVELOPMENT OF INNOVATIVE LOAD TRANSFER MECHANISM TO REDUCE HURRICANE-INDUCED FAILURES IN NEW AND EXISTING RESIDENTIAL CONSTRUCTION}

\author{
A thesis submitted in partial fulfillment of the \\ requirements for the degree of \\ MASTER OF SCIENCE \\ in \\ CIVIL ENGINEERING
}

by

Sheikh Saad Ahmed

2010 
To: Dean Amir Mirmiran

College of Engineering and Computing

This thesis, written by Sheikh Saad Ahmed, and entitled Development of Innovative Load Transfer Mechanism to Reduce Hurricane-Induced Failures in New and Existing Residential Construction, having been approved in respect to style and intellectual content, is referred to you for judgment.

We have read this thesis and recommend that it be approved.

Amir Mirmiran

Nakin Suksawang

Girma Bitsuamluk

Arindam Gan Chowdhury, Major Professor

Date of Defense: January 14, 2010

The thesis of Sheikh Saad Ahmed is approved.

Dean Amir Mirmiran

College of Engineering and Computing

Interim Dean Kevin O'Shea

University Graduate School

Florida International University, 2010 


\section{DEDICATION}

I dedicate this thesis to my parents, grandparents and my uncle and aunt. 


\section{ACKNOWLEDGMENTS}

Firstly, I would like to express my gratitude to Dr. Chowdhury for his encouragement and guidance throughout my studies. Working under his supervision was truly a privilege and a source of inspiration for me.

I am grateful to my committee members Dr. Mirmiran, Dr. Suksawang and Dr. Bitsuamluk for their sincere support.

I would like to thank Ivan Canino, Cetin Canbek and Tuan-Chun Fu for their help in this study along with all students and personnel of Florida International University Structures and Construction Laboratory.

I would also like to take this opportunity to thank my parents, my grandmother and my uncle and aunt whose efforts and continuous support has helped me in achieving my goal. It is also important to mention my dearest friends, Mohammad Azhar Saleem, Faisal Alavi, and Mohammad Amjad for reminding me that goals are achieved through hard work and dedication.

Finally, I acknowledge my Lord who gave me strength when I was weak, who helped me and guided me in all these hard times. Thank you so much! 


\begin{abstract}
OF THE THESIS
DEVELOPMENT OF INNOVATIVE LOAD TRANSFER MECHANISM TO REDUCE

HURRICANE-INDUCED FAILURES IN NEW AND EXISTING RESIDENTIAL CONSTRUCTION

by
\end{abstract}

Sheikh Saad Ahmed

Florida International University, 2010

Miami, Florida

Professor Arindam Gan Chowdhury, Major Professor

Implicit in current design practice of minimum uplift capacity, is the assumption that the connection's capacity is proportional to the number of fasteners per connection joint. This assumption may overestimate the capacity of joints by a factor of two or more and maybe the cause of connection failures in extreme wind events. The current research serves to modify the current practice by proposing a realistic relationship between the number of fasteners and the capacity of the joint.

The research is also aimed at further development of non-intrusive continuous load path (CLP) connection system using Glass Fiber Reinforced Polymer (GFRP) and epoxy. Suitable designs were developed for stud to top plate and gable end connections and tests were performed to evaluate the ultimate load, creep and fatigue behavior. The objective was to determine the performance of the connections under simulated sustained hurricane conditions. The performance of the new connections was satisfactory. 


\section{TABLE OF CONTENTS}

CHAPTER

PAGE

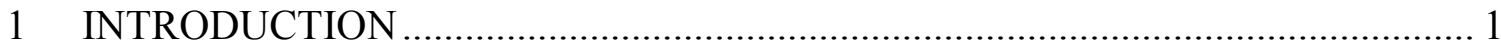

$1.1 \quad$ Hurricane damage to residential houses ........................................................ 1

1.2 Drawbacks of using metallic inter-component connections ................................. 4

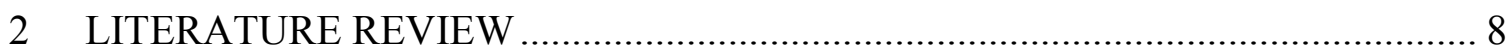

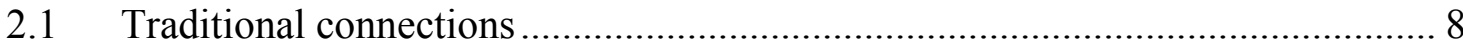

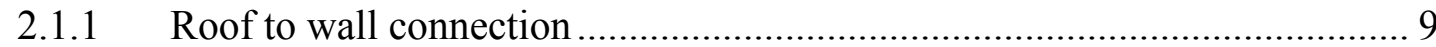

2.1.2 Top plate-to-stud connection ................................................................. 9

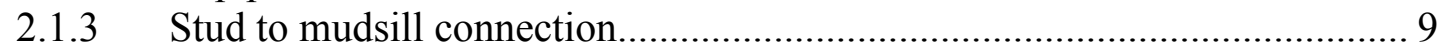

2.1.4 Gable end joist to double top plate connection .......................................... 9

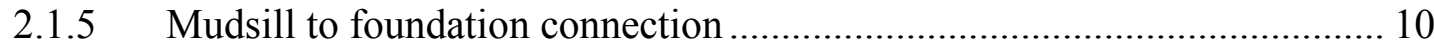

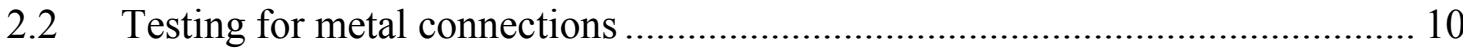

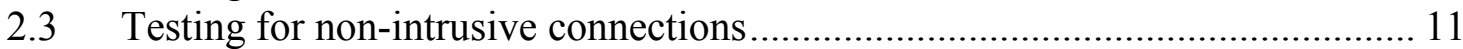

2.3.1 Material for non intrusive connection:...................................................... 11

2.3.2 Monotonic loading test ........................................................................ 13

2.3.3 Sustained loading test ....................................................................... 14

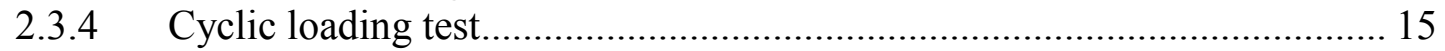

3 STUDY INTO THE CAPABILITY OF MULTIPLE MECHANICAL

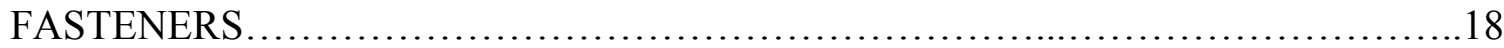

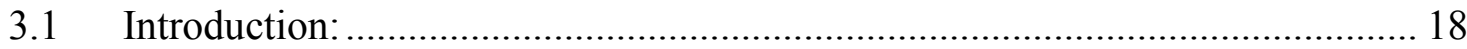

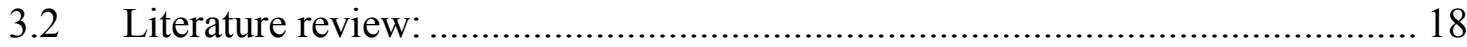

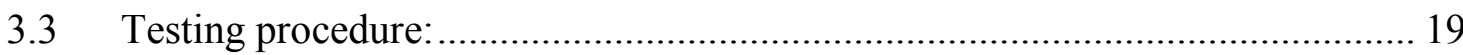

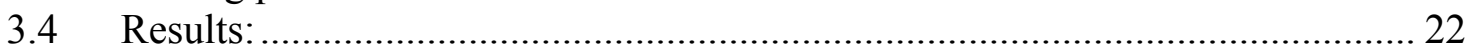

4 DEVELOPMENT OF NON-INTRUSIVE CONNECTION SYSTEM FOR

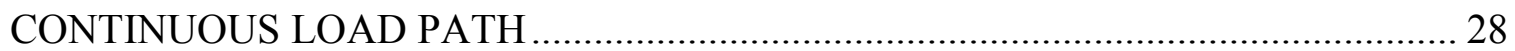

4.1 Development of non-intrusive ties for roof to wall connection: ........................ 28

4.2 Development of non-intrusive ties for stud to top plate and gable end

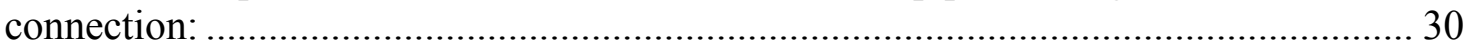

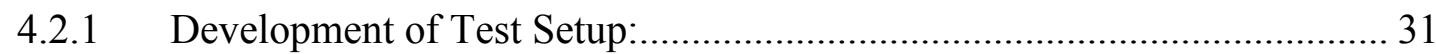

4.2.2 Development of FRP Ties:................................................................. 40

4.2.3 Feasibility of developed FRP ties: .......................................................... 52

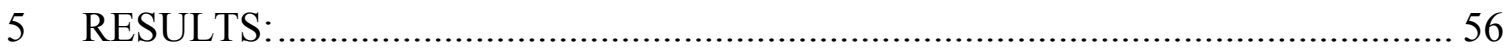

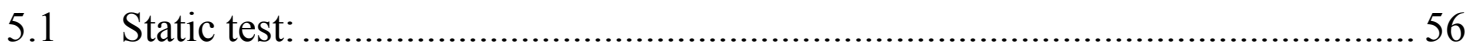

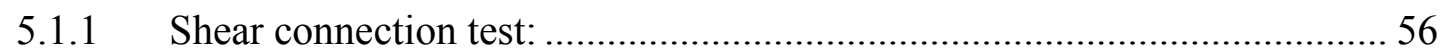

5.1.2 Stud to top plate connection.................................................................. 57

5.1.3 Gable end connection........................................................................... 58

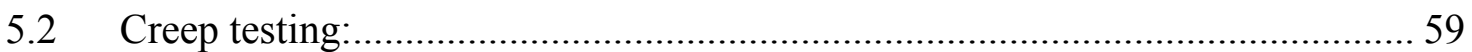

5.2.1 Creep results for stud to top plate and gable end connections ..................... 60 


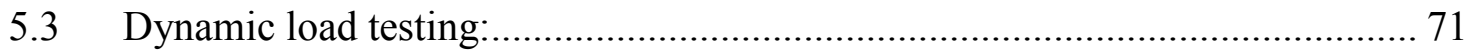

5.3.1 Dynamic loading results for Shear connection and Stud to top plate connection:

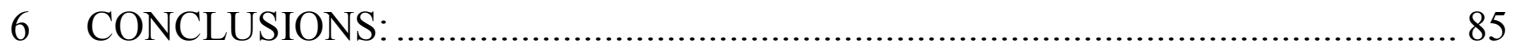

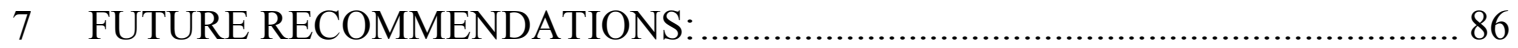

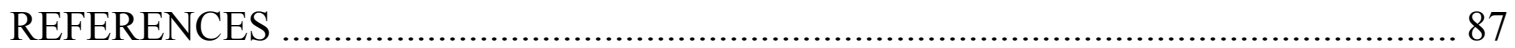




\section{LIST OF TABLES}

TABLES

PAGE

Table 1-1 Percent of damaged homes surveyed with damage levels greater than one-third (HUD, 1993) 3

Table 3-1 Testing Configuration for roof to wall connection...................................... 19

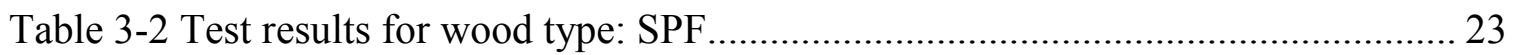

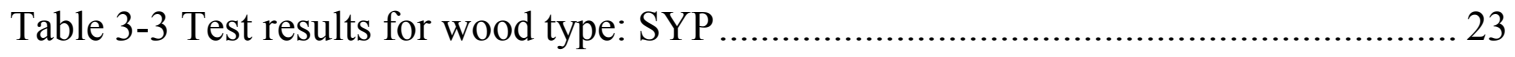

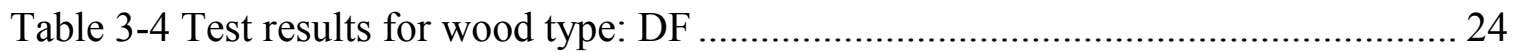

Table 3-5 Comparison of allowable load capacity per joint ...................................... 26

Table 3-6 Comparison of allowable load capacity per joint ........................................ 26

Table 3-7 Comparison of allowable load capacity per joint ........................................ 26

Table 3-8 Correction factor (Cnw) values for number of fasteners per joint and wood type

Table 4-1 Results for stud to top plate metallic connection.......................................... 35

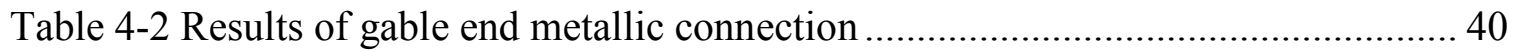

Table 4-3 Results of configuration 1-5 for stud to top plate connection ........................ 45

Table 4-4 Results of configuration 1-4 for gable end connection ............................... 51

Table 5-1 Results of shear connection test with static loading................................. 57

Table 5-2 Results of uplift load capacity of Stud to top plate connection .......................58

Table 5-3 Results of uplift load capacity of Gable end connection ............................... 59

Table 5-4 Creep analysis of 50\% ultimate load for Stud to top plate connection ........... 70

Table 5-5 Creep analysis of 75\% ultimate load for Stud to top plate connection ........... 70

Table 5-6 Creep analysis of $85 \%$ ultimate load for Stud to top plate connection ........... 70 
Table 5-7 Creep analysis of 50\% ultimate load for Gable end connection

Table 5-8 Creep analysis of 75\% ultimate load for Gable end connection ....... 71

Table 5-9 Creep analysis of 85\% ultimate load for Gable end connection 71 


\section{LIST OF FIGURES}

FIGURE

PAGE

Figure 1-1 Percentage dollar loss by type, 1986-1992 (Mehta, K.C., Douglas, A.S., and Ronald, H.C., 1994) ......................................................................................... 1

Figure 1-2 Comparison of coastal population densities with non coastal counties and

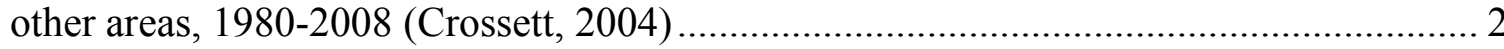

Figure 1-3 Shows the three failure modes of foundations (Simpson Strong Tie, 2006) .... 3

Figure 1-4 Failure of Hurricane clip connecting roof truss and wall with a corroded nails (Van de Lindt, 2005) ........................................................................................... 5

Figure 2-1 Traditional connection system (T-HFCG06, Simpson Strong Tie, 2006) ........ 8

Figure 2-2 Gable end wall connection (C-2008 Simpson Strong Tie, 2008) ................... 9

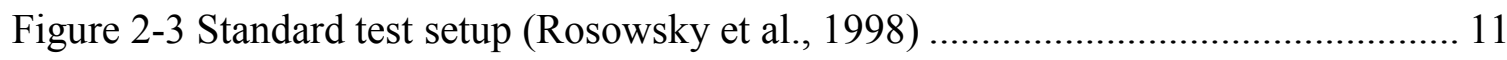

Figure 2-4 Specific material strengths (ratio of tension strength to density [m]) (Rene,

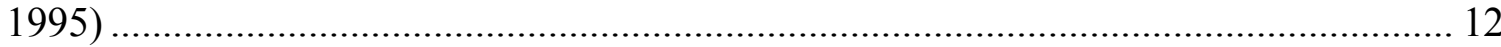

Figure 2-5 Experimental setup for creep test ........................................................ 15

Figure 2-6 Test specimens for Fatigue Testing........................................................ 17

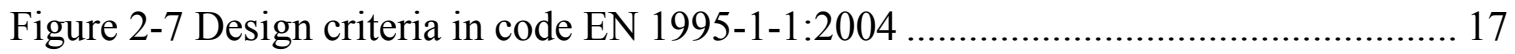

Figure 3-1 Test configurations for Spruce Pine Fir (SPF) and Southern Yellow Pine (SYP) wood types: (a) Single clip per joint, (b) Two clips per joint, (c) Four clips per joint.

Figure 3-2 Test configurations for Douglas Fir (DF) wood type: (a) Single clip per joint,

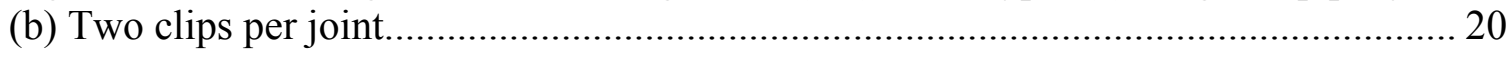

Figure 3-3 Universal Testing Machine with 22 kip capacity(Model Mark III, 22 EMF). 21

Figure 3-4 Experimental setup for testing clips using SPF and SYP wood types ........... 22

Figure 3-5 Experimental setup for testing clips using DF ....................................... 22 
Figure 3-6 Comparison of uplift load capacity per joint for current design approach vs. test results

Figure 4-1 Shear connection test (Canbek,2009) ……………..................................... 28

Figure 4-2 Test setup for the uplift capacity of roof to wall connection(Canbek,2009) .. 29

Figure 4-3 FRP Configuration with highest uplift load capacity for roof to wall

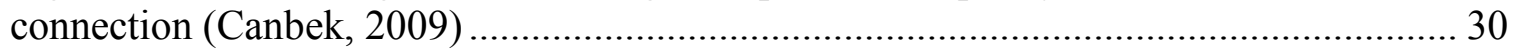

Figure 4-4 Test specimen for shear connection test......................................................... 31

Figure 4-5 Test setup for shear connection test ............................................................ 32

Figure 4-6 Test specimen for stud to top plate connection.............................................. 33

Figure 4-7 Test setup for stud to top plate connection..................................................... 34

Figure 4-8 Test specimen for gable end connection ..................................................... 36

Figure 4-9 Test setup for gable end connection........................................................... 38

Figure 4-10 Test setup for gable end connection........................................................... 39

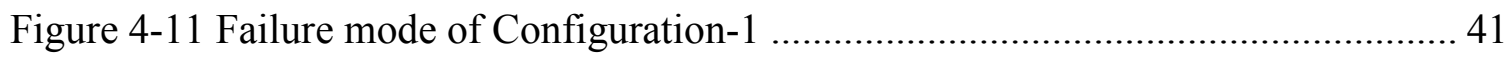

Figure 4-12 Failure mode of configuration-2 ……………....................................... 42

Figure 4-13 Failure mode of configuration-4 …………................................................. 43

Figure 4-14 Failure mode of configuration-5 ……………......................................... 44

Figure 4-15 Failure mode of configuration-2 (with nails) ................................................ 46

Figure 4-16 Failure mode of configuration-1 ………………...................................... 47

Figure 4-17 Failure mode of configuration-2 …………............................................... 48

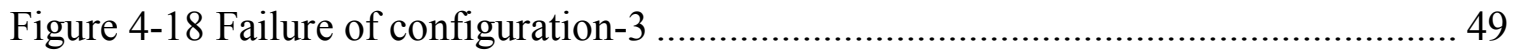

Figure 4-19 Failure mode of configuration-4 ………….......................................... 50

Figure 4-20 Load History for creep test........................................................................ 54

Figure 5-1 Failure mode of shear connection test....................................................... 56 
Figure 5-2 Mode of failure for stud to top plate connection

Figure 5-3 Failure mode of Gable end connection

Figure 5-4 Fractional deflection and Creep rate graph for 50\% stress ratio (Test-1) for Stud to top plate connection.

Figure 5-5 Fractional deflection and Creep rate graph for 50\% stress ratio (Test-2) for Stud to top plate connection. 61

Figure 5-6 Fractional deflection and Creep rate graph for 50\% stress ratio (Test-3) for Stud to top plate connection.

Figure 5-7 Fractional deflection and Creep rate graph for $75 \%$ stress ratio (Test-1) for Stud to top plate connection.

Figure 5-8 Fractional deflection and Creep rate graph for $75 \%$ stress ratio (Test-2) for Stud to top plate connection.

Figure 5-9 Fractional deflection and Creep rate graph for $75 \%$ stress ratio (Test-3) for Stud to top plate connection.

Figure 5-10 Fractional deflection and Creep rate graph for 85\% stress ratio (Test-1) for Stud to top plate connection.

Figure 5-11 Fractional deflection and Creep rate graph for $85 \%$ stress ratio (Test-2) for Stud to top plate connection.

Figure 5-12 Fractional deflection and Creep rate graph for $85 \%$ stress ratio (Test-3) for Stud to top plate connection.

Figure 5-13 Fractional deflection and Creep rate graph for 50\% stress ratio (Test-1) for Gable end connection.

Figure 5-14 Fractional deflection and Creep rate graph for 50\% stress ratio (Test-2) for Gable end connection.

Figure 5-15 Fractional deflection and Creep rate graph for 50\% stress ratio (Test-3) for Gable end connection

Figure 5-16 Fractional deflection and Creep rate graph for 75\% stress ratio (Test-1) for Gable end connection.

Figure 5-17 Fractional deflection and Creep rate graph for 75\% stress ratio (Test-2) for Gable end connection. 
Figure 5-18 Fractional deflection and Creep rate graph for $75 \%$ stress ratio (Test-3) for

Gable end connection.

Figure 5-19 Fractional deflection and Creep rate graph for 85\% stress ratio (Test-1) for Gable end connection.

Figure 5-20 Fractional deflection and Creep rate graph for $85 \%$ stress ratio (Test-2) for

Gable end connection.

Figure 5-21 Fractional deflection and Creep rate graph for $85 \%$ stress ratio (Test-3) for

Gable end connection.

Figure 5-22 Time history of Shear connection test (50\% Raw data).............................. 74

Figure 5-23 Time history of Shear connection test (50\% Filtered data).......................... 74

Figure 5-24 Time history of Shear connection test (75\% Raw data).............................. 75

Figure 5-25 Time history of Shear connection test (75\% Filtered data).......................... 75

Figure 5-26 Time history of Shear connection test (85\% Raw data).............................. 76

Figure 5-27 Time history of Shear connection test (85\% Filtered data).......................... 76

Figure 5-28 Displacement of Shear connection test using mean of means ...................... 80

Figure 5-29 Displacement of Shear connection test using mean of peaks ...................... 80

Figure 5-30 Stiffness of Shear connection test using mean of means ............................. 82

Figure 5-31 Stiffness of Shear connection test using mean of peaks .............................. 82

Figure 5-32 Stiffness degradation of shear connection test in percentage......................... 84

Figure 5-33 Time history of stud to top plate connection (50\% Raw Data).................... 77

Figure 5-34 Time history of stud to top plate connection (50\% Filtered Data)................ 77

Figure 5-35 Time history of stud to top plate connection (75\% Raw Data).................... 78

Figure 5-36 Time history of stud to top plate connection (75\% Filtered Data)............... 78

Figure 5-37 Time history of stud to top plate connection (85\% Raw Data).................... 79

Figure 5-38 Time history of stud to top plate connection (85\% Filtered Data)............... 79 
Figure 5-39 Displacement of Stud to Top plate connection using mean of means ......... 81

Figure 5-40 Displacement of Stud to Top plate connection using mean of peaks .......... 81

Figure 5-41 Stiffness of Stud to Top plate connection using mean of means ................. 83

Figure 5-42 Stiffness of Stud to Top plate connection using mean of peaks .................. 83

Figure 5-43 Stiffness degradation of Stud to Top plate connection in Percentage........... 84 


\section{Introduction}

\subsection{Hurricane damage to residential houses}

Hurricanes are considered to be one of the costliest natural disasters. Their damage surpassed the damage due to the earthquakes within the Unites States. For instance, \$22 billion of insured losses from Hurricane Andrew exceeded by about $\$ 7$ billion the insured losses for the Northridge California Earthquake (Pinelli and Simiu, 2004). During the period from 1986 to 1992 hurricanes have accounted for the majority of property insurance losses as described in Figure 1.1.

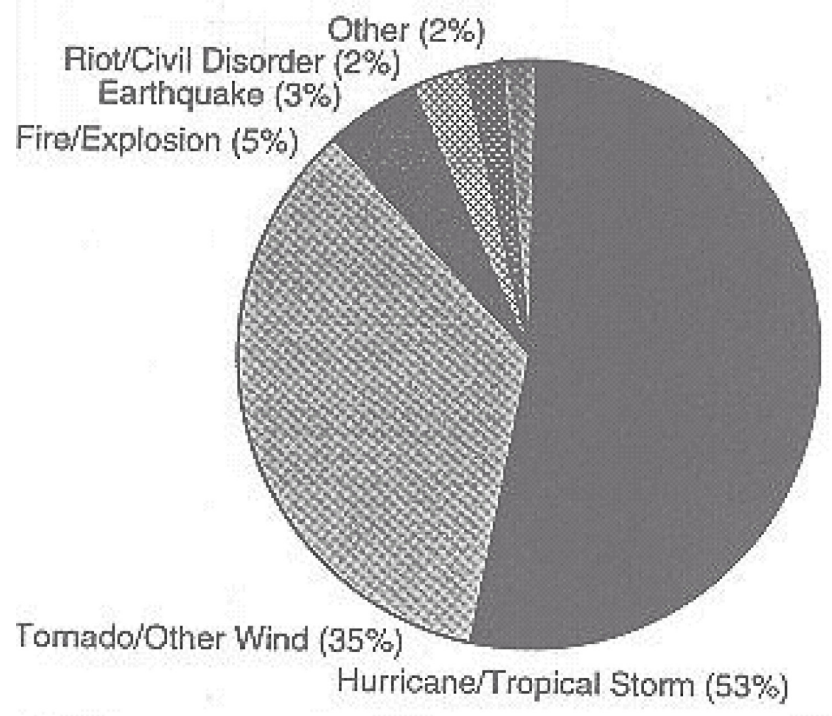

Figure 1-1 Percentage dollar loss by type, 1986-1992 (Mehta, K.C., Douglas, A.S., and Ronald, H.C., 1994)

Loss of life in United States due to hurricanes is decreased because of a improved warning system, but the property losses are rising due increase in coastal area population. Increase of population can be illustrated from the fact that during the year 1999-2003, 2.8 million building permits were issued for constructing single unit residential buildings (Crossett, 2004). The tremendous population growth along the coastal states has 
increased the volume of the residential construction, which enhances the risk of damage to those residential structures due to hurricanes and tropical storms. This population growth can be justified from Figure 1.2, which shows increase in coastal population during the years of 1980-2008.

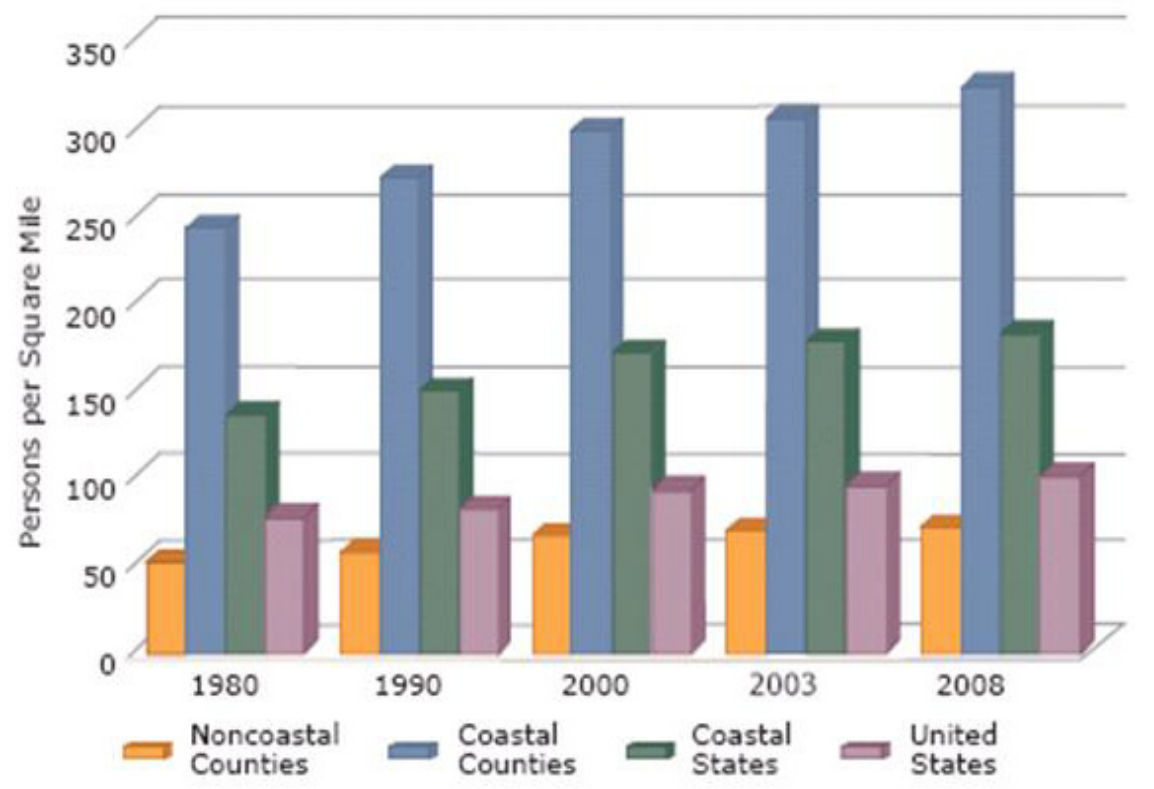

Figure 1-2 Comparison of coastal population densities with non coastal counties and other areas, 1980-2008 (Crossett, 2004)

Most houses in the United States are wood-frame buildings. Most of the woodframe residential buildings performed well under gravity loads, but significant damage is caused by loading generated during the hurricanes. Damages caused by the hurricanes underlined the weaknesses in the current wood-frame residential structures that need to be improved in order to reduce life and property losses.

Residential houses consist of several different components such as roof, walls and floors, which are joined using inter-component connections. The roof is attached to the walls using metallic connections between joist and the top plates of the walls. When 
typical houses are exposed to hurricane forces, the roofs are the most vulnerable, followed by the walls and the openings, and finally the foundation.

Wind forces may also cause several failure modes. First is racking which occurs when wind exerts a lateral force that causes the structure to lean over to one side; second is overturning, which occurs when a loaded structure rotates off its foundation; and the third is sliding as shown in Figure-1.3.
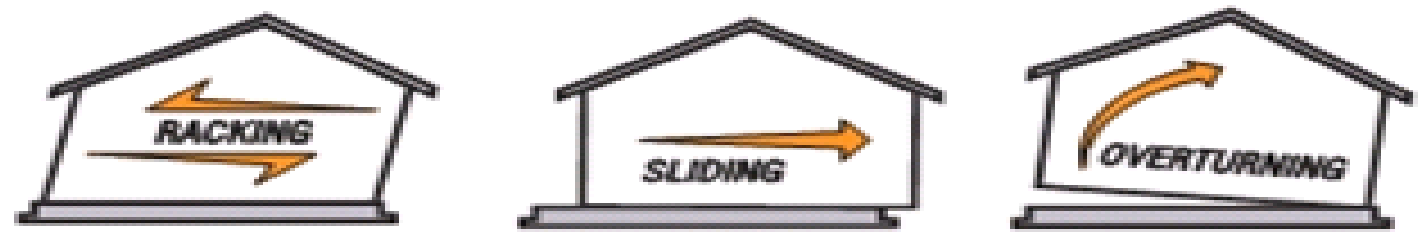

Figure 1-3 Shows the three failure modes of foundations (Simpson Strong Tie, 2006) Housing and urban development (HUD) performed a detailed a damage assessment study caused by Hurricane Andrew. Table-1.1 shows damage to each element of the house, with damage level more than one-third, according to the HUD scale.

\begin{tabular}{|c|c|}
\hline DAMAGE TYPE & HURRICANE ANDREW \\
\hline ROOF & 51 \\
\hline WALL & 15 \\
\hline FOUNDATION & 0 \\
\hline
\end{tabular}

Table 1-1 Percent of damaged homes surveyed with damage levels greater than onethird (HUD, 1993)

The damages done specifically to the roof, wall and foundation are due to the discontinuous load paths (Prevatt, 2007). If continuous load path can be established, load generated by the extreme winds is transferred from the roof sheathing to the rafters, from 
the rafters to the walls, and from the walls to the foundation. This continuous load path will increase the stability of the structure.

\subsection{Drawbacks of using metallic inter-component connections}

The most critical aspect in the stability of the residential structure against the extreme wind load is the method of connecting the structural members of the residential structure. Conventionally, metallic straps are used in the hurricane prone areas. Typically there are four types of connections:

(i) Roof to wall connection.

(ii) Stud to top/bottom plate connection.

(iii) Mudsill to foundation connection.

(iv) Gable end connection.

In metallic connections the failure modes could be the tear or buckling of metal plate or nail-withdrawal. Intense penetration due to nailing can crush the wood fibers. This generates cracks in the wood. Nail penetration may elevate the wood moisture content by water infiltration around the nail, resulting in corrosion of the nail as shown in Figure-1.4. Retrofitting the damaged house due to hurricanes using hurricane clips will further weaken the structural members by the intrusion of nails through the metallic plate. All the above stated problems may result in weaker connections and discontinuous load path. The severe drawbacks of intrusive connections have been demonstrated by past studies and experiments (Riley and Sadek, 2003; Rosowsky et al., 1998; Reed et al., 1997). 


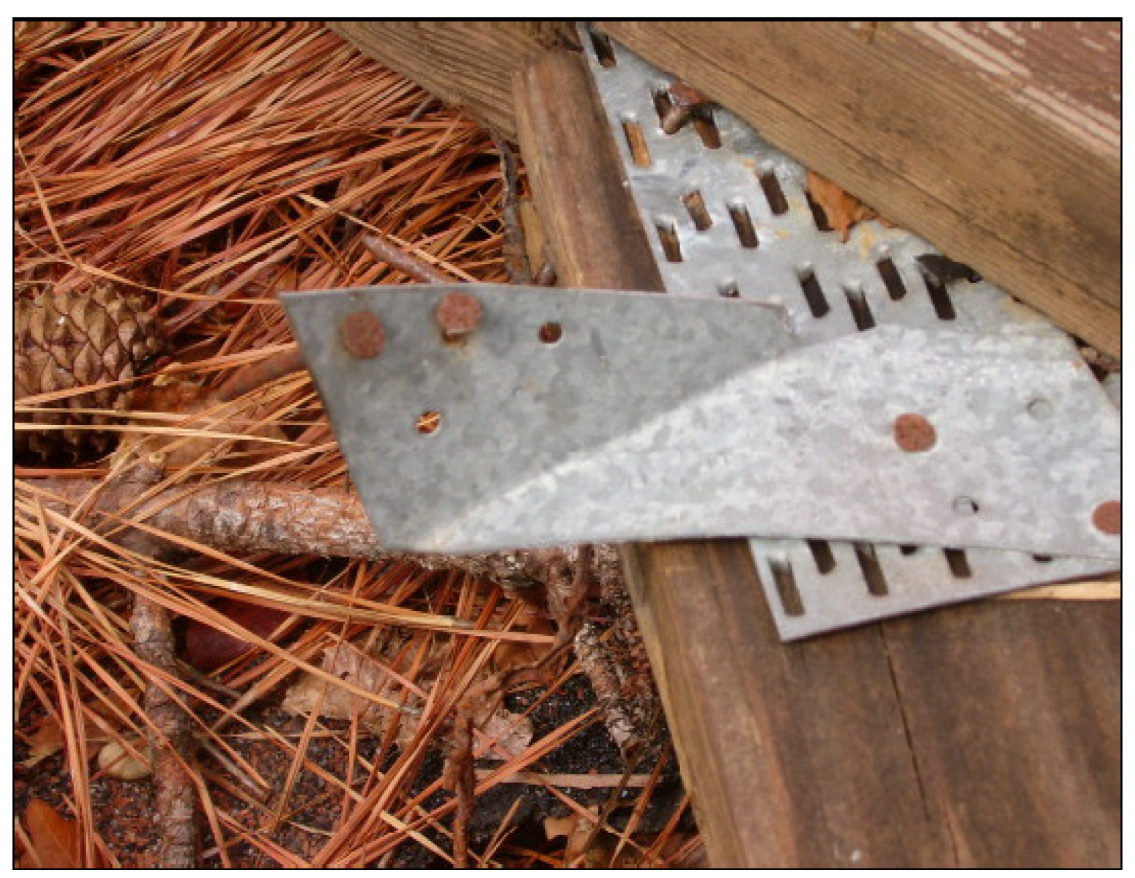

Figure 1-4 Failure of Hurricane clip connecting roof truss and wall with a corroded nails (Van de Lindt, 2005)

Manufacturers of existing metal fasteners base the allowable capacity of these fasteners on results of available test methods. To achieve the required minimum uplift capacity of wood-to-wood connections current design practice is to proportion the number of mechanical fasteners based on the design uplift force and the allowable capacity of one fastener as provided by the manufacturer. Implicit in this practice is the assumption that the connection's capacity is proportional to the number of fasteners per connection joint. This approach, based as it is on testing a single fastener per joint, disregards the fact that the failure modes of a connection joint may depend on the number of fasteners per joint. Under the current research testing was performed on metal connections to modify the current design approach and propose a realistic relationship between the capacity of the connection joint and the number of fasteners in the joint. The 
results showed that current design practices may overestimate the capacity of these joints by as much as a factor of about two and can therefore be the cause of roof-to-wall connection failures in extreme wind events.

In order to improve the structural performance of typical houses, continuous load path should be established by developing non-intrusive connections as an alternative to intrusive connections. Glass Fiber Reinforcement Polymer (GFRP) material connection could be a viable alternative to intrusive connections for several reasons:

- FRP has high tensile strength

- Loads are evenly distributed across the FRP connection

- It is very flexible and can adapt to any shape

- FRP is non-corrosive

- FRP connection will be more effective for retrofitting with minimal intrusion of the members.

The goal of the current research is to build upon prior work by investigating the capacity of the GFRP connection system in three different connection configurations under three different loading conditions: (i) monotonic static loading, (ii) short term sustained loading, and (iii) cyclic loading. These testing were necessary to evaluate the performance of various connections in the continuous load path system in terms of ultimate load, creep, and fatigue.

These FRP composites will improve resistance to hurricane-induced forces by creating continuous load paths and transmitting wind forces from building envelope (roof to wall) to the frame, and then to the foundation. This type of connection system will be a viable substitute for the hardware type connections. The strength of the new connection 
will be provided by the high performance fiber composites. The efficiency of the connection system is due to its non-intrusiveness, thus avoiding strength degradation of connected members. The new system will provide continuous and effective load path which enables transferring wind forces from the building envelope to the frame, and then to the foundation. 


\section{Literature review}

\subsection{Traditional connections}

For many years, risk of significant property loss due to hurricanes seemed to be small. However failure of residential structures during Hugo (1989) and Andrew (1992) highlighted the weakness of the mechanism connecting the structural members. During hurricanes when wind blows over the top of the structure it causes suction on the roof, thus causing the roof to be lifted. These uplift forces must be transferred down to the foundation to prevent damage. Several connections are required to create a continuous load path (Figure 2.1).

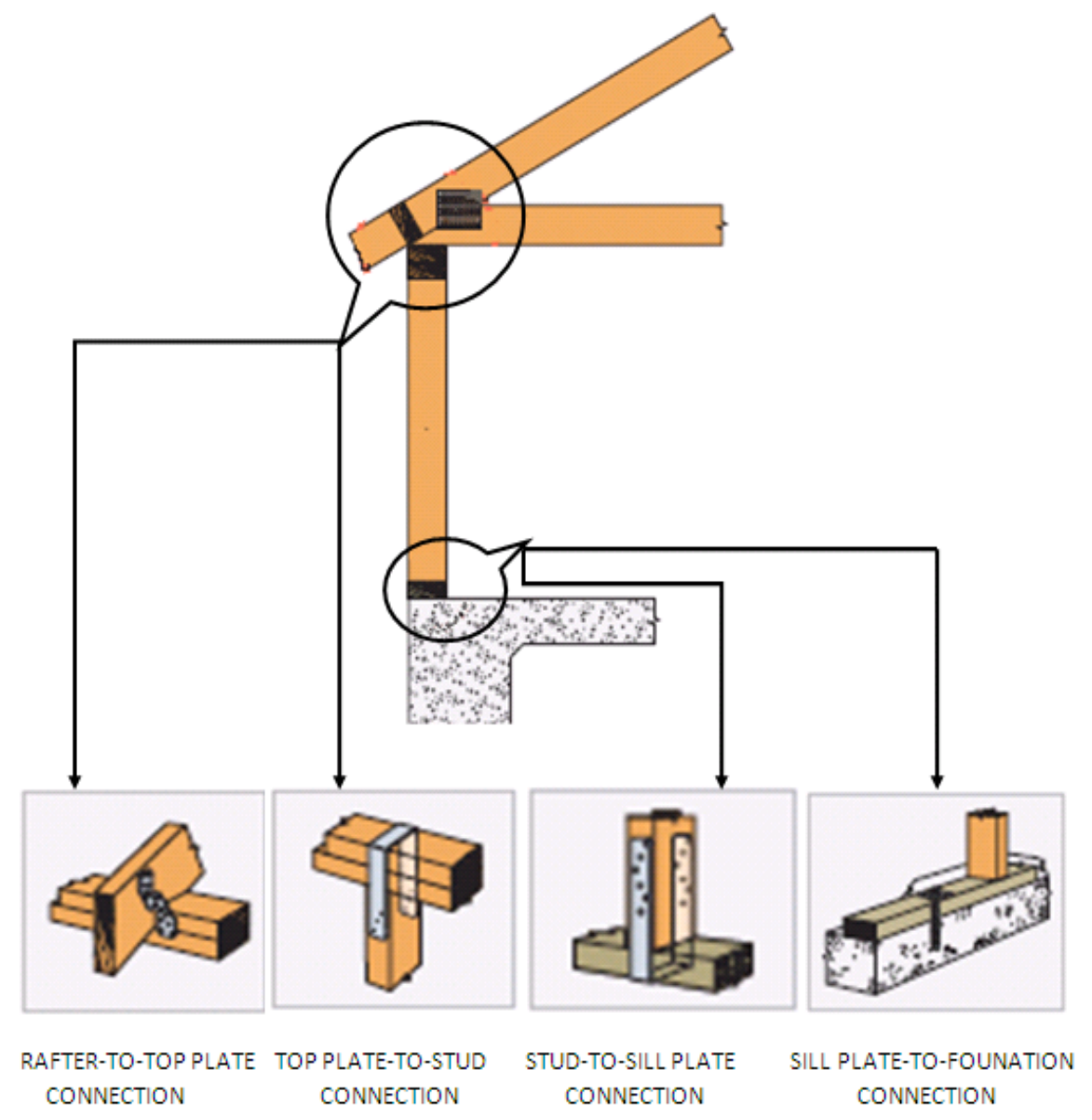

Figure 2-1 Traditional connection system (T-HFCG06, Simpson Strong Tie, 2006) 


\subsubsection{Roof to wall connection}

This connection provides resistance against the uplift forces acting upon the roof system and transfer forces from the roof to the top plate.

\subsubsection{Top plate-to-stud connection}

This connection provides resistance against the uplift forces transferred from the roof system and further transfer forces from the top plate to the wall stud.

\subsubsection{Stud to mudsill connection}

This connection provides resistance against the uplift forces and transfer forces from wall studs to the mudsill.

\subsubsection{Gable end joist to double top plate connection}

The gable end wall is a common area for wind damage. The continuous load path for the gable end wall should be from gable-end framing to the foundation. This gable end joist to double top plate connection provides resistance against the uplift forces through the roof system and transfer forces to the gable end wall framing as shown in the Figure 2.2.

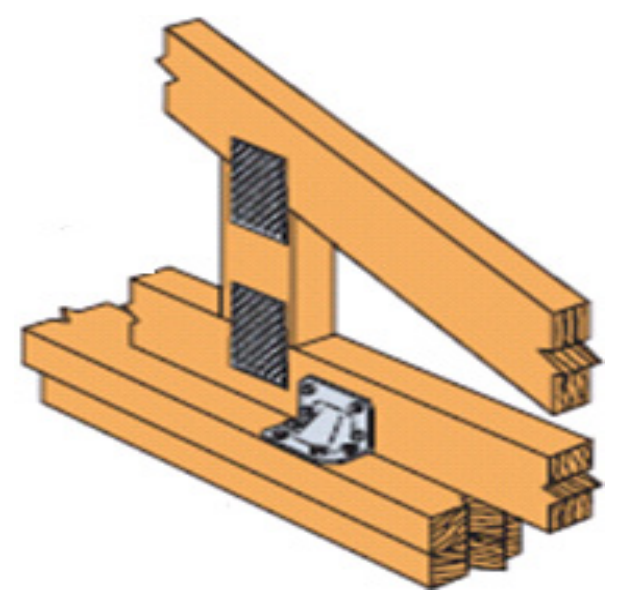

Figure 2-2 Gable end wall connection (C-2008 Simpson Strong Tie, 2008) 


\subsubsection{Mudsill to foundation connection}

Anchorage to the foundation completes the uplift load path. Anchoring the mudsill transfers the loads from mudsill to the foundation.

\subsection{Testing for metal connections}

Florida Building Code (FBC 2008) specifies minimum allowable uplift capacities of the metallic hurricane clips. Manufacturers publish design capacities for hurricane clips and straps based on the lowest value of the three test criteria defined by the ASTM D1761 "Testing Mechanical Fasteners in Wood” as mentioned below:

- The ultimate uplift load divided by three.

- The load at $1 / 8$ in deflection.

- Allowable design values for nails or other fasteners used to attach the connectors to the wood.

According to Rosowsky et al. (1998), manufacturers try to follow the idealized conditions rather than using the as-built conditions. This aspect can cause a drastic change in the published and the actual uplift capacity. Some of the major drawbacks in the manufacturer testing procedures are:

- Load transfer during component level testing does not reflect the actual loading conditions

- Material used to build the specimen is not appropriate

- Loading rate is different for every connection

- Preloading the specimen can manipulate the $1 / 8$ deflection criteria.

Rosowsky et al. (1998) developed a component level testing procedure to investigate the uplift capacity of various rafters to top-plate connections. The specimens 
were constructed using Southern yellow pine (SYP) double top-plates and either SYP or Spruce pine fir (SPF) rafter and wall studs. The rafter was 14 in long with a 1-3/8 inch overhang to accept the top-plate. The top-plate was nailed together with the rafter using six 8d nails through the metallic hurricane clips. Uplift loads were applied using hydraulic jacks mounted to a reaction frame. The loads were applied to rafter, on either side of the top-plate at a rate of between 0.1 and $0.2 \mathrm{in} / \mathrm{min}$. During the test load and deformation data were collected. Figure 2.3 shows the test setup for roof-to-wall connection developed by Rosowsky et al. (1998) with actual loading conditions.

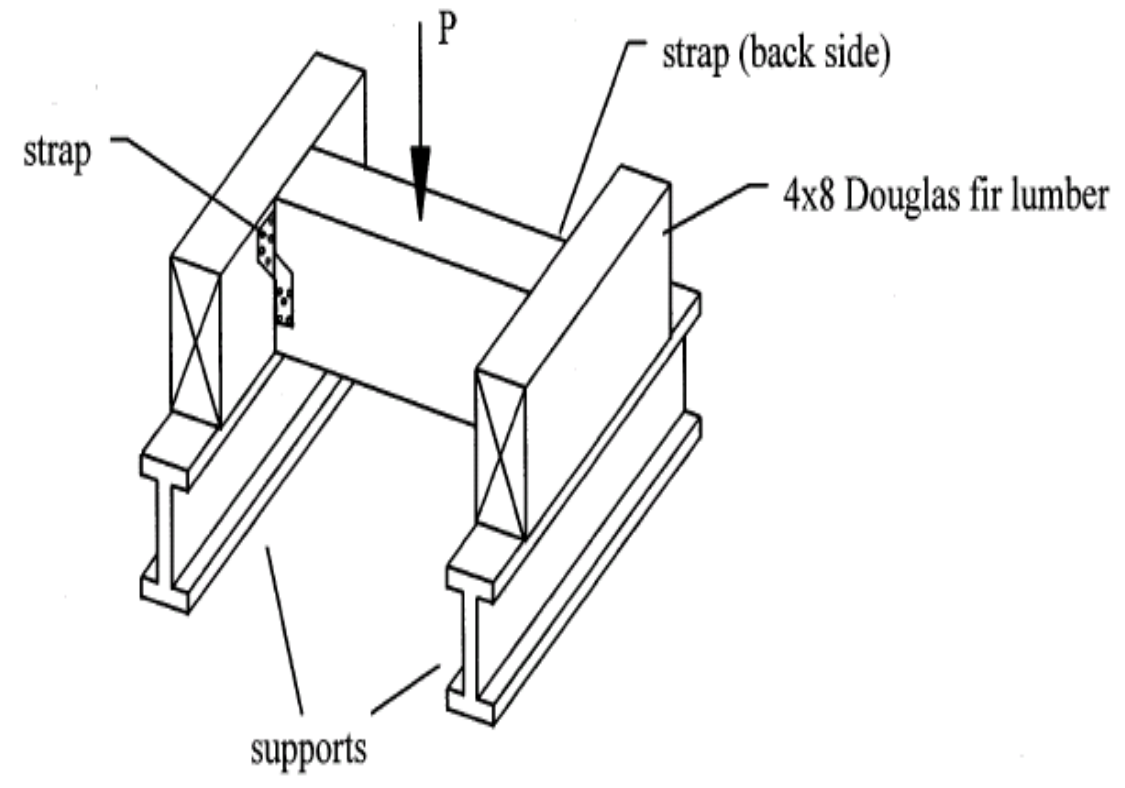

Figure 2-3 Standard test setup (Rosowsky et al., 1998)

\subsection{Testing for non-intrusive connections}

\subsubsection{Material for non intrusive connection:}

Fiber reinforced polymer (FRP) has an excellent scope to be used as a construction material due to its mechanical properties. However, traditional materials like 
concrete, steel and timber will remain there but FRP can perform as a supplement in strengthening the materials and their joints.

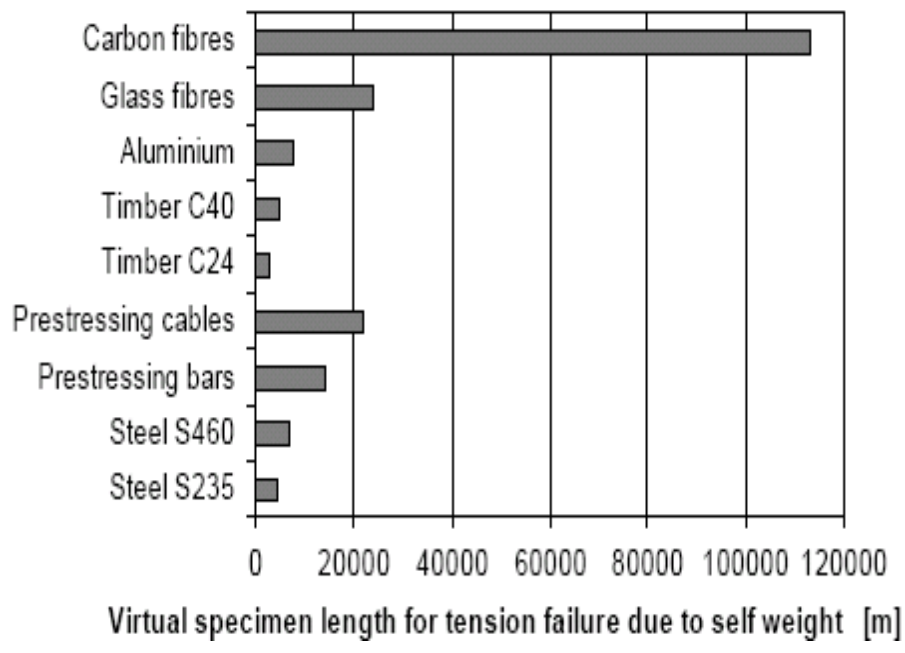

Figure 2-4 Specific material strengths (ratio of tension strength to density [m])

(Rene, 1995)

Adhesive bonding technology using fiber reinforced polymer has been studied for many years. It has played an essential role in the development and growth of the rehabilitation and repairing techniques of the structures. Due to high cost, the use of fiber reinforced polymer was mainly focused on retrofitting and strengthening of large span and heavy loaded structures. Most of such structures consisted of concrete and steel.

The use of FRP for the repair, strengthening and new configurations of timber construction opens new perspective for the design. The continuously decreasing prices of these high-tech materials made the use of this new technology more economical for residential construction. Several studies were performed to find the feasibility of the FRP as material used for retrofitting and joining the timber structures. 
Extensive study is performed on the tensile strength of FRP. Tensile test is performed with small FRP-spliced specimens with wood cross section 1.18 inch x 1.18 inch (30 mm x $30 \mathrm{~mm}$ ) (Kropf and Meierhofer, 2000). This test identified the parameters affecting the tensile strength of the wood-FRP connection. Some of those parameters were thickness of FRP, thickness of glue, and bonded area. Tensile test indicated satisfactory results showing tensile strength to increase with the increase in the bonded area up to a certain limit.

Most wood members are exposed to the climatic effects. Bending test was performed with a 110.236 inch $(2.8 \mathrm{~m})$ long beam after the exposure to the climatic effect for one year (Kropf and Meierhofer, 2000). Results indicated minor effect of climate on the strength of the beam. Beams of equal dimension were subjected to long-term creep test by applying bending load. Creep test results were considered satisfactory. However additional parameters still need to investigated such a fatigue testing for the tensile strength of wood-FRP bond. Creep was already investigated for the bending test but further study needs to be done for the tensile strength.

Testing in tension and bending of small FRP-spliced wooden specimens (Meierhofer, 1995) showed satisfactory results. The above studies encourage FRP's extensive use as a construction material.

\subsubsection{Monotonic loading test}

Monotonic loading test is defined as monotonic loading of the specimen with a constant loading rate until the specimen fails. Claisse and Masse (2006) investigated wood-FRP joint in tension. Sample was fabricated with two pieces of wood with FRP on either side of the joint and the load was applied axially and parallel to one of the wood 
grain direction. Several configurations were tested with different angles between the two pieces of timber using unidirectional and bidirectional FRP. Testing standard followed to perform the tension test was BS EN 26891. The common mode of failure was rupture of fibers and the delamination of the FRP from wood. Results showed that high tensile strength was obtained from unidirectional FRP in a configuration in which wood grains of both the wood pieces were parallel to the load.

\subsubsection{Sustained loading test}

Creep is defined as the time-dependant deformation exhibited by a material under sustained load. Most studies related to creep behavior of FRP emphasizes on concreteFRP bond using an epoxy, as FRP is commonly used in strengthening of concrete bridges. Nikolas and Thanasis (1995) conducted a detailed study to explain the behavior of woodFRP bond for a long term sustained load. This study was performed in variable and constant environment. The analytical results for creep deformation were verified by performing experiments. The test specimen consisted of a $65.51 \mathrm{in}(1664 \mathrm{~mm})$ long wood beam 1.78 in x 1.78 in $(45 \mathrm{~mm} \times 86 \mathrm{~mm})$ reinforced with epoxy bonded CFRP laminates. The flexural load was applied using air diaphragm cylinders as shown in the Figure-2.5. Results from this investigation showed that FRP played an important role in controlling the deformation during long term sustained load with a variable temperature and humidity conditions. The creep behavior of FRP reinforced wood was primarily dominated by the creep of wood. 


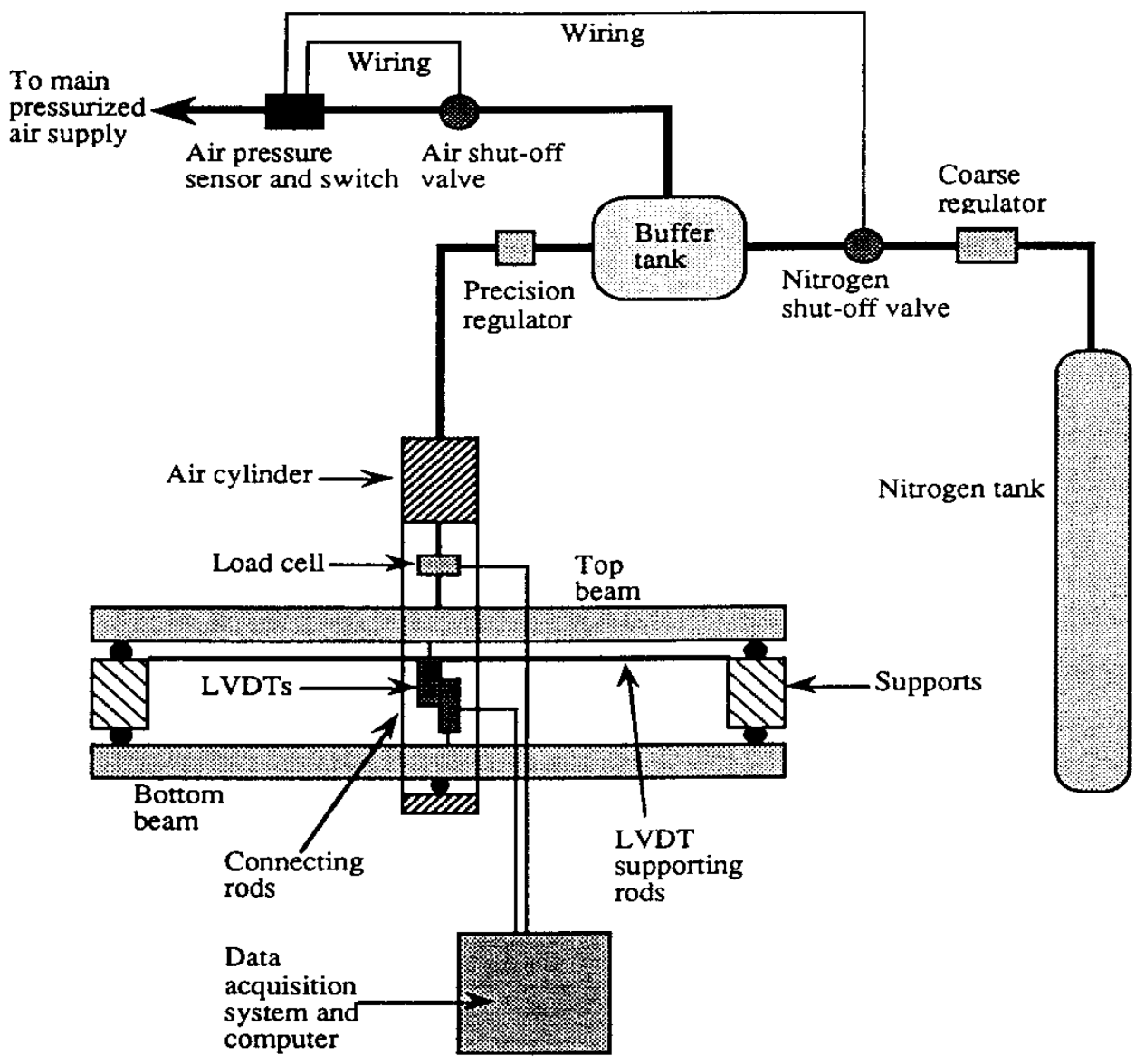

Figure 2-5 Experimental setup for creep test

\subsubsection{Cyclic loading test}

Fatigue life is defined as the number of stress cycles of a specified character that a specimen sustains before failure of a specified nature occurs. Fatigue tests under cyclic loading are characterized by the $\mathrm{R}$ ratio which is defined as $\mathrm{R}=\sigma_{\min } / \sigma_{\max }$, where, $\sigma_{\max }$ and $\sigma_{\min }$ are the minimum and maximum stresses applied during the cyclic loading. Relatively few studies were performed on the fatigue testing for wood-FRP bond. Hacker and Ansell (2001) had studied the fatigue damage of wood-FRP bond under constant amplitude fatigue test in tension-tension $(\mathrm{R}=0.1)$, compression-compression $(\mathrm{R}=10)$ and reverse 
loading $(\mathrm{R}=-1)$. Results for those tests showed that reverse cyclic loading is the most severe mode of fatigue testing. The results for tension-tension fatigue test strain remained constant throughout the test, until the specimen reached close to failure and the strain increased abruptly. This sudden increase of the strain was the initiation of the fatigue cracks along the wood grain.

A detailed study was performed to investigate the performance of wood-FRP joint concerning the fatigue resistance of the joint (Claisse et al., 2007). Authors used the European Spruce graded C16 to C24 to prepare the specimen of cross section 3.937 in x 1.96 in $(100 \times 50 \mathrm{~mm})$. The two pieces of timber were jointed butt end with unidirectional glass fibers on each side. Specimen was tested with the axial load applied to it as shown in the Figure-2.6. S-N curve was developed using thirteen samples with different cyclic loads. Results from the developed S-N curve were investigated by using Sutherland's Equation 2-1 (Sutherland, 1999) for fatigue behavior of composite material at constant R developed by using DOE/MSU database. The DOE/MSU database is for fiber composite with $25 \%$ fibers in the loading direction tested for tension-tension $\mathrm{R}=0.1$. When applying Equation 2-1, the good (fatigue resistant) materials have a slope $b=0.10$ and the poor have $b=0.14$. The slope of the S-N curve developed by Classie was 0.1002 concluding that the joint had good fatigue resistance. In this study fatigue resistance was also evaluated by comparing with the criteria in the design codes EN1995-1-1:2004. There was no failures below 0.4 ( $\%$ of static load) so a value of $\mathrm{K}_{\text {fat }}$ above 0.3 (Figure-2-7) was clearly indicted for the glass/epoxy joints. Result of the two evaluations done in this study concluded that wood-FRP joint performed well in fatigue. 


$$
\frac{\sigma}{\sigma_{0}}=C^{\prime}-\frac{1}{m} \log (N)=C^{\prime}-b \log
$$

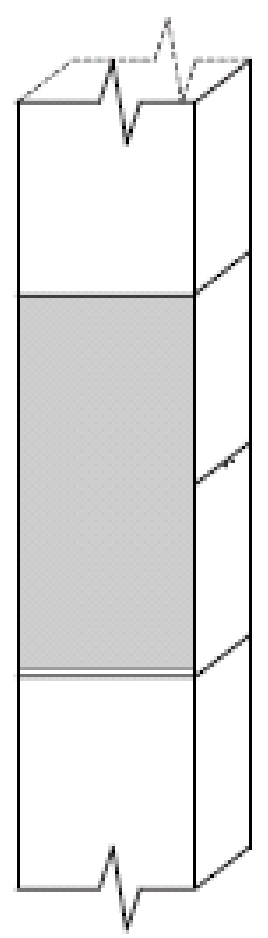

Figure 2-6 Test specimens for Fatigue Testing

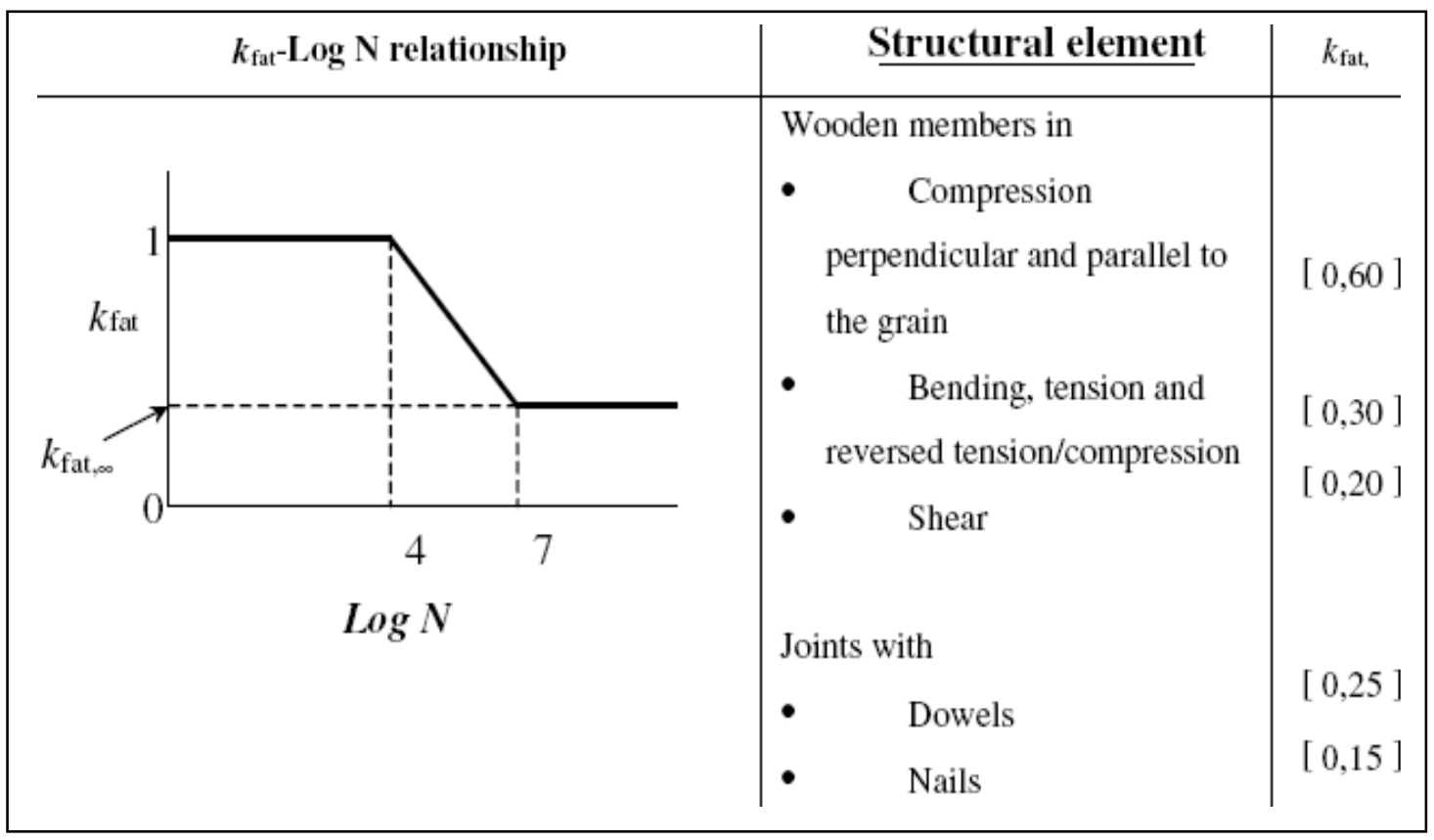

Figure 2-7 Design criteria in code EN 1995-1-1:2004 


\section{Study into the capability of multiple mechanical fasteners}

\subsection{Introduction:}

As it is discussed earlier in section 1.1, during the hurricane, when the roof is subjected to extreme wind loads which result in net uplift force, one of the most critical locations in the continuous load path is the roof to wall connection. This connection typically consists of metallic clips and the mechanical fasteners (nails). In order to calculate the uplift capacity of the hurricane clips, manufacturers use American Society of Testing Material ASTM D-1761 standard. This standard provides three different criteria to calculate the uplift capacity which include (i) ultimate uplift capacity divided by three; (ii) load at 1/8 inch deflection; (iii) allowable design value of the fastener to attach the clip. The current design practice is to calculate the number of mechanical fasteners based on the allowable uplift capacity of individual hurricane clip provided by the manufacturer. This study is performed to investigate the relationship between the connection capacity and the number of hurricane clips installed per connection, and suggests a modification of the current design approach for connections with multiple fasteners. The suggested modification would significantly improve the performance of timber construction in high winds.

\subsection{Literature review:}

Limited research was conducted focusing on the inter-component connection system. Clemson University performed a series of tests using single connection and the repetitive connection system of rafter to top plate (Reed et al., 1997). These single and multiple rafters to top plate connections are tested with several mechanical fasteners. Study showed that if a hurricane strap is installed outside the wall, uplift load capacity 
specified by the manufacturer is reduced due the eccentricity in the continuous load path. Testing with two clips on either side of the wall concluded that although using two clips per connection increases the allowable capacity of the connection, it would not get doubled. The research presented in this section suggests a method for evaluating the relationship between the capacity of the connection and the number of fasteners. This testing program investigates the actual relationship between the number of clips used per connection joint and the connection's uplift capacity.

\subsection{Testing procedure:}

\begin{tabular}{|c|l|c|}
\hline \multirow{2}{*}{ S.NO } & WOOD TYPE & NUMBER OF CLIPS \\
& PER JOINT \\
\hline \multirow{2}{*}{ Spruce pine fir (SPF) } & 1 \\
& & 2 \\
\hline \multirow{2}{*}{} & Southern yellow pine (SYP) & 4 \\
\hline $\mathbf{3}$ & Douglas fir (DF) & 2 \\
\hline & & 4 \\
\hline
\end{tabular}

Table 3-1 Testing Configuration for roof to wall connection

A single connection system specimen was fabricated with typical hurricane clip, which is commonly used in residential construction. Test procedure and the size of the test specimen were defined by the ASTM D1761 (ASTM, 2006) test standard. Cross section for wood type SPF and SYP was, 2inch x 6 inch except for wood type DF whose 
cross section was $4 \times 8$ inch. Testing configurations were developed with different number of clips per joint as mentioned in Table 3.1 and for different types of wood. Five tests were done with each configuration as shown in Figure 3.1 and Figure 3.2.
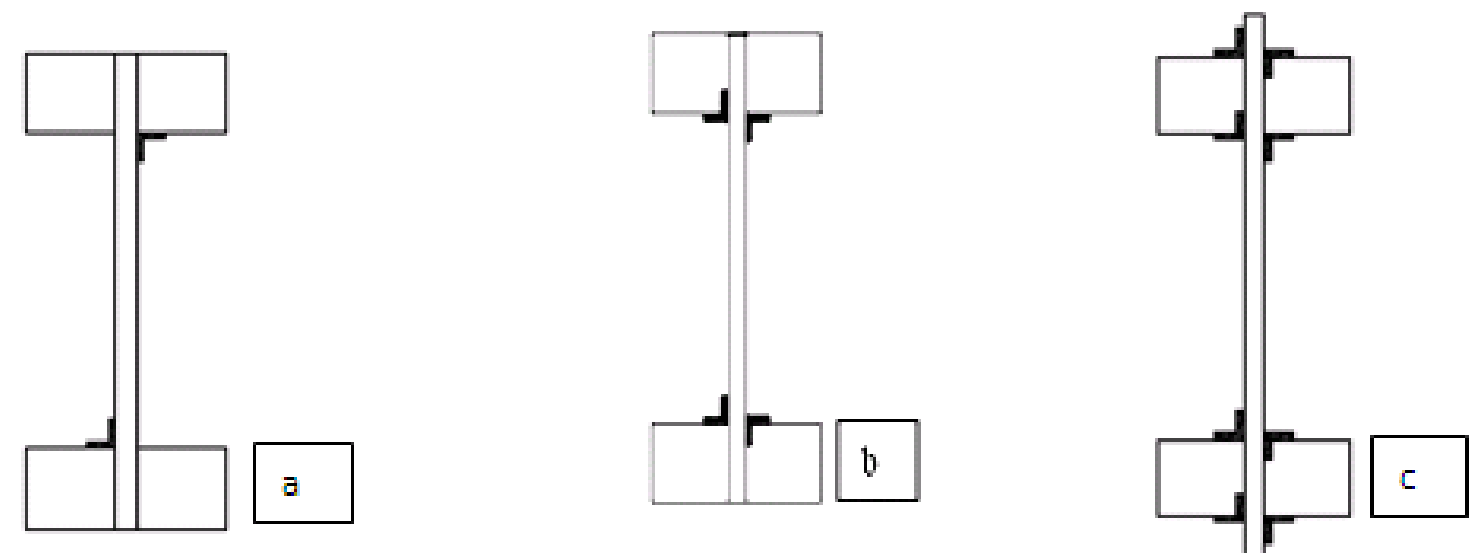

Figure 3-1 Test configurations for Spruce Pine Fir (SPF) and Southern Yellow Pine (SYP) wood types: (a) Single clip per joint, (b) Two clips per joint, (c) Four clips per joint.

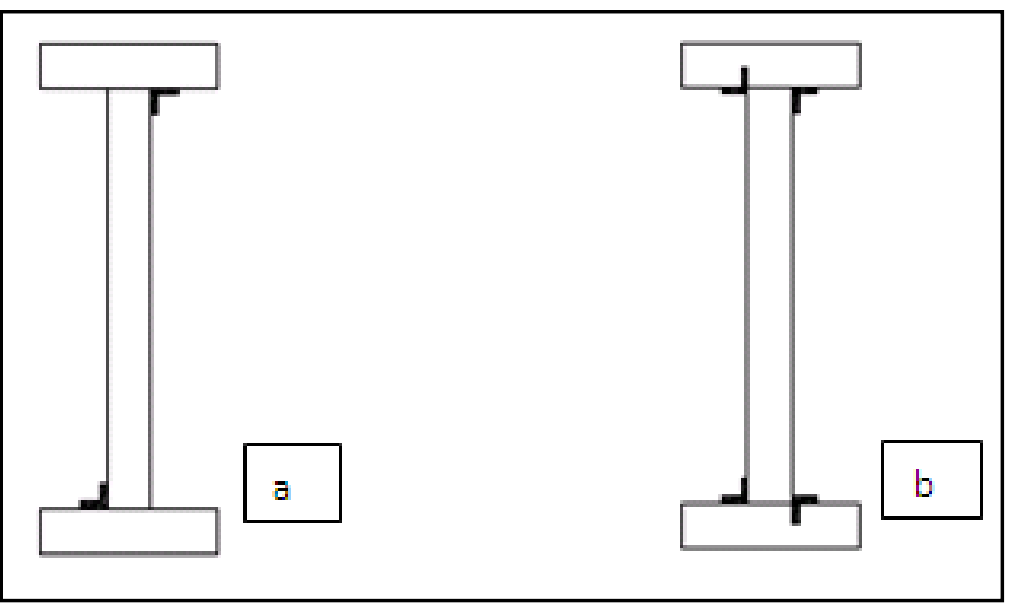

Figure 3-2 Test configurations for Douglas Fir (DF) wood type: (a) Single clip per joint, (b) Two clips per joint.

A universal testing machine with 22 kip capacity (model Mark III, 22 EMF) was used to perform all the tests as shown in Figure-3.3. 


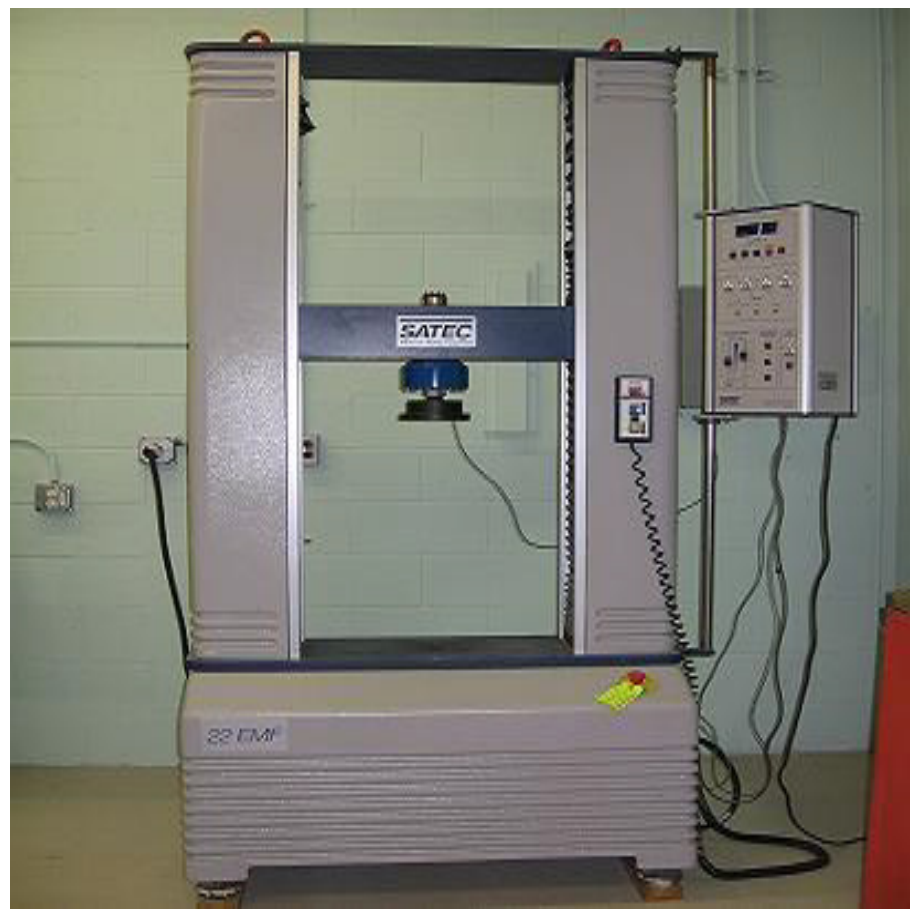

\section{Figure 3-3 Universal Testing Machine with 22 kip capacity}

(Model Mark III, 22 EMF)

The test specimen was setup on a steel tube frame which was built with a 1 in $\mathrm{x} 1$ in $\mathrm{x} 1 / 8$ in members. SYP and SPF specimens were bolted with the steel frame as shown in the Figure-3.4. Only the DF specimen was placed on the top of the frame as shown in the Figure-3.5. Specimens were loaded at the center of the joist using a rubber pad (14 in $\mathrm{x} 6$ in $\mathrm{x} 3 / 4 \mathrm{in}$ ) to spread the load over the joist from the machine. A loading rate of 0.035 in/min was maintained during the test until the ultimate load was achieved. Load at 1/8 in deflection and ultimate load at failure were recorded during each test. 


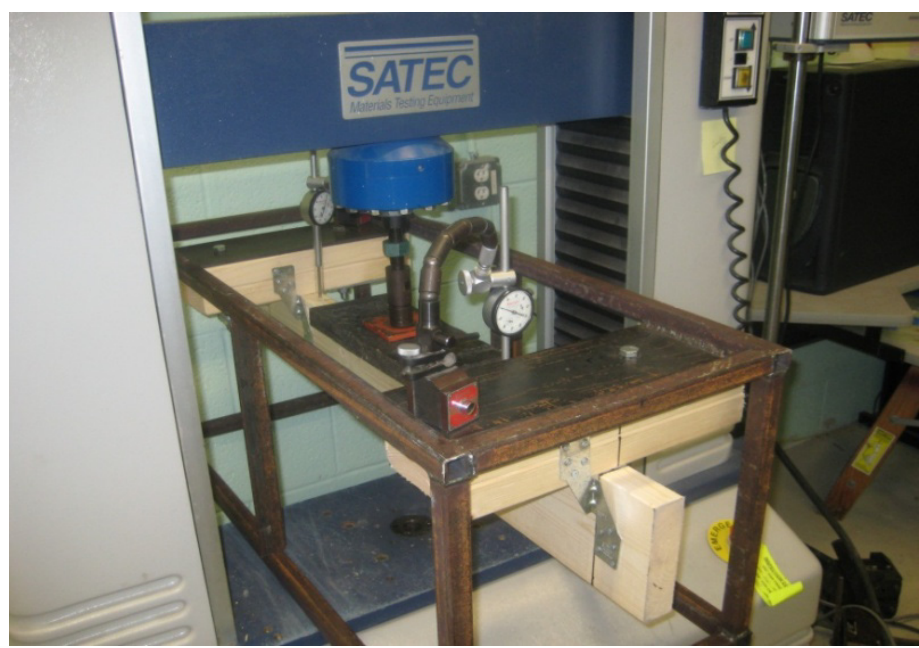

Figure 3-4 Experimental setup for testing clips using SPF and SYP wood types

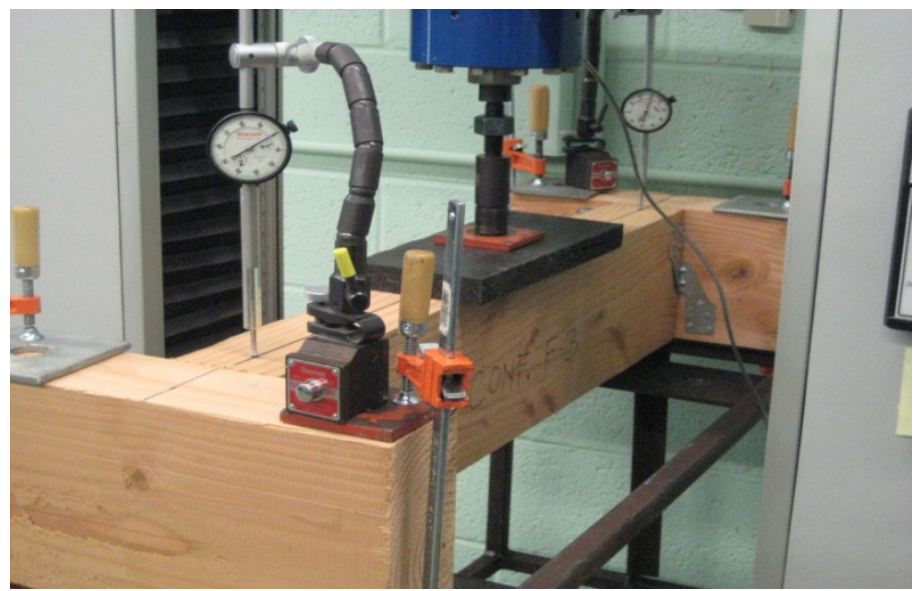

Figure 3-5 Experimental setup for testing clips using DF

\subsection{Results:}

The allowable load capacity of test specimen was selected as the lowest value of the (i) ultimate load divided by factor of safety three, (ii) the load at $1 / 8$ in deflection (Reed et al., 1997). In order to obtain the capacity per connection allowable load is divided by 2 , as there are two connections per specimen. Test results for wood type SPF, SYP, and DF are shown in Tables 3.2, 3.3 and 3.4 respectively. 


\begin{tabular}{|c|c|c|c|c|c|c|c|c|c|}
\hline \multirow[t]{2}{*}{ S.No } & \multirow[t]{2}{*}{ Load Type } & Test 1 & Test 2 & Test 3 & Test 4 & Test 5 & \multirow[t]{2}{*}{ Mean } & \multirow[t]{2}{*}{ STDV } & \multirow[t]{2}{*}{ COV } \\
\hline & & lb & lb & lb & $\mathbf{L b}$ & lb & & & \\
\hline \multirow{2}{*}{1} & $1 / 8^{\prime \prime} \mathrm{LOAD}$ & 450 & 465 & 560 & 655 & 620 & \multirow{2}{*}{437} & \multirow{2}{*}{58.01} & \multirow{2}{*}{0.13} \\
\hline & ULTIMATE & 478 & 385 & 420 & 385 & 515 & & & \\
\hline \multirow{2}{*}{2} & $1 / 8^{\prime \prime} \mathrm{LOAD}$ & 1190 & 1040 & 1235 & 1215 & 1320 & \multirow{2}{*}{591} & \multirow{2}{*}{76.40} & \multirow{2}{*}{0.13} \\
\hline & ULTIMATE & 680 & 645 & 595 & 550 & 487 & & & \\
\hline \multirow{2}{*}{4} & $1 / 8^{\prime \prime} \mathrm{LOAD}$ & - & 2655 & 2200 & - & 2770 & \multirow{2}{*}{887} & \multirow{2}{*}{78.82} & \multirow{2}{*}{0.09} \\
\hline & ULTIMATE & 843 & 937 & 835 & 820 & 1002 & & & \\
\hline
\end{tabular}

Table 3-2 Test results for wood type: SPF

\begin{tabular}{|c|c|c|c|c|c|c|c|c|c|}
\hline \multirow{2}{*}{ S.No } & \multirow{2}{*}{ Load Type } & Test 1 & Test 2 & Test 3 & Test 4 & Test 5 & \multirow{2}{*}{ Mean } & \multirow{2}{*}{ STDV } & \multirow{2}{*}{ COV } \\
\hline & & lb & Ib & lb & lb & Ib & & & \\
\hline \multirow{2}{*}{1} & $1 / 8^{\prime \prime} \mathrm{LOAD}$ & 550 & 525 & 715 & 440 & 605 & \multirow{2}{*}{459} & \multirow{2}{*}{33.08} & \multirow{2}{*}{0.07} \\
\hline & ULTIMATE & 485 & 487 & 458 & 405 & 460 & & & \\
\hline \multirow{3}{*}{2} & 1/8" LOAD & 1300 & 1750 & 1350 & 1135 & 1430 & \multirow{3}{*}{711} & \multirow{3}{*}{73.62} & \multirow{3}{*}{0.10} \\
\hline & IUI TIMA TE & 612 & 707 & 755 & 678 & 805 & & & \\
\hline & ULIIMAIE & 012 & 101 & 155 & $0 / 8$ & 805 & & & \\
\hline \multirow{3}{*}{4} & $1 / 8^{\prime \prime} \mathrm{LOAD}$ & 2270 & 2125 & 2595 & 3020 & 1580 & \multirow{3}{*}{931} & \multirow{3}{*}{95.33} & \multirow{3}{*}{0.10} \\
\hline & IU TIMATE & 853 & 013 & 805 & 1007 & 808 & & & \\
\hline & ULTIMATE & 853 & 913 & 895 & 1097 & 898 & & & \\
\hline
\end{tabular}

Table 3-3 Test results for wood type: SYP 


\begin{tabular}{|c|c|c|c|c|c|c|c|c|c|}
\hline \multirow{2}{*}{ S.No } & Load Tyne & Test 1 & Test 2 & Test 3 & Test 4 & Test 5 & \multirow{2}{*}{ Mean } & \multirow{2}{*}{ STDV } & \multirow{2}{*}{ COV } \\
\hline & & $1 \mathrm{~b}$ & $1 b$ & $1 b$ & $\mathrm{Lb}$ & $1 b$ & & & \\
\hline \multirow{2}{*}{1} & 1/8" LOAD & 1040 & 995 & 985 & 470 & 990 & \multirow{2}{*}{640} & \multirow{2}{*}{59.37} & \multirow{2}{*}{0.09} \\
\hline & ULTIMATE & 565 & 698 & 695 & 648 & 595 & & & \\
\hline \multirow{2}{*}{2} & $1 / 8^{\prime \prime} \mathrm{LOAD}$ & 1795 & 1725 & 1570 & 1300 & 1625 & \multirow{3}{*}{753} & \multirow{3}{*}{73.28} & \multirow{3}{*}{0.10} \\
\hline & & & & & & & & & \\
\hline & ULTIN & 757 & 687 & 690 & 765 & 867 & & & \\
\hline
\end{tabular}

Table 3-4 Test results for wood type: DF

It is evident from the test results for the three wood types; allowable load capacity of the connection joint with two fasteners is less than twice the allowable load capacity of the connection with one fastener. According to the result shown in Figure 3.6, the current design practice overestimates the capacity of these joints and can therefore may results in the failure of roof to wall connection.

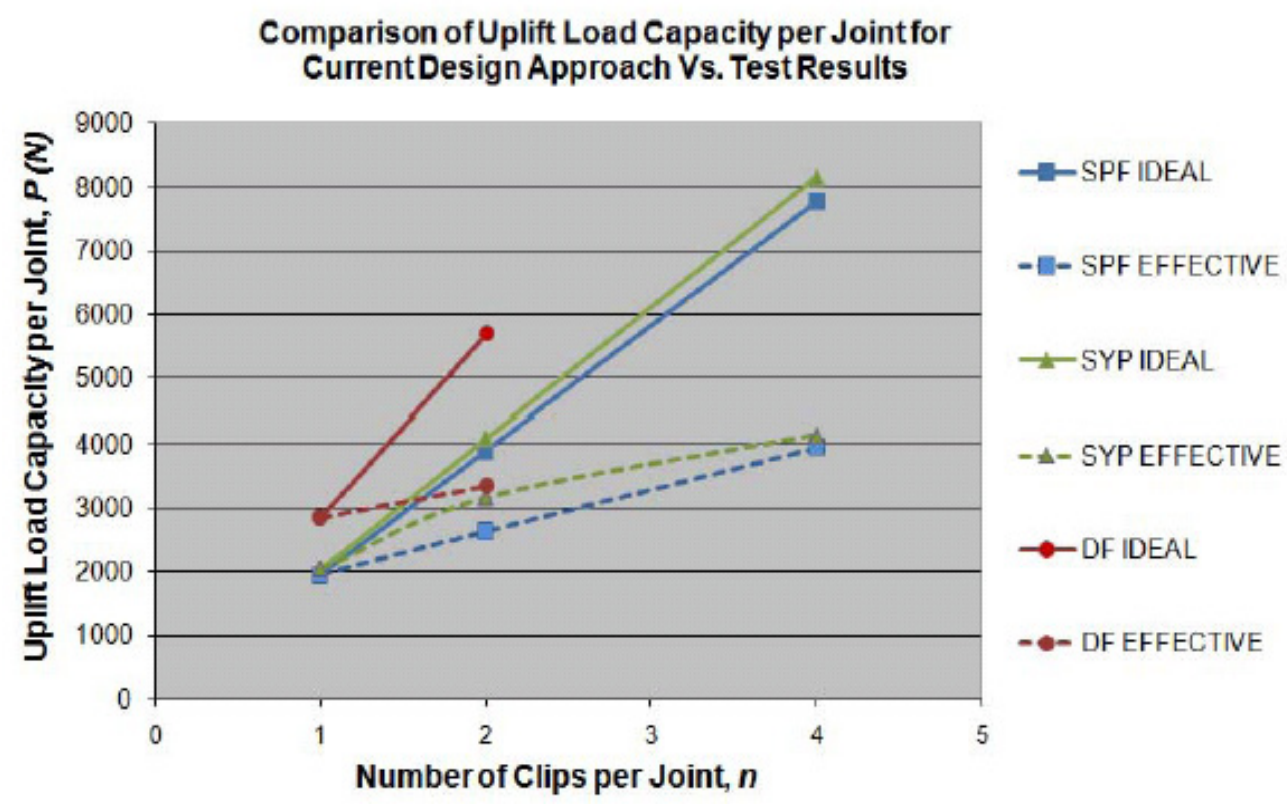

Figure 3-6 Comparison of uplift load capacity per joint for current design approach vs. test results. 
The current design practice assumes that the joint's allowable uplift load carrying capacity is proportional to the number of fasteners per joint. This relationship is written as:

$\mathbf{P}(\mathbf{n})=\mathbf{P}(\mathbf{1})[\mathbf{n}]$

(Equation 3-1)

Where,

$P(n)=$ the ideal allowable load carrying capacity of a joint with " $n$ " fasteners.

$\mathrm{P}(1)=$ the individual fastener's allowable capacity provided by the manufacturer.

Test results showed that the current design practice is erroneous and correction factor $\mathrm{C}_{\mathrm{nw}}$ was incorporated to obtain the actual allowable load capacity $\mathrm{P}_{\text {eff }}$ of the connection. $\mathrm{P}_{\text {eff }}$ depends on the number of fasteners " $n$ " per connection and the wood type. $\mathrm{P}_{\text {eff }}$ can be written as:

$\mathbf{P}_{\text {eff }}(\mathbf{n})=\mathbf{P}(\mathbf{1})\left[1+\mathbf{C}_{\mathrm{nw}}(\mathbf{n}-\mathbf{1})\right]$

(Equation 3-2)

Correction factor $\mathrm{C}_{\mathrm{nw}}$ can be written as:

$C_{n w}=\left[P_{\text {eff }}(n) / P(1)-1\right] /(n-1)$, for $n=2,4$

(Equation 3-3)

Table 3.5, 3.6 and 3.7 show the effective allowable load capacity $\mathrm{P}_{\text {eff }}$ of the joints, the percentage reduction of that capacity with respect to current design practice and the values of the correction factor $\mathrm{C}_{\mathrm{nw}}$. 


\begin{tabular}{|c|c|c|c|c|}
\hline $\begin{array}{c}\text { No of } \\
\text { clips }\end{array}$ & $\begin{array}{c}\text { Current Design } \\
\text { Approach }\end{array}$ & $\begin{array}{c}\text { Based on Test } \\
\text { Results }\end{array}$ & $\begin{array}{c}\text { Reduction } \\
\text { in P(n) }\end{array}$ & Correction \\
\hline $\mathbf{n}$ & $\mathrm{P}(\mathrm{lbs})$ & $\mathrm{P}_{\mathrm{eff}}(\mathrm{lb})$ & $\%$ & $\mathrm{CW}$ \\
\hline $\mathbf{1}$ & 437 & 437 & - & - \\
$\mathbf{2}$ & 874 & 591 & 32.33 & 0.35 \\
$\mathbf{4}$ & 1748 & 887 & 49.23 & 0.34 \\
\hline
\end{tabular}

Table 3-5 Comparison of allowable load capacity per joint

\begin{tabular}{|c|c|c|c|c|}
\hline $\begin{array}{c}\text { No of } \\
\text { clips }\end{array}$ & $\begin{array}{c}\text { Current Design } \\
\text { Approach }\end{array}$ & Based on Test & Reduction & Correction \\
\hline $\mathbf{n}$ & $\mathbf{P ( l b s )}$ & Peff (lb) & in P(n) & Constant \\
\hline $\mathbf{1}$ & 459 & 459 & 0 & $\mathbf{C W}$ \\
$\mathbf{2}$ & 918 & 711.4 & 22.50 & 0.549 \\
$\mathbf{4}$ & 1836 & 931.2 & 49.28 & 0.342 \\
\hline
\end{tabular}

Table 3-6 Comparison of allowable load capacity per joint

\begin{tabular}{|c|c|c|c|c|}
\hline No of & $\begin{array}{c}\text { Current Design } \\
\text { clips }\end{array}$ & Based on Test & Reduction & Correction \\
\hline $\mathbf{n}$ & $\mathbf{P}(\mathbf{l b s})$ & Peff $(\mathbf{l b})$ & $\mathbf{\%}$ & $\mathbf{C W}$ \\
\hline $\mathbf{1}$ & 641 & 640.2 & 0.124805 & - \\
$\mathbf{2}$ & 1282 & 753.2 & 41.24805 & 0.175039 \\
\hline
\end{tabular}

Table 3-7 Comparison of allowable load capacity per joint

These values of the correction factor can be used to modify the current design criteria depending on the number of fasteners and the type wood as shown in Table 3.8. 


\begin{tabular}{|c|c|c|c|}
\hline \multirow{2}{*}{$n$} & \multicolumn{3}{|c|}{ Wood Type } \\
\cline { 2 - 4 } & SPF & SYP & DF \\
\hline 2 & 0.4 & 0.5 & 0.2 \\
\hline 4 & 0.3 & 0.3 & - \\
\hline
\end{tabular}

Table 3-8 Correction factor (Cnw) values for number of fasteners per joint and wood type 


\section{Development of non-intrusive connection system for continuous load path}

\subsection{Development of non-intrusive ties for roof to wall connection:}

The development of roof-to-wall FRP connection was performed by Canbek (2009). In order to develop non-intrusive connection system preliminary test was done using FRP to determine the FRP-wood bond strength in shear. Specimen used for shear connection test consisted of two wood pieces with 1.5 inch spacing between them. Two pieces were joined together using two FRP ties on either side of the wood as shown in the Figure 4-1.

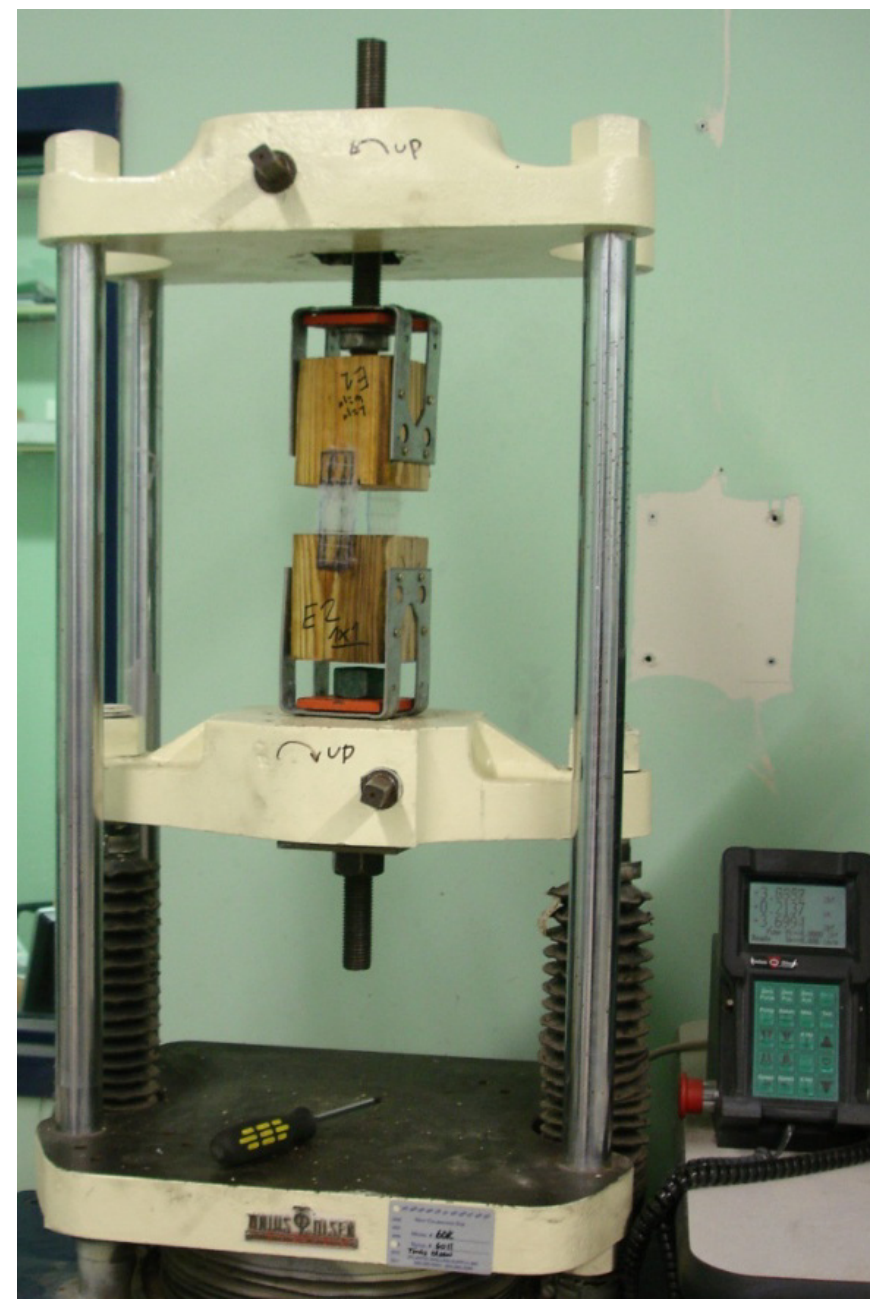

Figure 4-1 Shear connection test (Canbek,2009) 
This test was done with five different sizes of FRP. The failure mode of shear connection test was de-bonding of FRP from wood. The results showed that beyond 9 sq inch of area there would not be any increase in the failure load.

Development of roof to wall connection was started with the test specimen and test setup as shown in Figure 4-2.

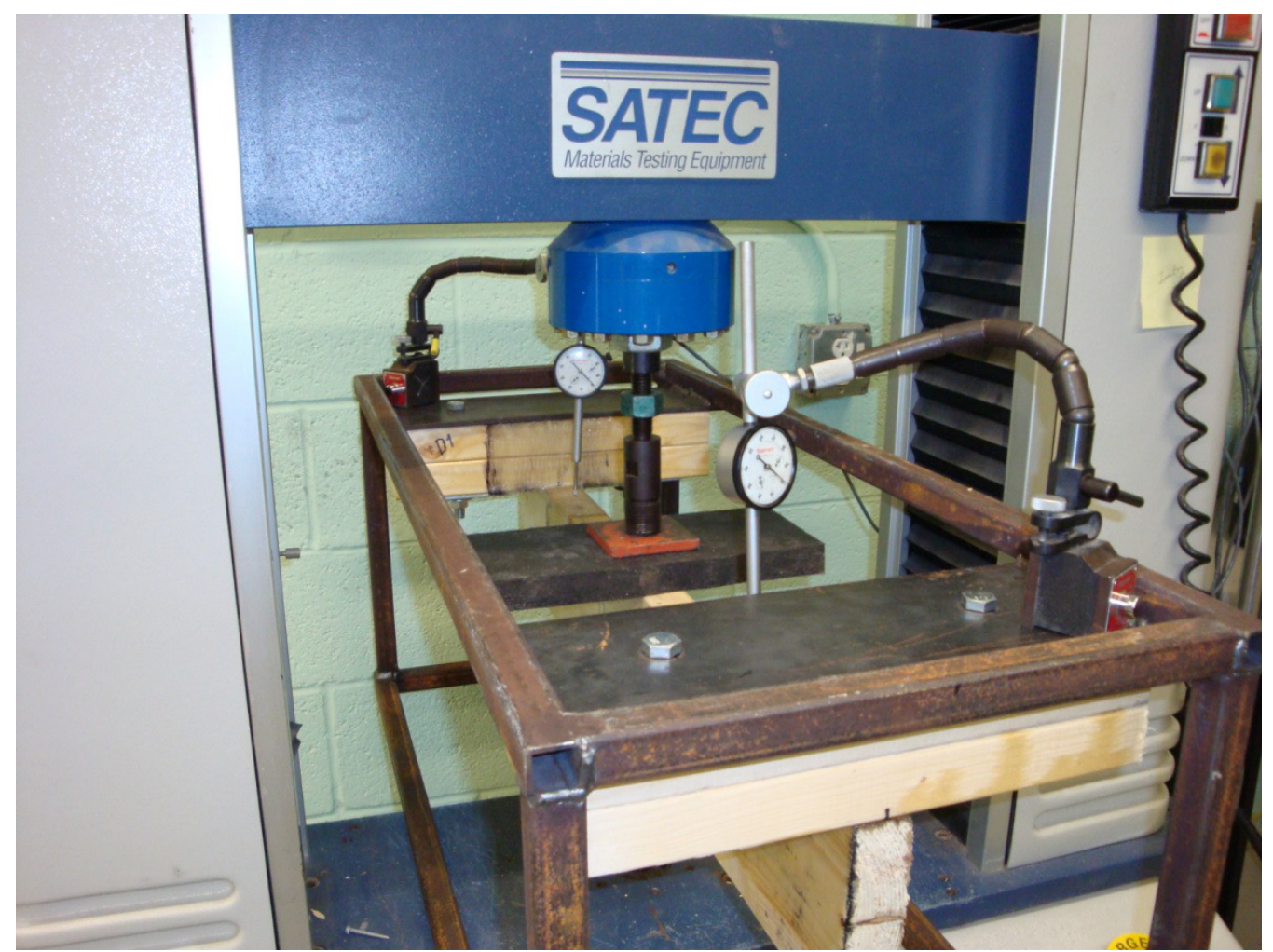

Figure 4-2 Test setup for the uplift capacity of roof to wall connection(Canbek,2009)

Five different configurations were tested with uni-axial CFRP and GFRP. The results showed that CFRP specimen failure load was $20 \%$ higher than GFRP. The configuration which showed that maximum failure load of $4320 \mathrm{lbs}$, is shown in the Figure 4-3. 

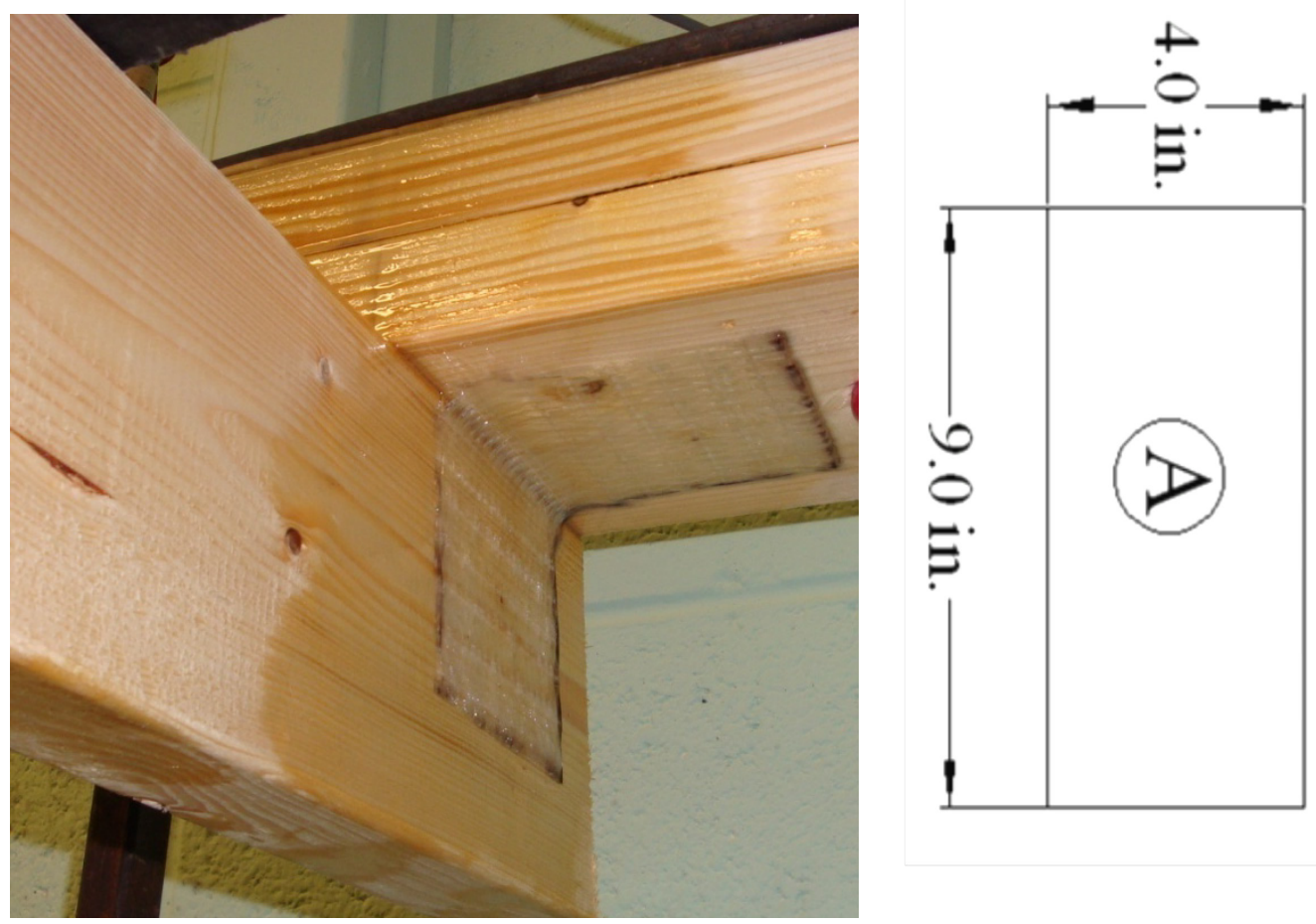

Figure 4-3 FRP Configuration with highest uplift load capacity for roof to wall connection (Canbek, 2009)

\subsection{Development of non-intrusive ties for stud to top plate and gable end connection:}

This research was performed in continuation of the previous research done by Canbek (2009) for the development of non-intrusive roof to wall connection. The methodology of the research involved development of FRP ties with GFRP for gable end connection and stud to top plate connection. Stud to top plate non intrusive connection was further tested for creep and fatigue effects and gable end connection was tested for the creep effects. Testing of shear connection for sustained and cyclic loads was also performed in order to determine the behavior of wood-FRP bond under creep and fatigue testing. 


\subsubsection{Development of Test Setup:}

\subsubsection{Shear connection test:}

This setup utilized a simple geometry of the wood members. There was only one 2 inch $x 6$ inch cross-section utilized for preparing the test specimen. The wood type used for this test setup was Spruce Pine Fir and consisted of two 14.5 inch long pieces of wood. These two wood pieces were connected vertically such that there was a 1.5 " spacing between the two wood pieces. The 1.5 inch spacing was maintained by placing a wood piece with cross-section 2 inch $\times 6$ inch, 1.5 inch in length, between the two vertical pieces of shear connection specimen. Once the wood pieces were put together, 1.5 inch $x 4.5$ inch FRP was placed on either side such that the bonded area on each side was be $4.5 \mathrm{sq}$ inch. After applying the FRP the specimen was cured for a week.

In-order to fit the specimen into the testing assembly two 1.5 inch diameter holes were drilled 4.5 inch below each end of the specimen as shown in Figure 4-4. The 1.5 inch separator was removed before testing the specimen.

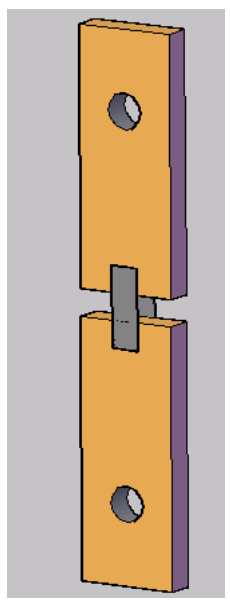

Figure 4-4 Test specimen for shear connection test 
The test assembly which was used to apply the load on the specimen consisted of two U-shaped metallic plates. The base of one of the U-shaped plates was connected to the reacting beam and the other was connected to the actuator using bolts. This would provide an upward force on one end and a downward force on the other, resulting in a tension force being created on the FRP. In-order to connect the test specimen with the assembly a 1.5 inch diameter hole was drilled at the same level, in both of the vertical stems of the U-shaped assembly. Once the specimen was placed inside the U-shaped metallic assembly a rod was passed through the holes in the stems and the specimen at both ends. This resulted in the anchoring of the specimen with the U-shaped metal assembly and allowed for the transfer of load from the machine to the specimen. This assembly is shown in Figure 4-5.

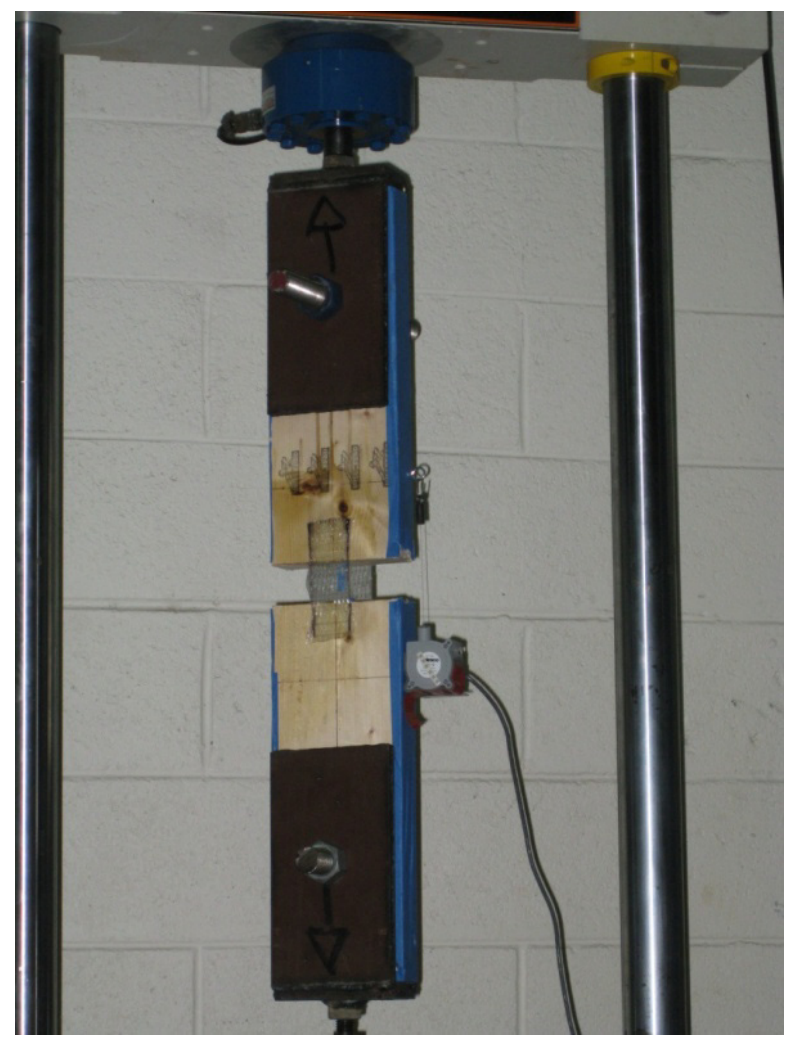

Figure 4-5 Test setup for shear connection test 


\subsubsection{Stud to top plate connection}

The uplift load test assembly consisted of:

1) A double top plate simulator made by using two 14 inches long wood pieces each having a cross-section of 2 inch $\times 6$ inch joined together by four 2.0 inch long nails;

2) A stud simulator made by using a 14.5 inch long wood piece having a crosssection 2 inch $\times 6$ inch.

The double top plate was placed at the top of the stud as shown in Figure 4-6. The wood type used for preparing the test assembly was spruce pine fir.

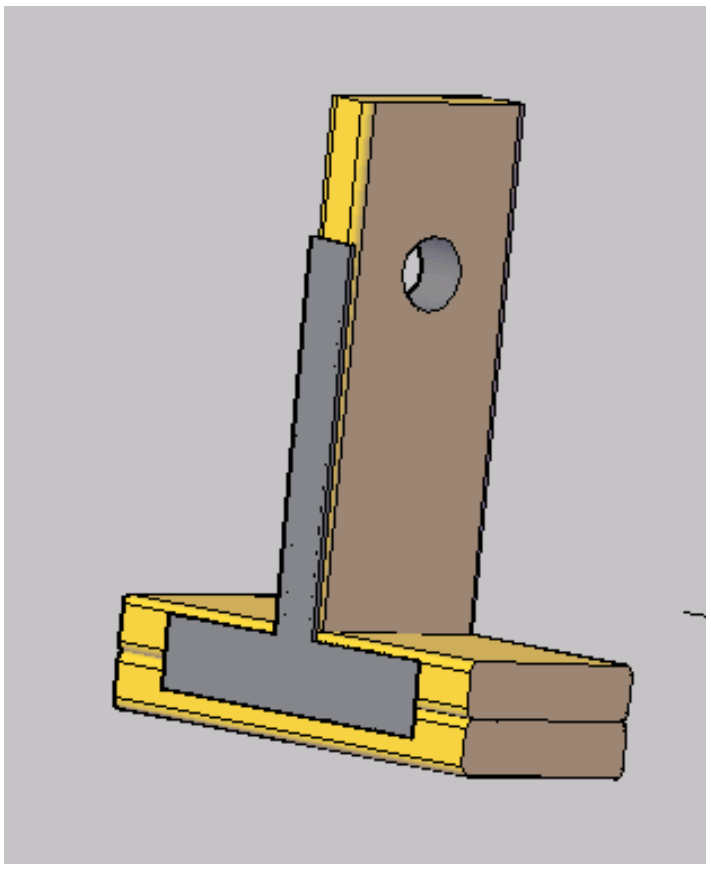

Figure 4-6 Test specimen for stud to top plate connection

The testing was conducted by placing the double top plate simulator on the bottom metal piece of the Testing Machine, and anchored using bolts. The bottom metal 
plate was then attached to the actuator and would provide the downward force on the test specimen.

In-order to provide the upward force on the specimen, the stud simulator was attached to a U-shaped metal assembly which in turn was attached to the reacting beam. To anchor the test specimen with the U-shaped metal assembly a 1.5 inch diameter hole was drilled at the same level (4.5 inch from the top), in both of the vertical stems of the U-shape. Once the stud-simulator was placed inside the U-shaped metallic assembly, a rod was passed through the holes in the stems and the specimen. This resulted in the anchoring of the specimen with the U-shaped metal assembly and allowed for the transfer of the upward force from the reacting beam to the test specimen. This assembly is shown in Figure 4-7.

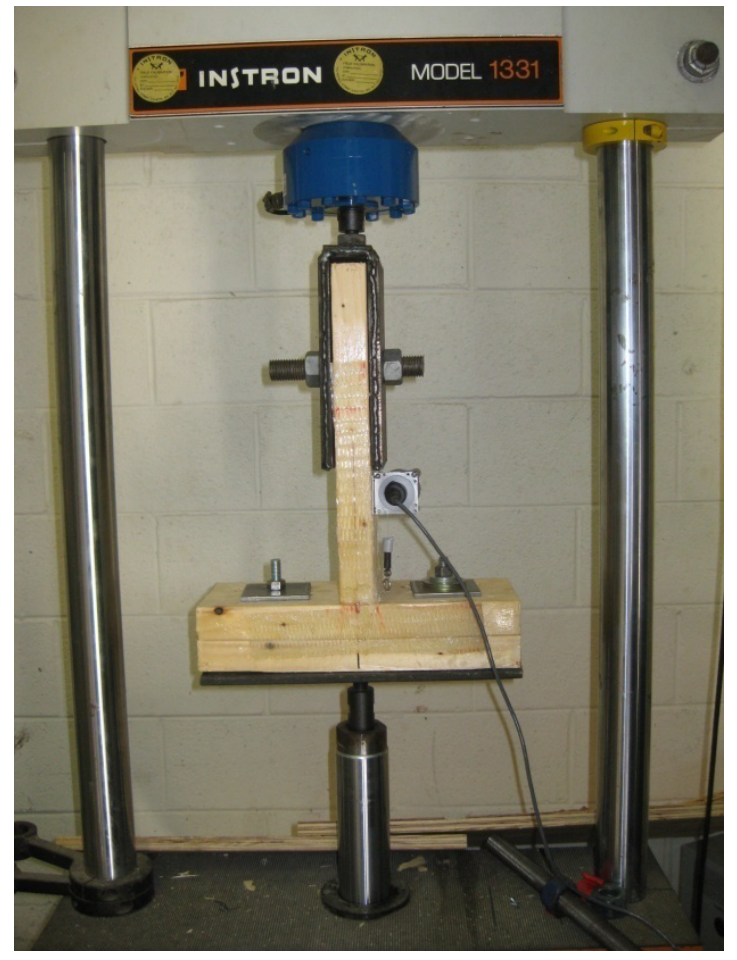

Figure 4-7 Test setup for stud to top plate connection 
In this setup, the FRP tie is expected to replace the metallic stud to top plate connection. Prior to the placement of the FRP ties it was intended to see if the test specimen setup was suitable for producing results similar to the test results given by product manufacturers. This was done by using rated metallic hurricane ties in the specimen and testing. The factored uplift strength of the stud to top plate connection provided by the publisher was 760 lbs for SP6 (Simpson Strong Tie C-2008). Results in Table 4-1 showed that the average load per clip was 829 lbs. These results proved that this test setup for stud to top plate connection was satisfactory and FRP ties could be tested using this setup.

\begin{tabular}{|c|c|c|c|c|c|c|}
\hline Test & $\begin{array}{c}\text { 1/8" } \\
\text { Deflection }\end{array}$ & $\begin{array}{l}\text { Ultimate } \\
\text { Load }\end{array}$ & $\begin{array}{l}\text { Governing Load } \\
\text { of Mechanism }\end{array}$ & Failure Mode & Average & $\begin{array}{l}\text { Coefficient } \\
\text { of Variation }\end{array}$ \\
\hline & $\mathbf{L b}$ & $\mathbf{L b}$ & $\mathbf{L b}$ & & lb & \\
\hline 1 & 830 & 2530 & 830.0 & $\begin{array}{c}\text { Nail failure in } \\
\text { stud }\end{array}$ & \multirow{5}{*}{828.67} & \multirow{5}{*}{0.04} \\
\hline 2 & 870 & 2860 & 870.0 & $\begin{array}{c}\text { Nail failure in } \\
\text { stud }\end{array}$ & & \\
\hline 3 & 910 & 2530 & 843.3 & $\begin{array}{c}\text { Nail failure in } \\
\text { stud }\end{array}$ & & \\
\hline 4 & 820 & 2790 & 820.0 & $\begin{array}{c}\text { Nail failure in } \\
\text { stud }\end{array}$ & & \\
\hline 5 & 780 & 2880 & 780.0 & $\begin{array}{c}\text { Nail failure in } \\
\text { stud }\end{array}$ & & \\
\hline
\end{tabular}

Table 4-1 Results for stud to top plate metallic connection 


\subsubsection{Gable end connection:}

This setup utilized two cross-sections, namely the wood members having a 2 inch x 6 inch cross-section was used as a joist, while the wood members utilized for the double top plates had a cross-section of 2 inch $\times 10$ inch. The wood type used for all the members was Southern Yellow Pine. As mentioned earlier, the hurricane ties were utilized to evaluate if the test setup was suitable. The test specimen used for testing uplift load capacity consisted of:

1) The double top plate simulated by two 22 inch long pieces. These two pieces were connected together using 2.0 inch nails.

2) The joist or the bottom chord of the truss simulated by 33 inch long piece.

The 33 inch long joist simulator was placed horizontally at the center of the double top plate and two hurricane clips were installed. The hurricane clip installed on one side of the joist was at one end of the junction between the double top plate and the joist. The second hurricane clip joining the double top plate and the joist was placed on the other side such that it was diagonal in position, relative to the first hurricane clip. This entire arrangement is shown in Figure 4-8.

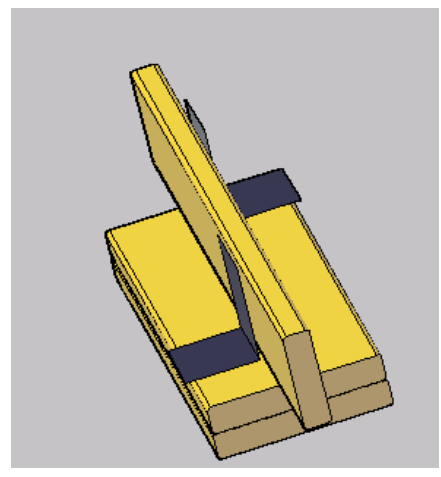

Figure 4-8 Test specimen for gable end connection 
This setup involved two U-shaped wood structures in order to carry out the testing. The function of the U-shaped wood members was to transfer the load applied by the machine directly to the connection between the joist and the double top plate.

The first of the U-shaped wood member (as shown in Figure 4-9) was responsible for transferring the downward force from the top metallic plate of the testing machine to the joist. This U-shaped member (shown as dark brown in figure) was placed in a manner that the two stems of the $U$ are resting on the joist while the horizontal member joining the two stems was responsible for receiving and transferring the load from the machine. This particular U-shaped member was comprised of:

1) The stems each with two wood pieces having a cross-section of 2 inch x10 inch. These two pieces were connected together using 2.0 inch nails.

2) The horizontal member joining the two stems together and made of two wood pieces, each was having a cross-section of 2 inch x10 inch. These two pieces were connected together using 1.5 inch nails.

Therefore the downward force on the test specimen would be provided by the Umember described above. To transfer this downward force, one U-shaped member was placed below the test specimen. It was placed in a manner such that its stems would push against the double top plate. Therefore in summary, when the load was applied, the top U-member (shown as dark brown in figure) pushed the joist downwards. The bottom Umembers (shown as light brown) used the reaction force imparted to push the double top plate upwards, thereby creating a tensile force in the connection between the double top plate and the joist. 
The bottom U-members were comprised of the stems each with two wood pieces each was having a cross-section of 2 inch $\mathrm{x} 10$ inch. These two pieces were connected together using 2.0 inch nails.

The horizontal member joining the two stems together was made of two wood pieces each with a cross-section of 2 inch $\times 10$ inch. These two pieces were connected together using 2.0 inch nails (Figure 4-10).
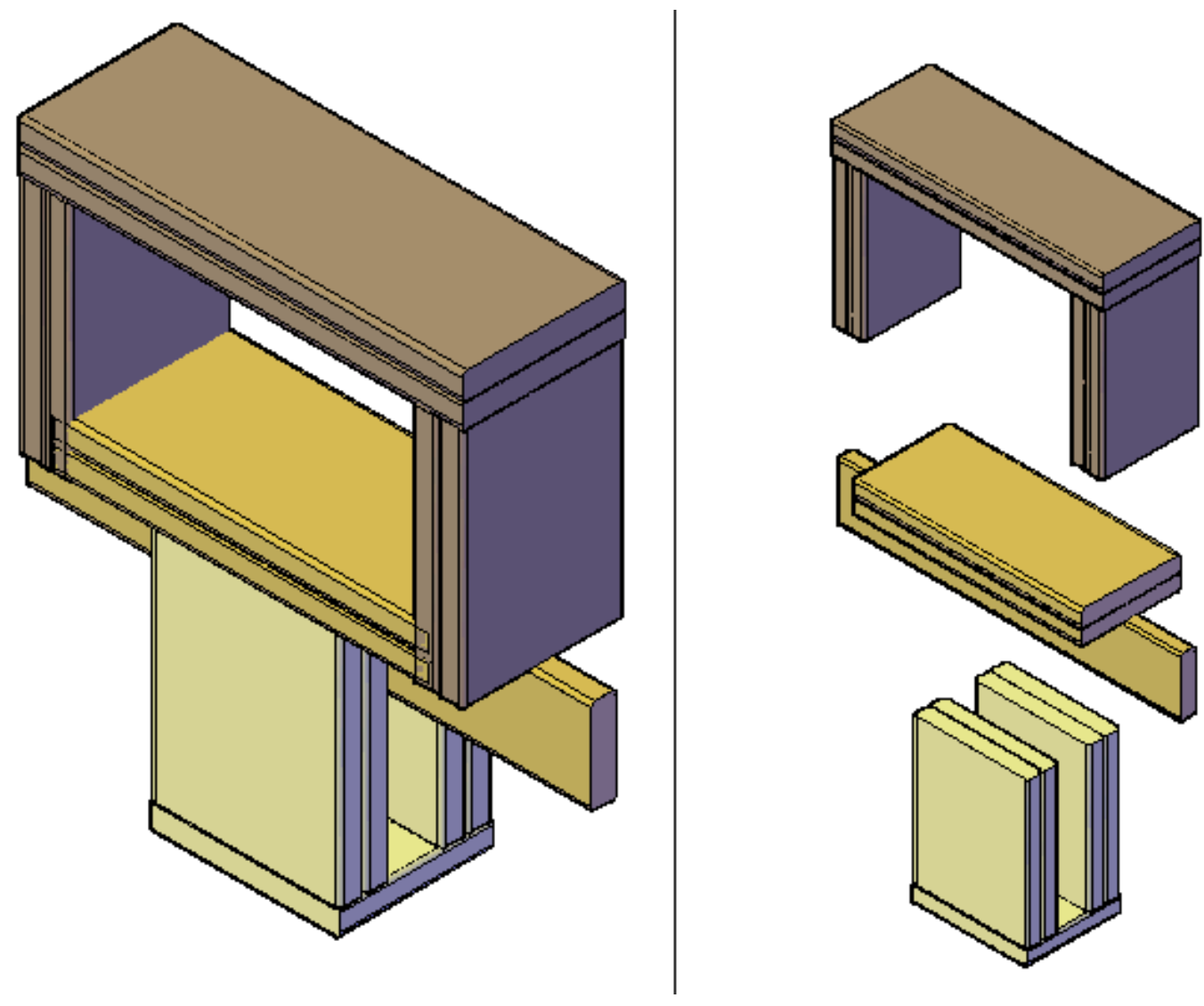

Figure 4-9 Test setup for gable end connection 


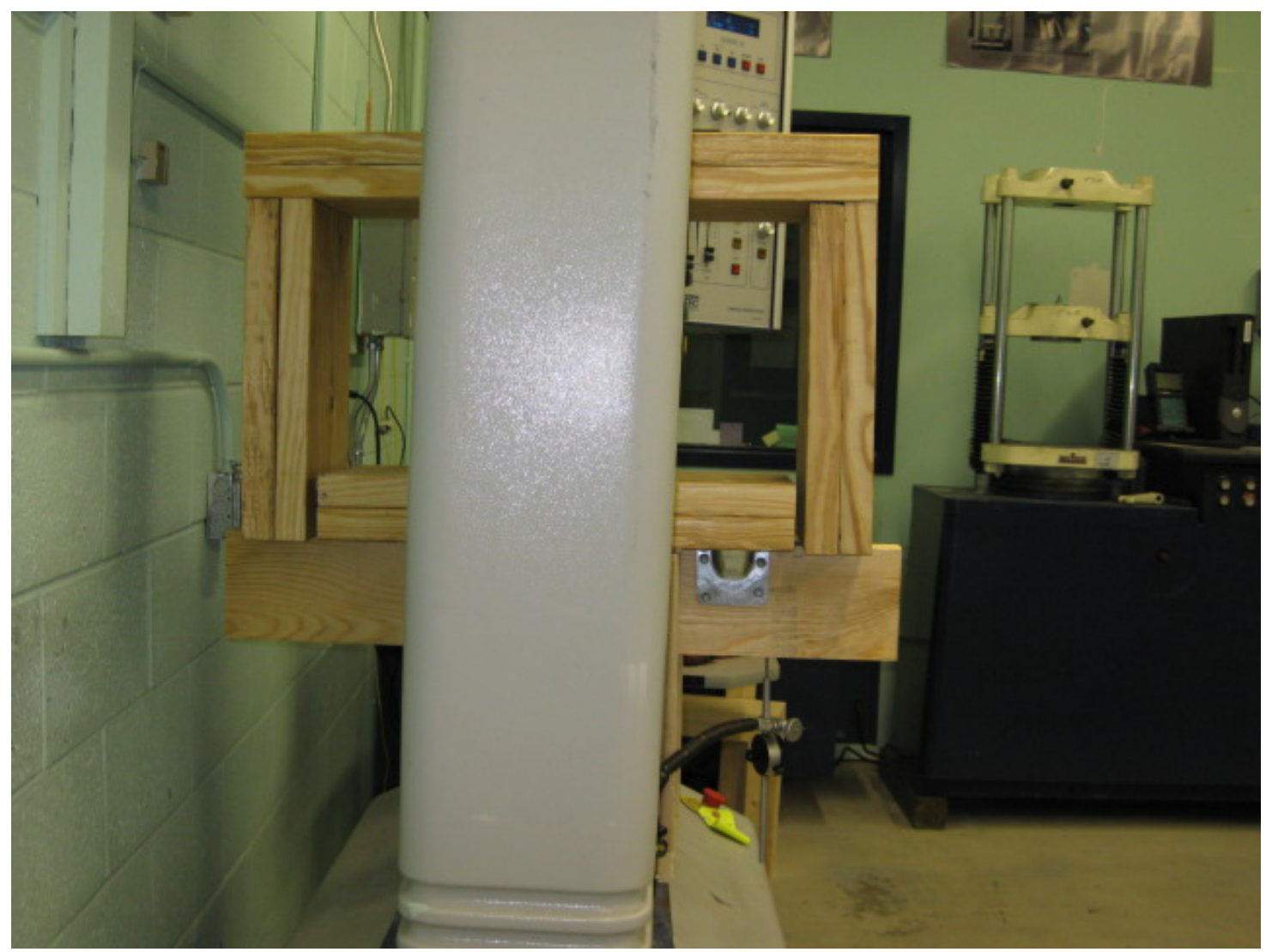

Figure 4-10 Test setup for gable end connection

In this setup, the angled FRP tie was expected to replace the metallic gable end connection. Prior to the placement of the FRP ties it was intended to see if the test specimen setup was suitable. This was done by using rated metallic hurricane ties in the specimen and testing. The factored uplift strength of the stud to top plate connection provided by the publisher was 500 lbs for HGA10 (Simpson Strong Tie C-2008). Results in Table 4-2 showed that the average load per clip was $774 \mathrm{lbs}$. These results proved that this test setup for gable end connection was satisfactory and FRP ties could be tested using this setup. 


\begin{tabular}{|c|c|c|c|c|c|c|}
\hline $\begin{array}{l}\text { Test } \\
\text { No }\end{array}$ & $\begin{array}{c}1 / 8^{\prime \prime} \\
\text { Deflection }\end{array}$ & $\begin{array}{c}\text { Ultimate } \\
\text { Load }\end{array}$ & $\begin{array}{c}\text { Governing } \\
\text { Load per } \\
\text { clip }\end{array}$ & $\begin{array}{l}\text { Failure } \\
\text { Mode }\end{array}$ & $\begin{array}{c}\text { Averag } \\
\text { e }\end{array}$ & $\begin{array}{c}\text { Coefficient } \\
\text { of } \\
\text { Variation }\end{array}$ \\
\hline & $\mathbf{l b}$ & Ib & Ib & & & \\
\hline 1. & 1320.00 & 2570.00 & 856.67 & $\begin{array}{c}\text { Wood crack } \\
\text { in joist }\end{array}$ & \multirow{5}{*}{774.00} & \multirow{5}{*}{0.22} \\
\hline 2. & 1210.00 & 1600.00 & 533.33 & $\begin{array}{c}\text { Wood crack } \\
\text { in joist }\end{array}$ & & \\
\hline 3. & 1300.00 & 2020.00 & 673.33 & $\begin{array}{c}\text { Wood crack } \\
\text { in joist }\end{array}$ & & \\
\hline 4. & 1510.00 & 2550.00 & 850.00 & $\begin{array}{c}\text { Wood crack } \\
\text { in joist }\end{array}$ & & \\
\hline 5. & 1470.00 & 2870.00 & 956.67 & $\begin{array}{c}\text { Wood crack } \\
\text { in joist }\end{array}$ & & \\
\hline
\end{tabular}

Table 4-2 Results of gable end metallic connection

\subsubsection{Development of FRP Ties:}

\subsubsection{Stud to top plate connection:}

\subsection{Configuration-1:}

Initially, development of the stud to top plate FRP connection was similar to the FRP connection used for the roof-to-wall connection. This angle connection (4 inch $\mathrm{x} 9$ inch) was placed on either side of the stud. Hence, there were four FRP angle connections per specimen. The failure of the connection was observed to occur at $510 \mathrm{lbs}$ before the 0.125 inch deflection limit was reached. Using the factor of safety as 3 , the factored ultimate 
load per connection (two FRP angles per connection) was actually $170 \mathrm{lbs}$. The failure of configuration-1 was observed to be due to the peeling of the FRP from the top plate with some wood fibers attached to it as shown in the Figure 4-11.

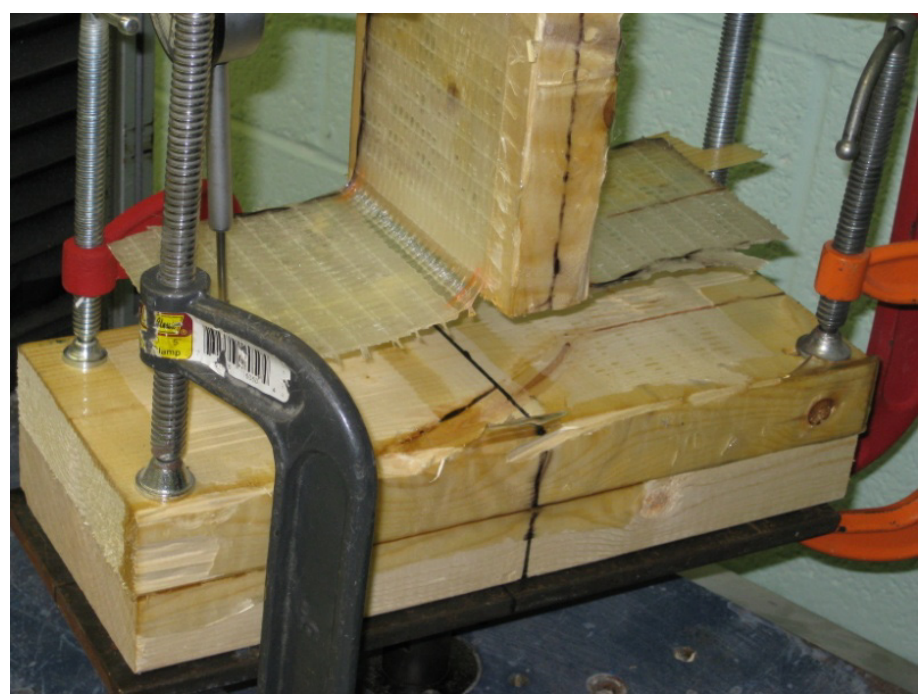

Figure 4-11 Failure mode of Configuration-1

\subsection{Configuration-2:}

This configuration consisted of a T-shape FRP piece which was applied to the test assembly in a manner that the flange of the T-shape was attached to the double top plate and the web of the T-shape was attached to the stud. The FRP ties were attached to the front and rear side of the top and bottom connections providing two connections per specimen. The area of each T-shape FRP piece was $35.75 \mathrm{inch}^{2}$. The failure of the connection was observed at $4,050 \mathrm{lbs}$ before the 0.125 inch deflection limit was reached. The factored ultimate load per connection (two T-shaped FRP pieces per connection) was found to be $1350 \mathrm{lbs}$. The failure mode of configuration-2 was determined to be shear failure from the double top plate with some wood fibers attached to it, as shown in Figure 4-12. 


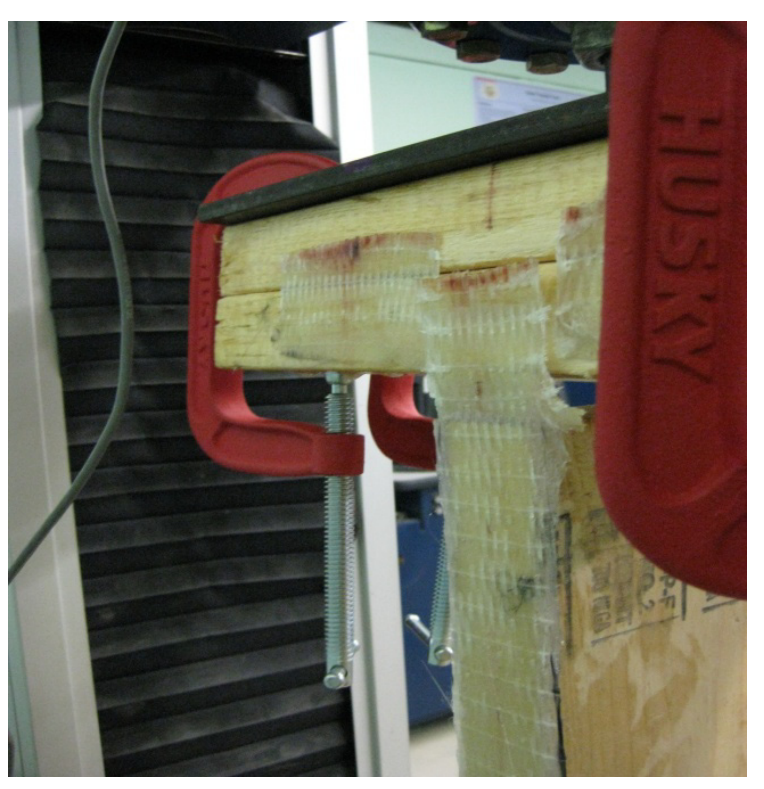

Figure 4-12 Failure mode of configuration-2

\subsection{Configuration - 3:}

This particular configuration consisted of two pieces of FRP each with dimension 24 inch x 1.5 inch. Two pieces of FRP were attached to the specimen starting from the top of the double top plate, overlapping at the junction of the double top plate and the stud and the ends of the FRP were then attached on either side of the stud, as shown in Table 4-3. As these FRP straps were only attached on one side of the specimen the specimen collapsed at the initial stage of loading.

\subsection{Configuration - 4.}

As discussed earlier, the failure mode of configuration-1 was the peeling of FRP from the top plate. The configuration-1 angle connection was modified by placing a double layer of FRP on the peeling side. This FRP angle connection was applied in the same manner as utilized in configuration-1. In configuration-4 one 4.5 inch $x 4.0$ inch piece of FRP was placed underneath the FRP angle. The area of connection including the double layer 
and the FRP angle connection was 54 sq inch. The failure of the connection was observed at $1560 \mathrm{lbs}$ before the 0.125 inch deflection limit was reached. Therefore the factored ultimate load per connection mechanism was $520 \mathrm{lbs}$. The failure mode of configuration1 was shear failure on one side of the stud and peeling of the upper layer of FRP on the opposite side as shown in Figure 4-13.

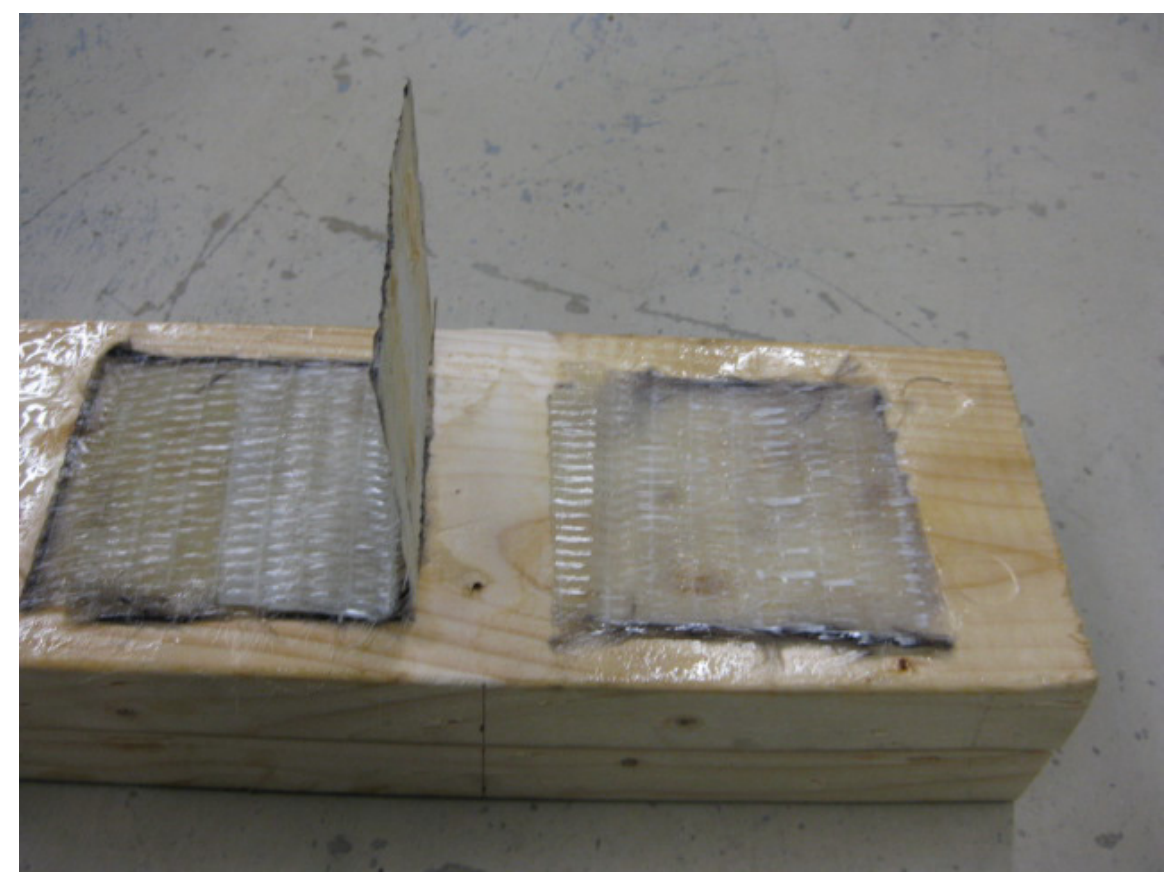

Figure 4-13 Failure mode of configuration-4

\subsection{Configuration 5:}

This configuration was the modified form of configuration-4. As the failure mode in configuration 4 was both peeling and shear therefore a double layer of FRP was added on the side exhibiting shear failure. In this configuration a 4.5 inch $\times 4.0$ inch piece of FRP was placed on both the top plate simulator and stud simulator before applying the angle on top of it. The area of angle connection, including double layer on the top plate and stud was $72 \mathrm{sq}$ inch. The failure of the connection was observed at $230 \mathrm{lbs}$ before 0.125 
inch deflection limit was reached. Therefore, the factored ultimate load per mechanism (Two FRP connection in each mechanism) was $76.7 \mathrm{lbs}$. The failure mode of configuration-5 was peeling of the upper layer on the one side and peeling of the upper layer with the partial rupturing of the bottom layer as shown in Figure 4.14. By placing the double layer on the stud shear failure was restricted but there was no increase in the ultimate load capacity.

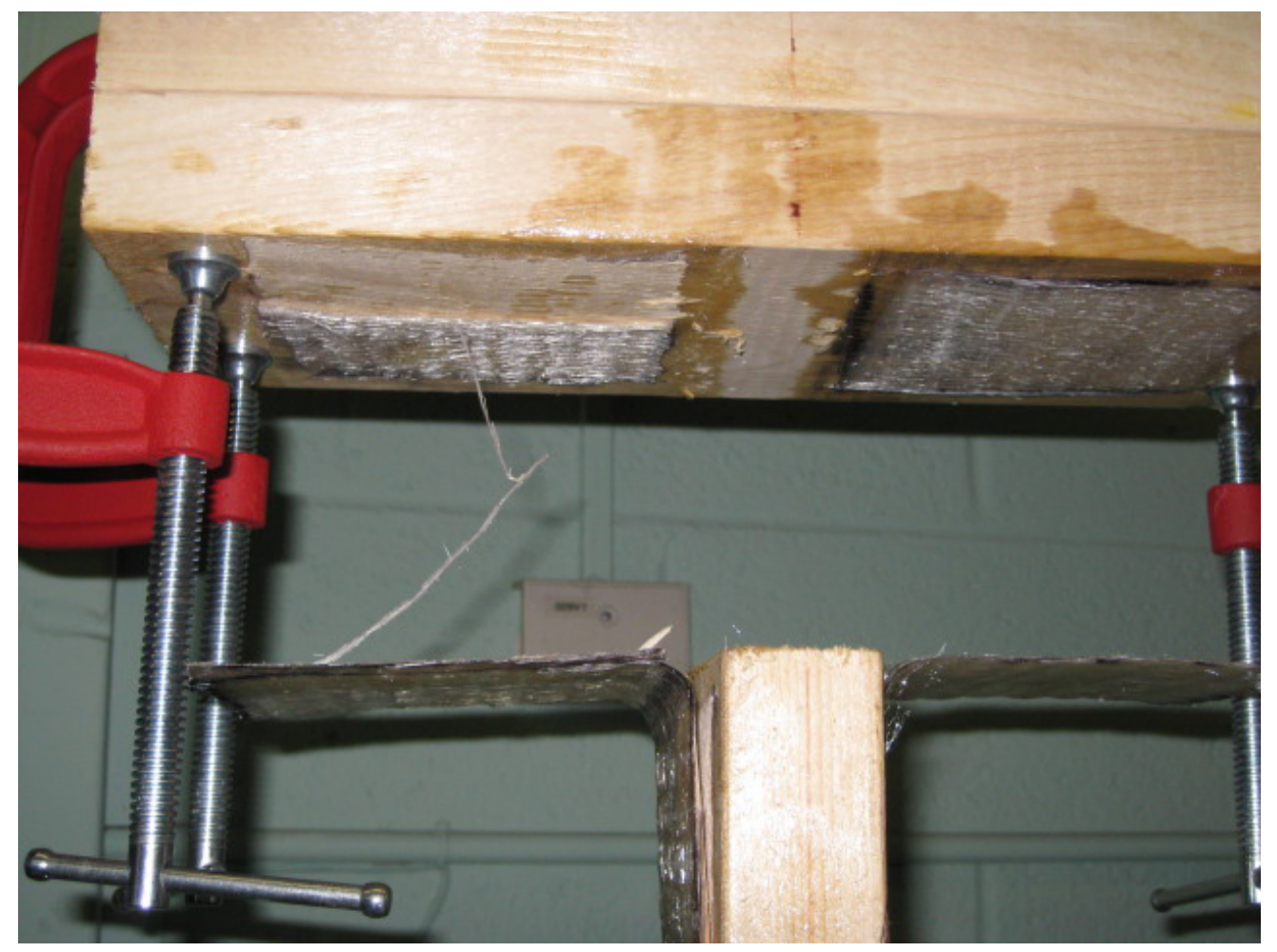

Figure 4-14 Failure mode of configuration-5

\subsection{Results of configuration ( $1-5)$ for gable end connection:}

Results from Table 4-3 shows that configuration- 2 worked better than all the other configurations. The factored ultimate load of the FRP connection was 1.8 times $(1350 / 760=1.8)$ the manufacturer published ultimate uplift strength of strap anchor. Therefore configuration-2 was the only configuration used for future testing. 


\begin{tabular}{|c|c|c|c|}
\hline CONFIGURATION & $\begin{array}{c}\text { ULTIMATE } \\
\text { LOAD }\end{array}$ & $\begin{array}{l}\text { FAILURE } \\
\text { MODE }\end{array}$ & PICTURE \\
\hline $\begin{array}{c}\text { CONFIGURATION- } \\
1\end{array}$ & 510 & $\begin{array}{l}\text { Peeled from } \\
\text { top plate }\end{array}$ & \\
\hline $\begin{array}{c}\text { CONFIGURATION- } \\
2\end{array}$ & 4050 & Shear failure & \\
\hline $\begin{array}{c}\text { CONFIGURATION- } \\
3\end{array}$ & 0 & $\begin{array}{l}\text { Fail at initial } \\
\text { loading stage }\end{array}$ & \\
\hline $\begin{array}{c}\text { CONFIGURATION- } \\
4\end{array}$ & 1560 & $\begin{array}{l}\text { Peeled from } \\
\text { top plate }\end{array}$ & \\
\hline $\begin{array}{c}\text { CONFIGURATION- } \\
5\end{array}$ & 230 & $\begin{array}{l}\text { Peeled from } \\
\text { top plate }\end{array}$ & \\
\hline
\end{tabular}

Table 4-3 Results of configuration 1-5 for stud to top plate connection 
Configuration-2 was further tested with the nails (Figure 4-15) to know the effect of nailing through the FRP ties as plywood sheathing should be attached at the exterior face of the stud using nails thus puncturing the FRP ties. The failure mode of configuration-2 with nails was same as the previous test done without the nails. The failure load showed only $2.7 \%$ decrease.

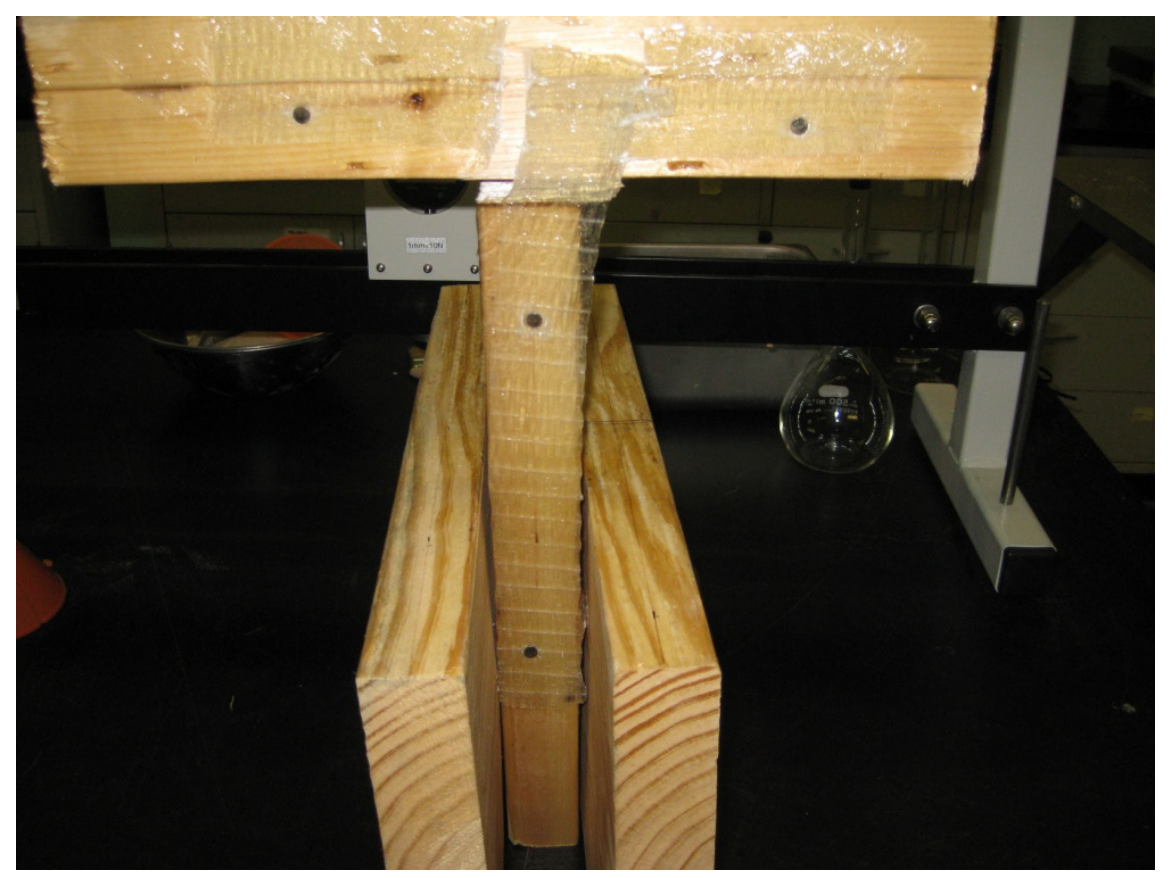

Figure 4-15 Failure mode of configuration-2 (with nails)

\subsubsection{Gable end connection:}

\subsection{Configuration-1:}

Development of FRP connection in-order to replace the metallic gable end connection was initiated with the 4 inch $x 9.5$ inch piece of FRP which is represented by configuration-1. This connection was designed for 2 inch x 6 inch wood cross-section, as it is the most commonly used wood cross-section for the construction of residential buildings. This 9.5 inch long piece of FRP was placed in between the double top plate 
and the bottom chord such that the 4 inch length of FRP was attached on the double top plate and the rest was attached to the bottom chord of the truss (joist). The area of angle connection was $38 \mathrm{sq}$ inch. The failure of the connection was observed at $2020 \mathrm{lbs}$ before the 0.125 inch deflection limit was reached. Therefore, the factored ultimate load per clip was $336 \mathrm{lbs}$. The failure mode of configuration- 2 was peeling from the double top plate as shown in Figure 4-16.

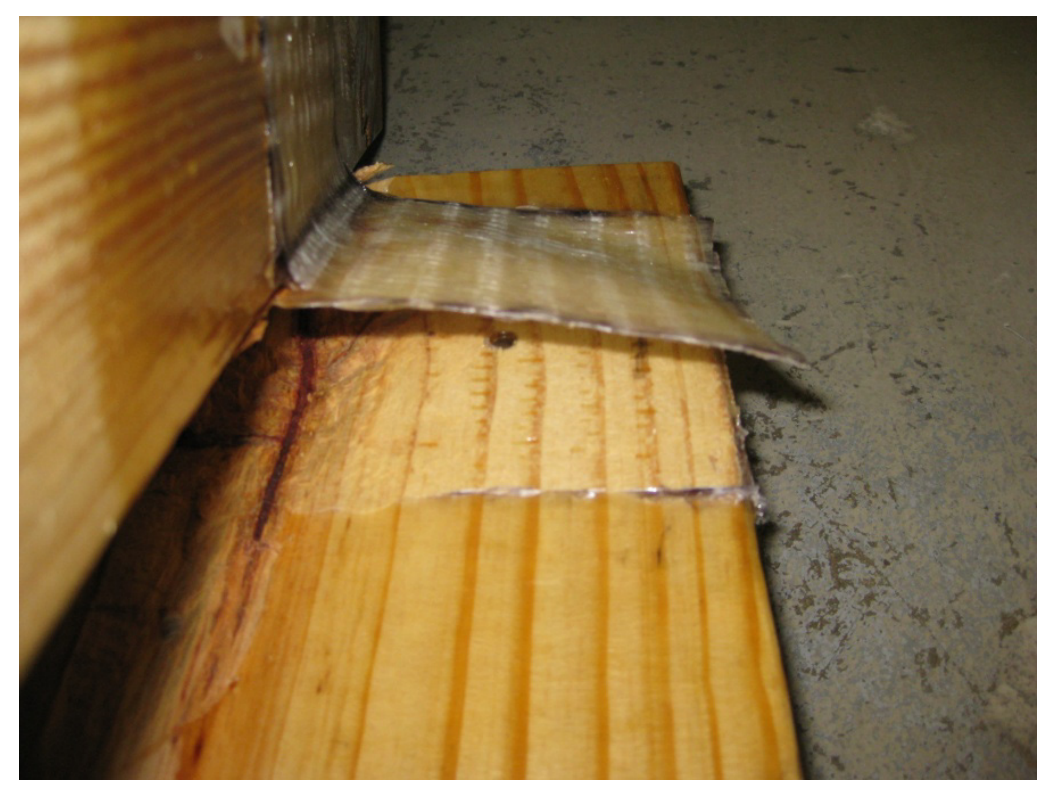

Figure 4-16 Failure mode of configuration-1

\subsection{Configuration-2:}

This configuration consisted of 4 inch x 16.5 inch piece of FRP. This connection was designed for 2 inch x 6 inch wood cross-section, as it is the most commonly used wood cross-section for the construction of residential buildings. This FRP connection was folded and applied in such a manner that 3 inch length of an FRP was applied on the shear side of the double top plate, and 4 inch length of FRP was applied to the double top plate on the peeling side and the rest was wrapped around the bottom chord. The area 
of angle connection was $56 \mathrm{sq}$ inch. The failure of the connection was observed at 2900 lbs before the 0.125 inch deflection limit was reached. Therefore, the factored ultimate load per clip was $483 \mathrm{lbs}$. The failure mode of configuration-2 was the peeling of FRP from the double top plate as shown in Figure 4-17.

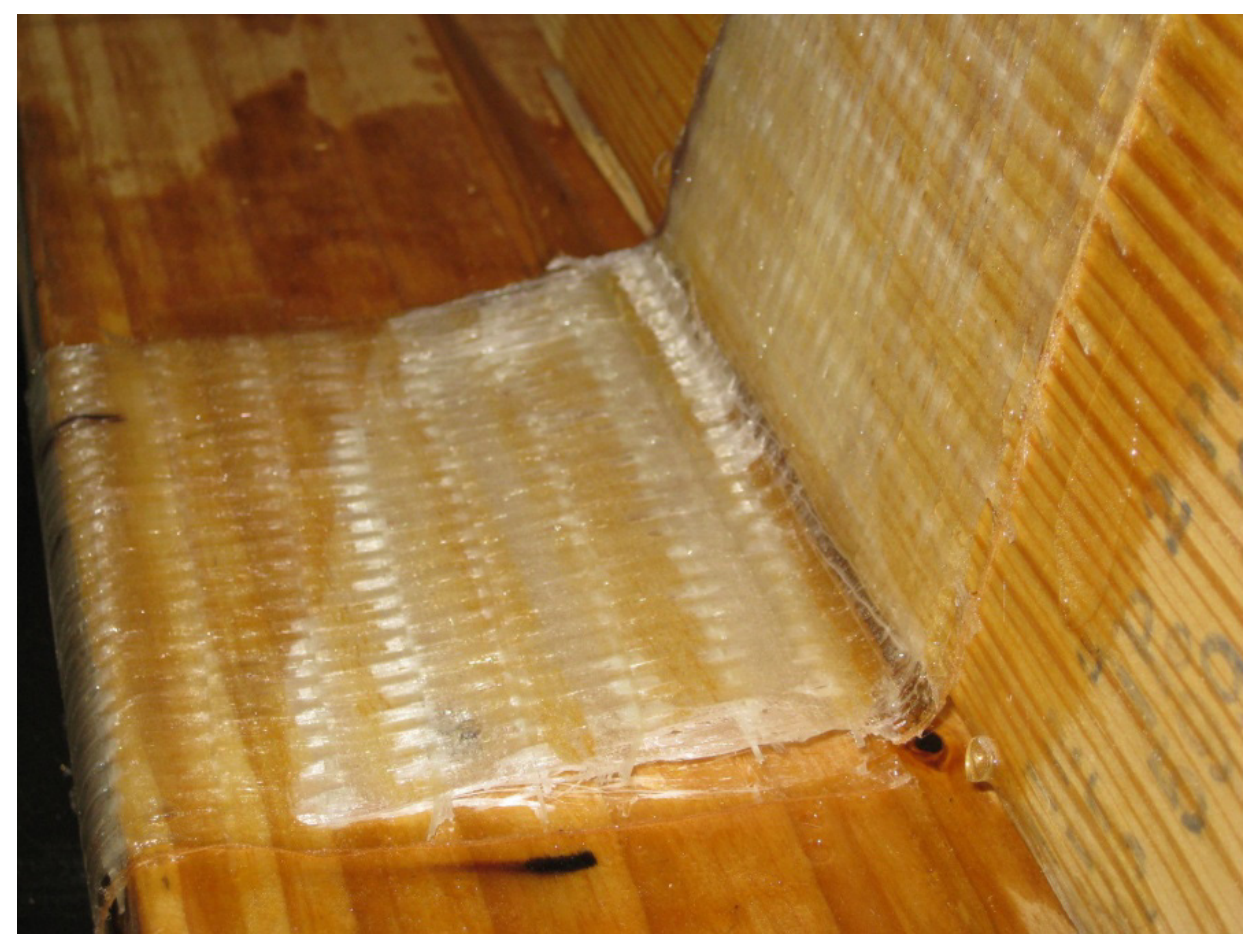

Figure 4-17 Failure mode of configuration-2

\subsection{Configuration-3:}

This configuration consisted of 4 inch $\times 9$ inch piece of FRP and this connection was the modified form of configuration-1. As it was seen the failure mode of configuration-1 was peeling, to strengthen the connection double layer of FRP was placed on the peeling side. This FRP connection was applied in such a manner that before applying the folded angle FRP a 4 inch $\mathrm{x} 4$ inch piece of FRP was placed on the peeling face. The area of angle connection was $52 \mathrm{inch}^{2}$. The failure of the connection was observed at $3980 \mathrm{lbs}$ before 0.125 inch deflection limit was reached. Therefore, the 
factored ultimate load per connection was $663 \mathrm{lbs}$. The failure mode of configuration-3 was the peeling of FRP from the double top plate as shown in Figure 4-18.

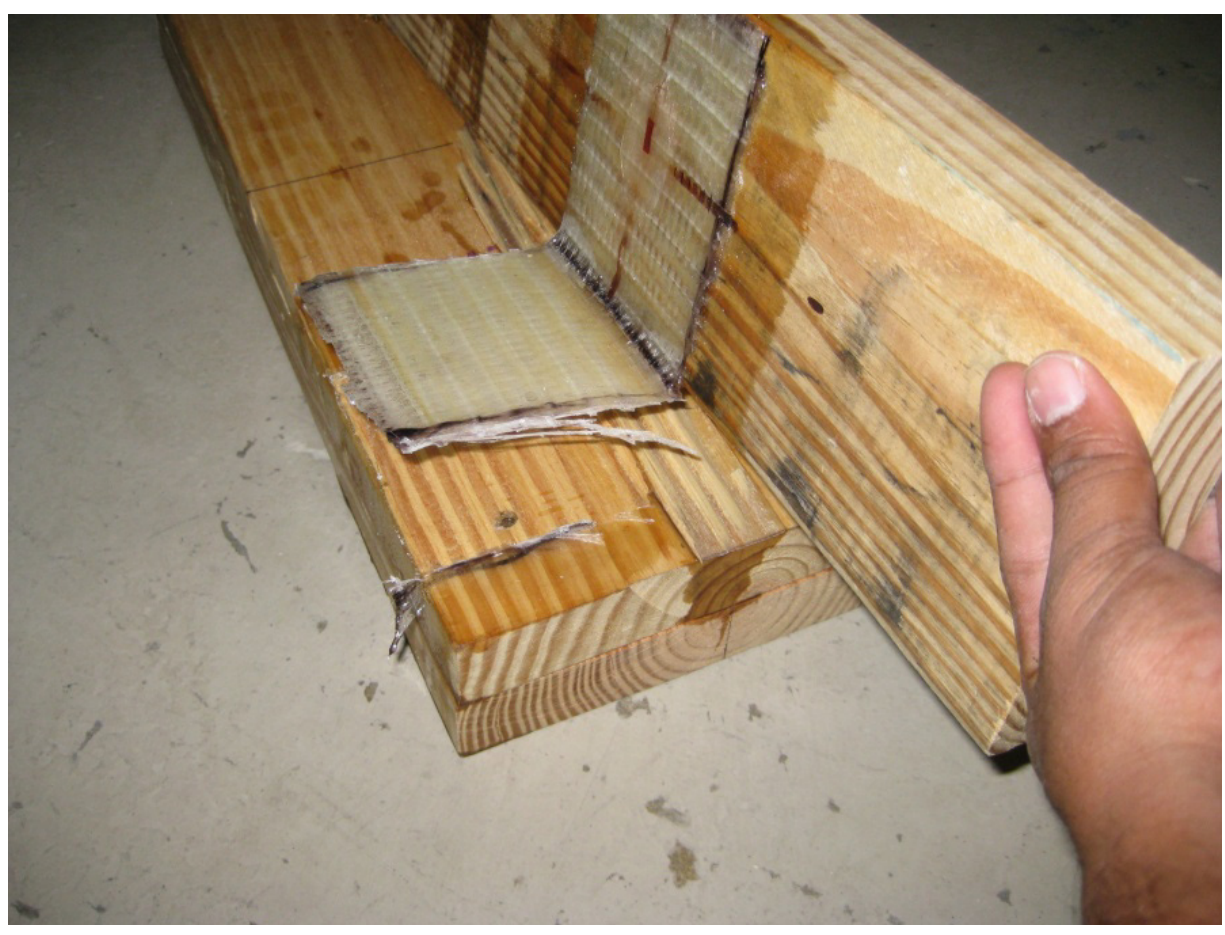

Figure 4-18 Failure of configuration-3

\subsection{Configuration-4:}

Configuration-4 was a modification of configuration-3, and involved placing an additional layer on the shear face as well. This FRP connection was applied in such a manner that before applying the folded angle FRP a 4 inch $\mathrm{x} 4$ inch piece of FRP was placed on the peeling face (double top plate) and 4 inch $\times 5$ inch piece of FRP was placed on the shear face (joist). The area of angle connection was $72 \mathrm{sq}$ inch. The failure of the connection was observed at $4650 \mathrm{lbs}$ before the 0.125 inch deflection limit was reached. Therefore, the factored ultimate load per clip was $775 \mathrm{lbs}$. The failure mode of configuration-3 was the peeling of FRP from the double top plate as shown in Figure 4-19. 


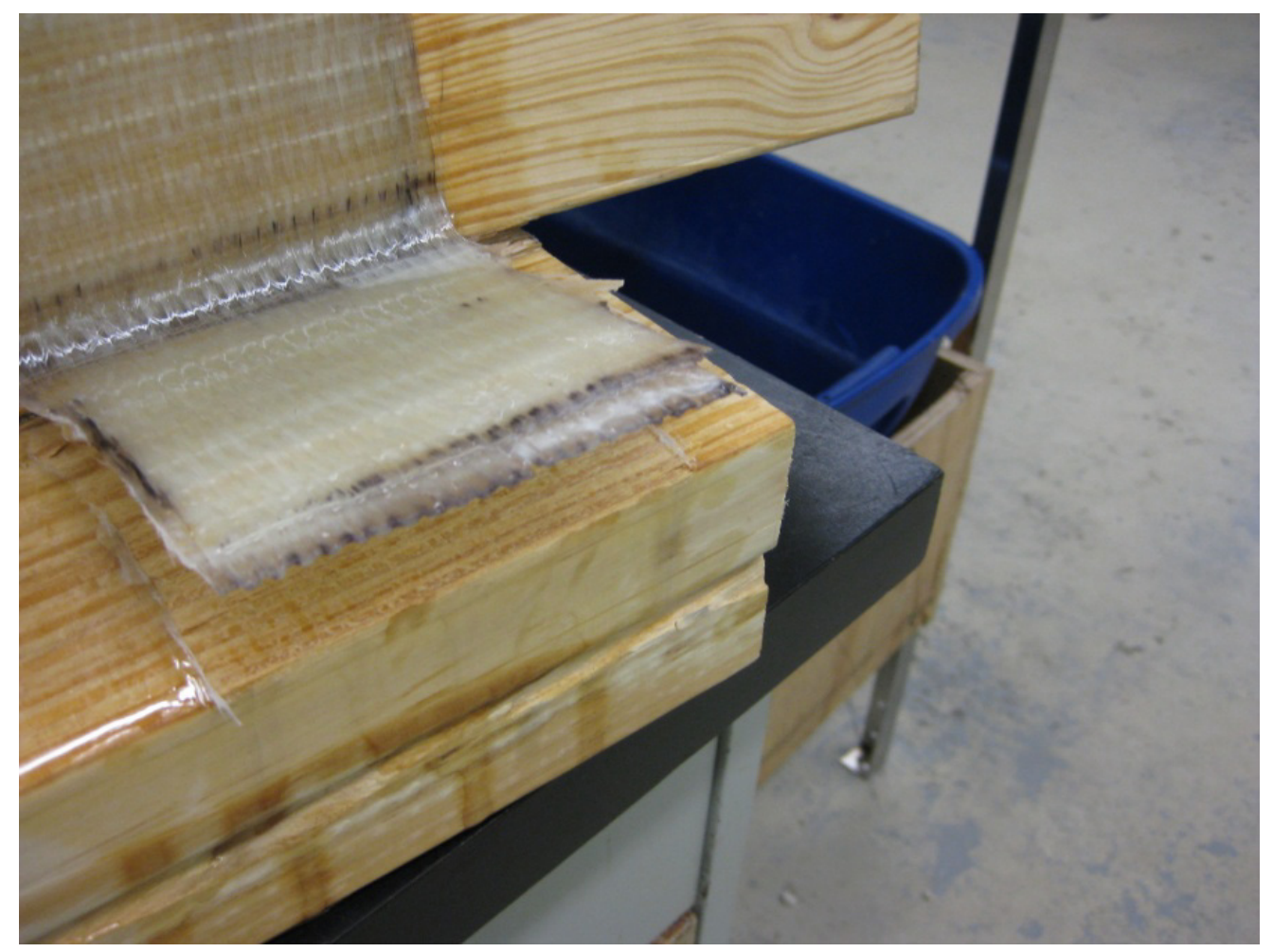

Figure 4-19 Failure mode of configuration-4

\subsection{Results of configurations 1-4:}

Results from Table 4-4 showed that configuration 3 and 4 uplift capacity was more than uplift capacity of the metallic clip which was rated as 1500 lbs per clip. Configuration-3 uplift capacity was $24 \%$, and configuration- 4 was $35 \%$ higher than the uplift capacity of the metallic connection. As less FRP was used in configuration-3, that configuration was considered more economical and was adopted for further testing. 


\begin{tabular}{|c|c|c|c|}
\hline CONFIGURATION & $\begin{array}{l}\text { ULTIMATE } \\
\text { LOAD }\end{array}$ & FAILURE MODE & PICTURES \\
\hline $\begin{array}{c}\text { CONFIGURATION- } \\
1\end{array}$ & 1010 & $\begin{array}{c}\text { Peeled from top } \\
\text { plate }\end{array}$ & \\
\hline $\begin{array}{c}\text { CONFIGURATION- } \\
2\end{array}$ & 1450 & $\begin{array}{c}\text { Peeled from top } \\
\text { plate }\end{array}$ & \\
\hline $\begin{array}{l}\text { CONFIGURATION- } \\
3\end{array}$ & 1990 & $\begin{array}{l}\text { Peeled from top } \\
\text { plate }\end{array}$ & \\
\hline $\begin{array}{c}\text { CONFIGURATION- } \\
4\end{array}$ & 2325 & $\begin{array}{l}\text { Peeled from top } \\
\text { plate }\end{array}$ & \\
\hline
\end{tabular}

Table 4-4 Results of configuration 1-4 for gable end connection 


\subsubsection{Feasibility of developed FRP ties:}

Once the FRP ties were developed, this research examined the technical feasibility of FRP ties for stud to top plate and gable end connections. In order to prove the feasibility of the FRP ties these connections were tested with three different loading conditions:

1) Static load test (to obtain the ultimate load capacity).

2) Sustained load test (for creep testing)

3) Dynamic load test (for fatigue testing).

\subsubsection{Static load test:}

Monotonic loading tests were performed to determine the ultimate uplift load capacity of the developed FRP ties. A total of 9 tests were performed under monotonic loading and out of those 9 tests, 3 tests were for shear connection, 3 tests for stud to top plate connection, and 3 tests for gable end connection. These tests were performed in accordance with ASTM D-1761 and at a rate of loading equal to $3.5 \mathrm{lb} / \mathrm{sec}$. As ASTM does not specify the loading rate for load control testing, the specimens were previously tested under the displacement control with $0.035 \mathrm{in} / \mathrm{min}$ loading rate. This was done in order to calculate the loading rate for load control testing. The loading rate of $3.5 \mathrm{lb} / \mathrm{sec}$ was the minimum loading rate calculated from the data collected from the tests performed under $0.035 \mathrm{in} / \mathrm{min}$ loading rate. String potentiometers (string pots) were used to monitor the displacement of the connections. Testing was carried out with a universal testing machine (Instron Model 1331) and the loading arrangement was similar to the one previously explained in section 4.2.1 for shear connection test and for each of the connections. Once the specimen was in place the string pots were initialized through the 
data acquisition system as being at zero position. The data collection sampling rate for monotonic loading test was $1 \mathrm{~Hz}$, and the load was continuously applied until failure.

\subsubsection{Sustained load test:}

The goal of this testing was to check the short-term creep deformation of the FRP ties during 3 hours of sustained high wind force. This creep testing did not involve the effect of physical aging, temperature and long-term creep deformation. In this research each specimen was tested for three different stress ratios (nominal stress to the ultimate stress) which were $50 \%, 75 \%$ and $85 \%$ of the minimum failure load from the three static tests. Total 9 tests were performed with each connection, 3 tests being performed for each stress ratio. These tests were performed in accordance with ASTM D-6815-02A. According the ASTM 6815-02A the loading rate for creep test specimen should be such that the average time to attain the sustained stress level does not exceed the average time to failure of the monotonic loading test. Rate of loading was kept $3.5 \mathrm{lb} / \mathrm{sec}$ as it did not

exceed the average time to failure of the monotonic loading test. The load history (Figure-4-20) was such that after time $\mathrm{T}_{0}$ the specimen was subjected to the sustained load for up to 3 hours. Specimens that survived up to 3 hours were unloaded at $T_{R}$ and loaded with a rate of $3.5 \mathrm{lb} / \mathrm{sec}$ till failure to investigate the residual ultimate strength. 


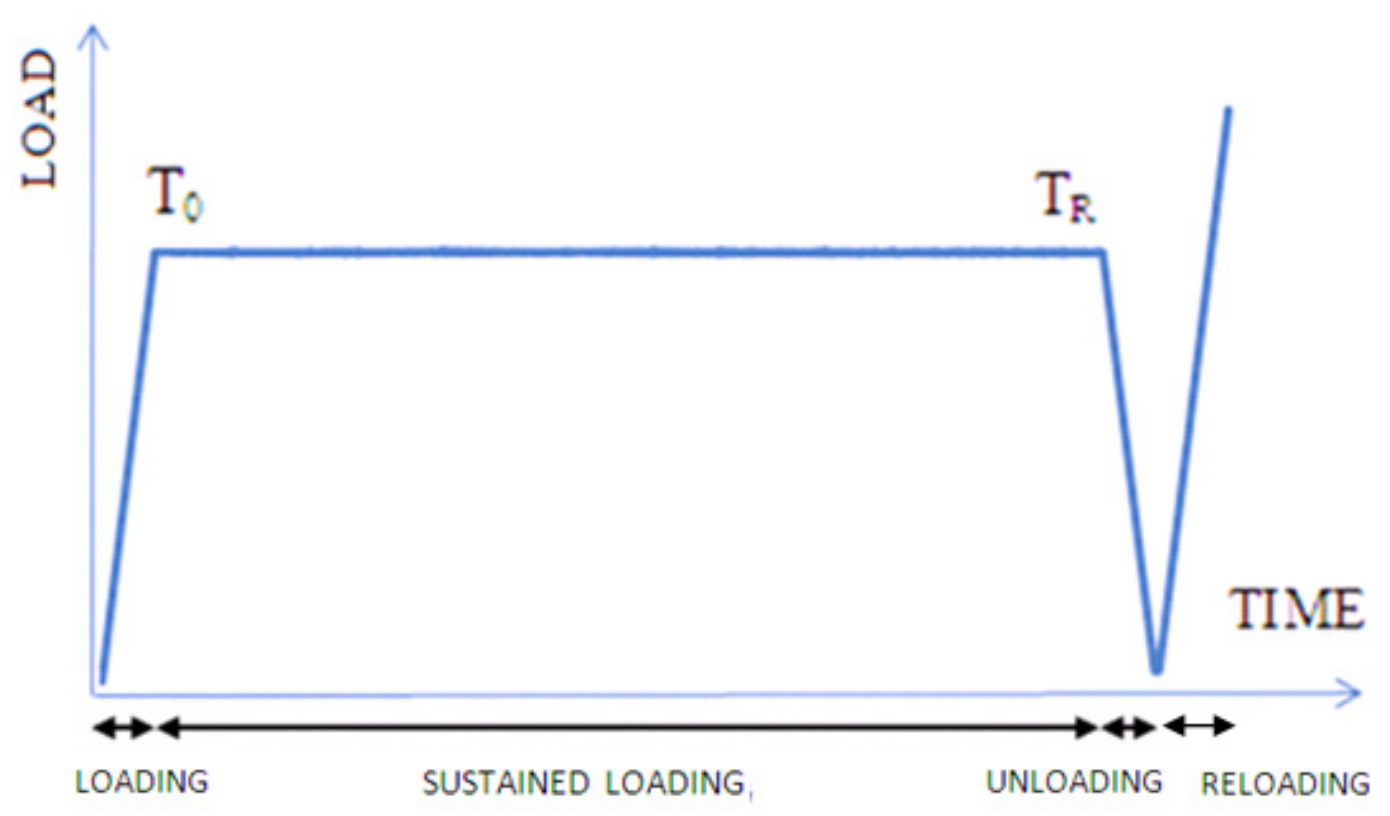

Figure 4-20 Load History for creep test

\subsubsection{Dynamic load test:}

Fatigue resistance of the FRP connection could also be found by using conventional fatigue testing. Mode of fatigue testing by which all the FRP connections were tested is tension-tension at $\mathrm{R}=0.1$ ( $\mathrm{R}$ is the minimum stress divided by the maximum stress) with three different stress levels in-order to plot the S-N curve. A hydraulic testing machine (Instron Model 1331) was selected to carry out the fatigue test and this machine is equipped with a 12.5 kip load cell that worked in both tension and compression. The machine was used with a MMI (Control Unit) and a data acquisition system which received data from linear voltage string pot and load cell. The frequency of loading in the fatigue tests was intended to simulate 3 second wind gust (frequency of the test was 0.3 $\mathrm{Hz}$ ). In order to make sure the sample was never subjected to compressive stress, it was decided to limit the minimum stress to $10 \%$ of the maximum stress, and to have a loading 
condition with an $\mathrm{R}=0.1$. The load history should be such that the initial loading on the specimen should reach up to the mean stress level at a loading rate of $3.5 \mathrm{lb} / \mathrm{sec}$. After reaching the mean stress level, the cyclic loading was initiated. The maximum duration to run this test was 6 hours.

In case there was no failure during the 6 hours test a new test matrix was used in order to evaluate the stiffness degradation under the dynamic loading. For such evaluation three specimens for each type connection were tested under cyclic loading for 6 hours using three different stress ratios, i.e, $50 \%, 75 \%$ and $85 \%$. For the minimum load $\mathrm{R}=0.1$ was used as explained earlier. The time period for each cycle was 4 seconds (frequency being $0.25 \mathrm{~Hz}$ ) and the data sampling rate was $25 \mathrm{~Hz}$. So there were 100 points in each cycle. If the specimen didn't fail in 6 hours, it was unloaded and quickly re-loaded up to failure in order to investigate the residual ultimate strength. 


\section{Results:}

\subsection{Static test:}

\subsubsection{Shear connection test:}

The typical mode of failure was delamination, as shown in the Figure 5-1, which occurred between the wood and FRP for shear connection test revealing that the tension strength of the FRP was higher than the bond strength. The ultimate uplift capacity of shear connection test is shown in Table 5-1. The difference between the maximum displacements of the three tests as shown in Table 5-1 can be attributed due to the inconsistency in the thickness of epoxy while preparing the specimen.

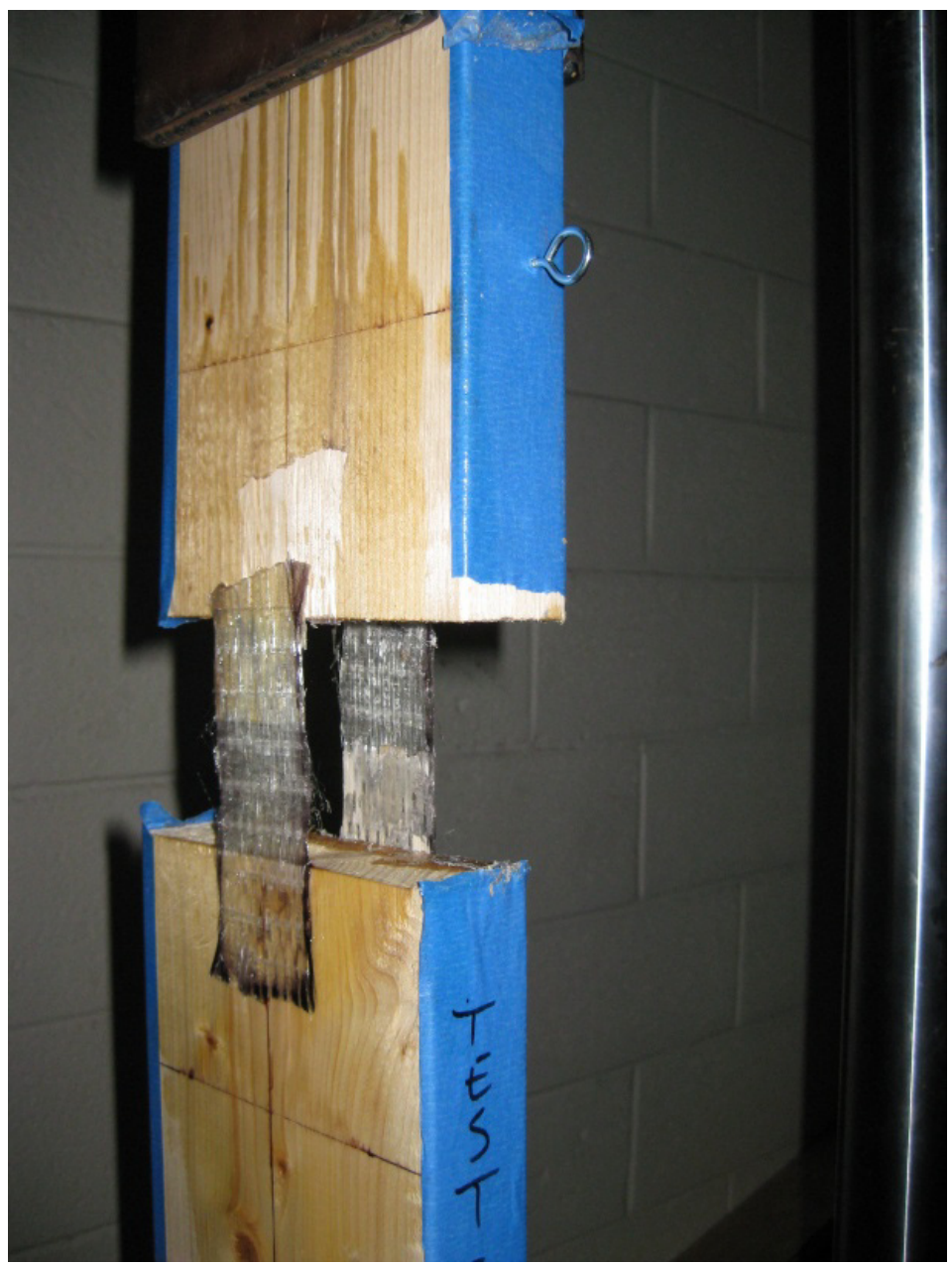

Figure 5-1 Failure mode of shear connection test. 


\begin{tabular}{|c|c|c|c|c|c|}
\hline $\begin{array}{c}\text { Test } \\
\text { No }\end{array}$ & $\begin{array}{c}\text { Ultimate } \\
\text { uplift } \\
\text { load } \\
\text { capacity }\end{array}$ & $\begin{array}{c}\text { Maximum } \\
\text { displacement }\end{array}$ & Failure mode & $\begin{array}{c}\text { Average } \\
\text { ultimate } \\
\text { load }\end{array}$ & $\begin{array}{c}\text { Coefficient } \\
\text { of variation } \\
\text { for ultimate } \\
\text { load }\end{array}$ \\
\hline Test-1 & 3686.33 & 0.0420 & Shear failure & & \\
\cline { 1 - 3 } Test-2 & 3146.40 & 0.0316 & Shear failure & \multirow{2}{*}{3425.83} & \multirow{2}{*}{0.29} \\
\cline { 1 - 3 } Test-3 & 3444.75 & 0.0570 & Shear failure & & \\
\hline
\end{tabular}

Table 5-1 Results of shear connection test with static loading.

\subsubsection{Stud to top plate connection}

The typical mode of failure for stud to top plate connection was delamination and rupturing of FRP from the face of the double top plate as shown in Figure 5-2. As the FRP used for the preparation of this connection was uni-directional the rupturing of FRP took place in the direction parallel to the fibers. The ultimate uplift load capacity of three specimens for stud to top plate connection is shown in Table 5-2. The results showed that the average ultimate capacity of the stud to top plate connection in uplift is 2.1 times greater than the rated metallic hurricane clip. The difference between the maximum displacements of the three tests as shown in Table 5-2 can be attributed due to the inconsistency in the thickness of epoxy while preparing the specimen.

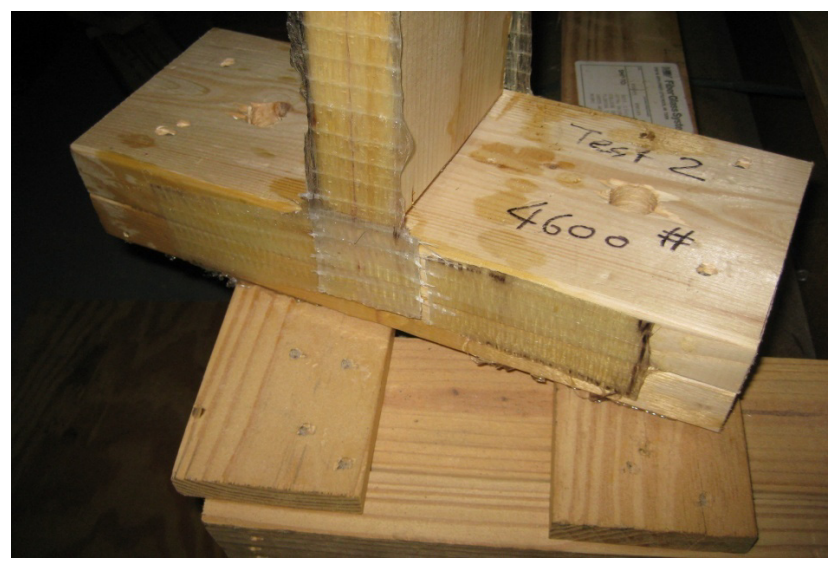

Figure 5-2 Mode of failure for stud to top plate connection 


\begin{tabular}{|c|c|c|c|c|c|}
\hline $\begin{array}{c}\text { Test } \\
\text { No }\end{array}$ & $\begin{array}{c}\text { Ultimate } \\
\text { uplift } \\
\text { load } \\
\text { capacity }\end{array}$ & $\begin{array}{c}\text { Maximum } \\
\text { Displacement }\end{array}$ & Failure Mode & $\begin{array}{c}\text { Averag } \\
\text { e } \\
\text { ultimat } \\
\text { e load }\end{array}$ & $\begin{array}{c}\text { Coefficient } \\
\text { of variation }\end{array}$ \\
\hline Test-1 & 5345.67 & 0.0878 & Shear failure & & \multirow{2}{*}{ lb } \\
\cline { 1 - 4 } Test-2 & 4637.38 & 0.0666 & Shear failure & 4799.35 & \multirow{2}{*}{0.10} \\
\cline { 1 - 4 } Test-3 & 4414.99 & 0.0566 & Shear failure & & \\
\hline
\end{tabular}

Table 5-2 Results of uplift load capacity of Stud to top plate connection

\subsubsection{Gable end connection}

The typical mode of failure for gable end connection was peeling of FRP from the double top plate as shown in Figure 5-3.

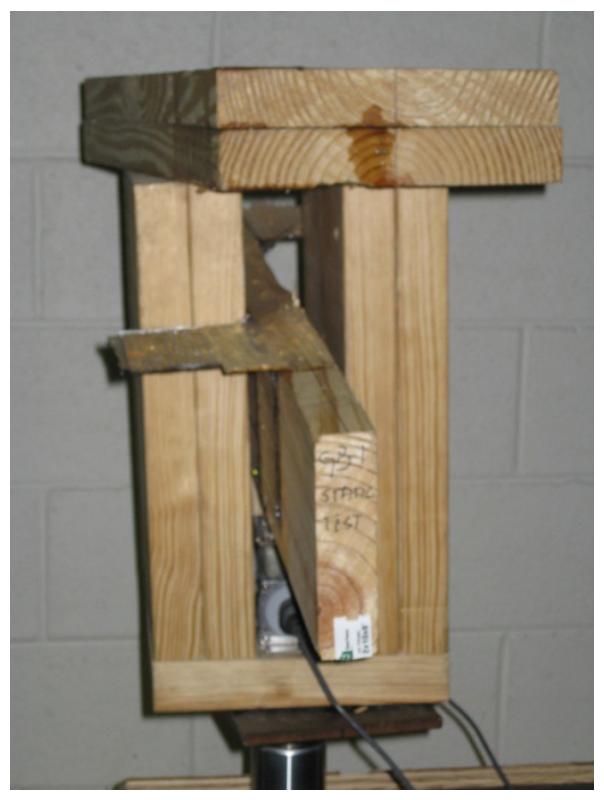

Figure 5-3 Failure mode of Gable end connection

In some specimens top FRP angle was peeled from the bottom layer of FRP, as the double layer of FRP was placed on the peeling face. The ultimate uplift load capacity of stud to top plate connection is shown in Table 5-3. The results showed that the average ultimate capacity of the stud to top plate connection in uplift is 1.13 times greater 
than the rated metallic hurricane clip. The difference between the maximum displacements of the three tests as shown in Table 5-3 can be attributed due to the inconsistency in the thickness of epoxy while preparing the specimen.

\begin{tabular}{|c|c|c|c|c|c|}
\hline Test & $\begin{array}{l}\text { Ultimate } \\
\text { uplift load } \\
\text { capacity }\end{array}$ & $\begin{array}{c}\text { Maximum } \\
\text { displacement }\end{array}$ & Failure Mode & $\begin{array}{c}\text { Average } \\
\text { ultimate } \\
\text { load }\end{array}$ & $\begin{array}{l}\text { Coefficient } \\
\text { of variation }\end{array}$ \\
\hline & lb & inch & & $\mathbf{l b}$ & \\
\hline Test-1 & 3471.38 & 0.0824 & $\begin{array}{l}\text { Peeling from the top } \\
\text { plate }\end{array}$ & \multirow{3}{*}{3406.12} & \multirow{3}{*}{0.17} \\
\hline Test-2 & 3311.24 & 0.0626 & $\begin{array}{l}\text { Peeling from the top } \\
\text { plate }\end{array}$ & & \\
\hline Test-3 & 3435.75 & 0.0612 & $\begin{array}{l}\text { Peeling from the top } \\
\text { plate }\end{array}$ & & \\
\hline
\end{tabular}

Table 5-3 Results of uplift load capacity of Gable end connection

\subsection{Creep testing:}

Creep test result was analyzed using the ASTM D-6815-02a. According to this specification each surviving specimen tested under a constant load should experience a decreasing creep rate with a fractional deflection less than or equal to 2.0 in order to be declared as a creep resistant wood composite.

Based on the above mentioned acceptance criteria the decrease of creep rate for 3 hour sustain load, can be proved by equation 5-1 and fractional deflection is calculated by using equation 5-2.

1) Decrease in creep rate (in per hour or in per min) can be proved by equation 5-1.

$$
\text { D1-Di > D3-D2 }
$$

2) Fractional deflection is calculated by using:

$$
\mathrm{FD}_{\mathrm{j}}=\mathrm{D}_{\mathrm{j}} / \mathrm{Di}<2.0 \quad \mathrm{j}=1,2,3
$$

(Equation 5-2) 
where,

$\mathrm{Di}=$ initial deflection measured one minute after applying the sustained load.

D1, D2, D3 = deflection measured on the 1st, 2nd and 3rd hour.

\subsubsection{Creep results for stud to top plate and gable end connections}

During the 3 hours sustained load no abnormal behavior or sign of failure was observed for the stud to top plate and gable end connections. The results of creep testing for the shear connection were non-conclusive due to the inadequacy of the shear connection test set up under sustained loading because of uncontrollable load distribution between the two FRP ties separated by a gap. A more effective test set up needs to be developed to perform such creep testing.

The fractional deflection and creep rate under sustained loading for three stress ratios $(50 \%, 75 \%$, and $85 \%$ of ultimate failure load) are shown in Figure 5-4 to 5-21. If the connection would experience a decreasing creep rate with a fractional deflection less than or equal to 2.0 , the composite system could be declared as a creep resistant.

Fractional deflection was calculated by dividing each value of the deflection measured at $1^{\text {st }}, 2^{\text {nd }}$ and $3^{\text {rd }}$ hour with the value of initial deflection measured one minute after applying the sustained load. Decreasing creep rate can be proved if the difference between the deflection measured at the first hour and the initial deflection measured one

minute after applying the sustained load is greater than the difference between the deflections measured at the $2^{\text {nd }}$ and $3^{\text {rd }}$ hour. The results of fractional deflection and creep rate are shown in Table 5-4 to 5-9. These results imply that the test specimens experienced a decreasing creep rate and had a fractional deflection less than 2.0. Therefore it can be concluded that there is no effect of creep on the wood-FRP bond 


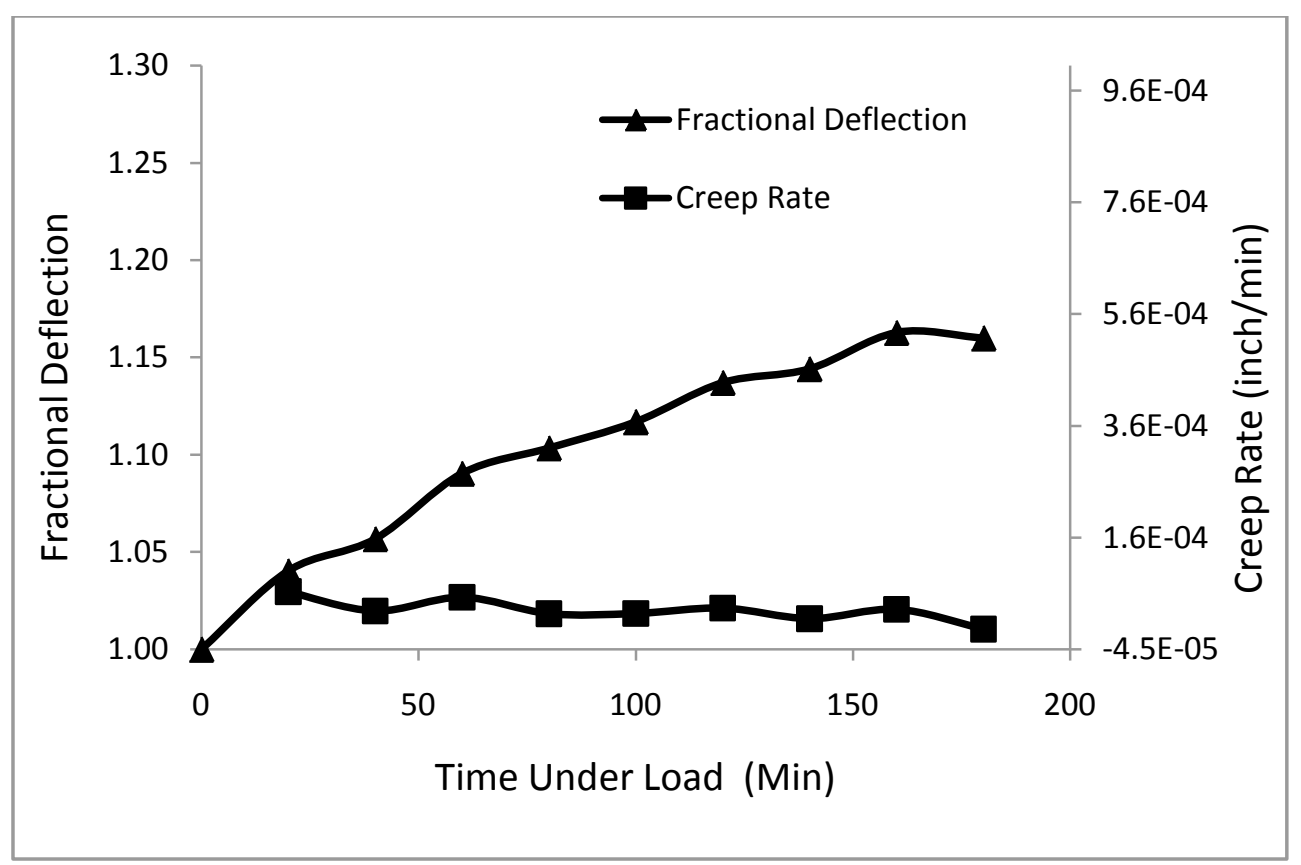

Figure 5-4 Fractional deflection and Creep rate graph for 50\% stress ratio (Test-1) for Stud to top plate connection

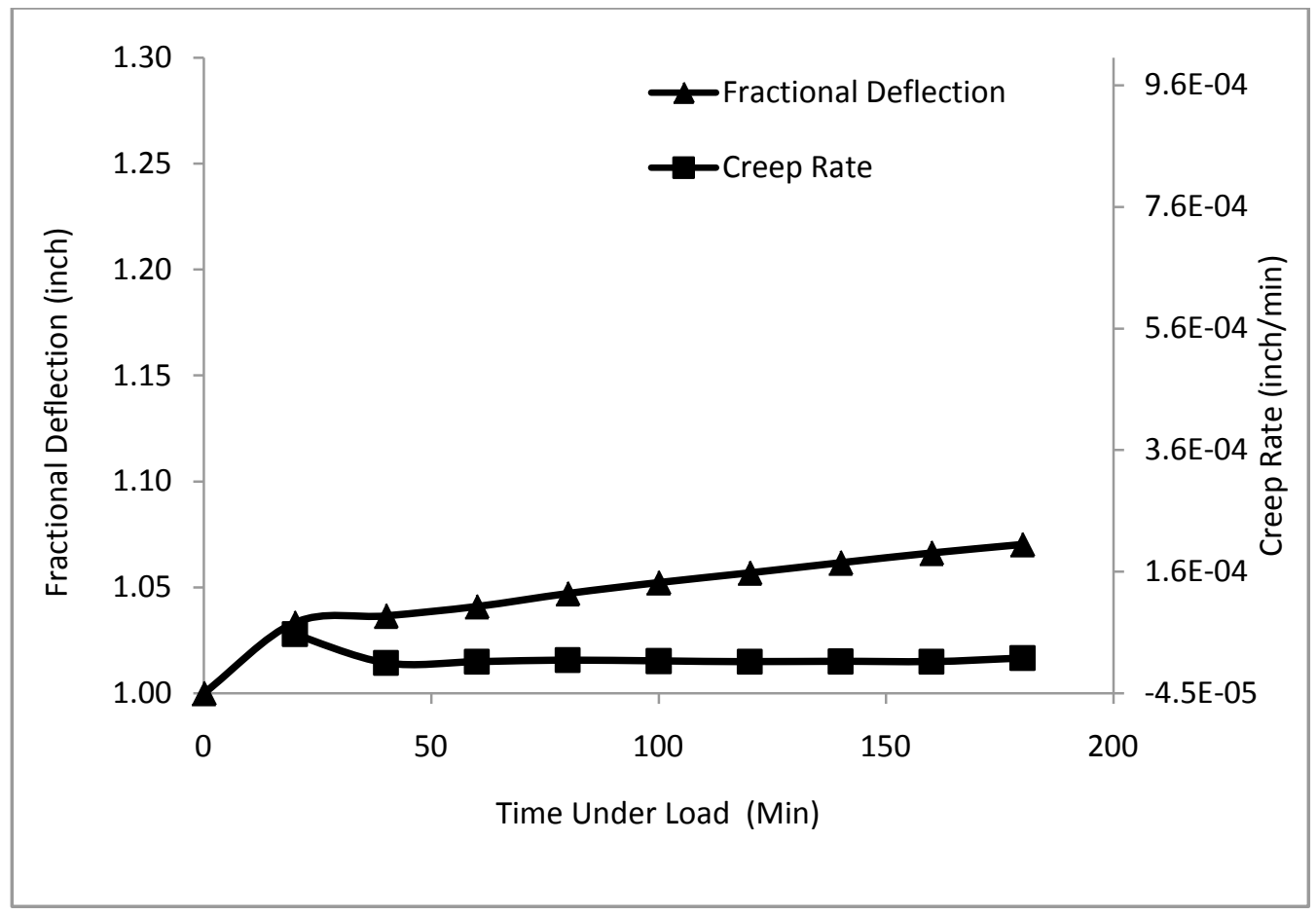

Figure 5-5 Fractional deflection and Creep rate graph for 50\% stress ratio (Test-2) for Stud to top plate connection 


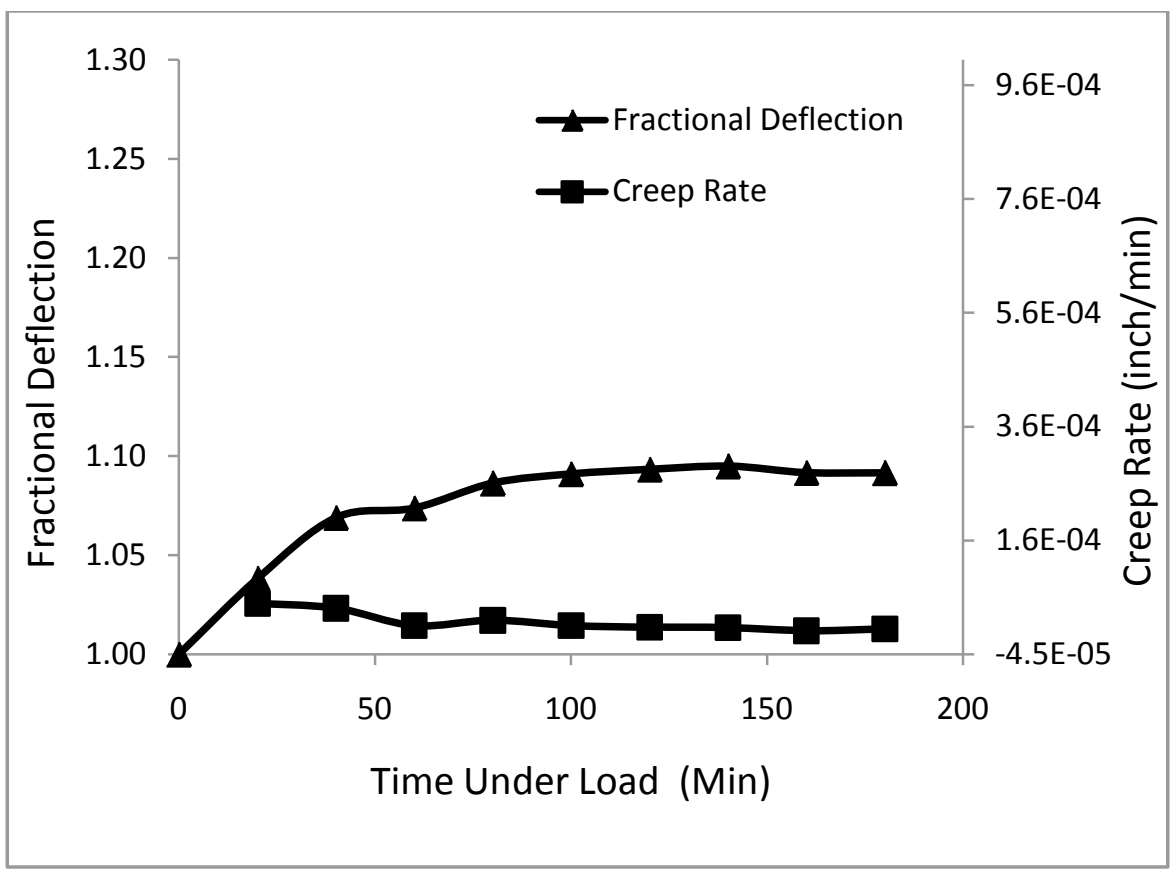

Figure 5-6 Fractional deflection and Creep rate graph for 50\% stress ratio (Test-3) for Stud to top plate connection

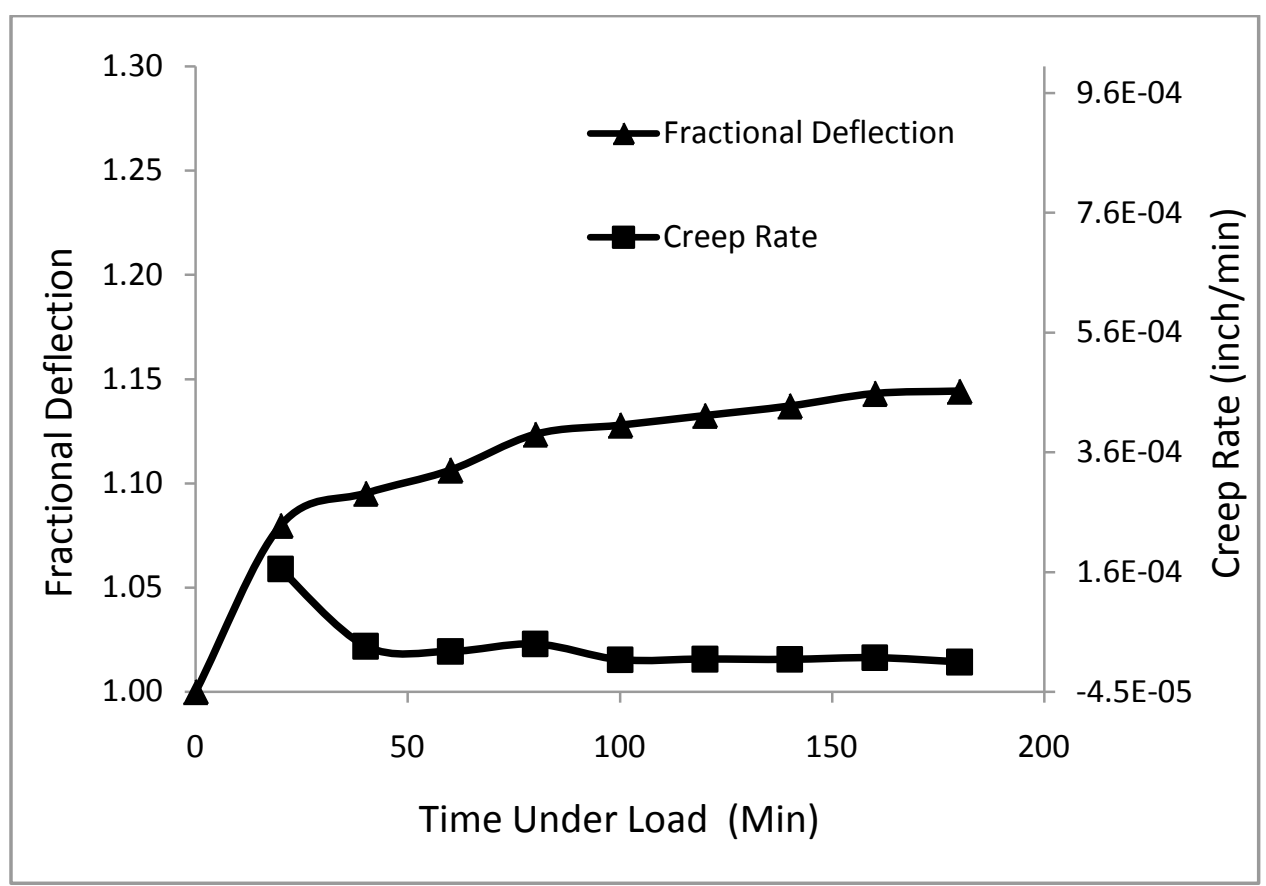

Figure 5-7 Fractional deflection and Creep rate graph for 75\% stress ratio (Test-1) for Stud to top plate connection 


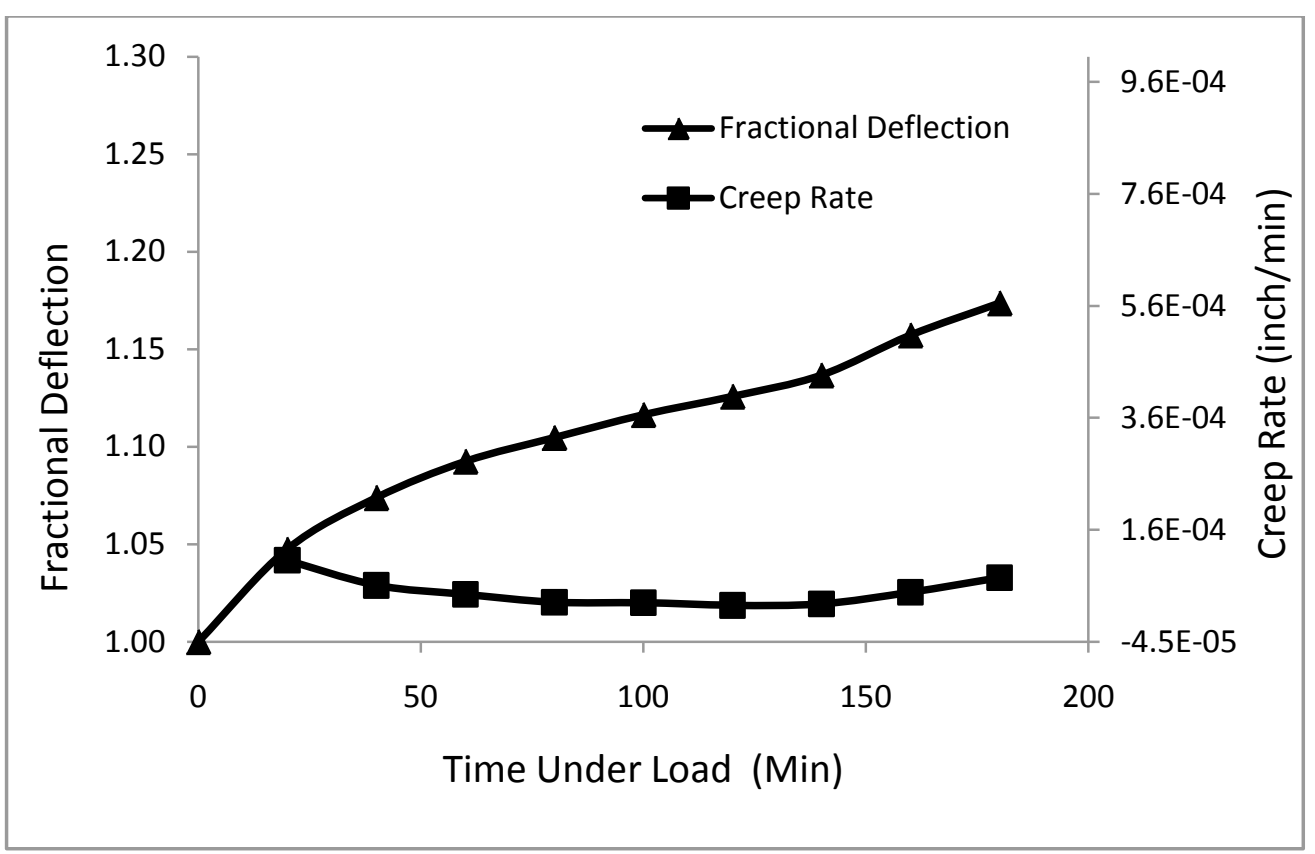

Figure 5-8 Fractional deflection and Creep rate graph for 75\% stress ratio (Test-2) for Stud to top plate connection

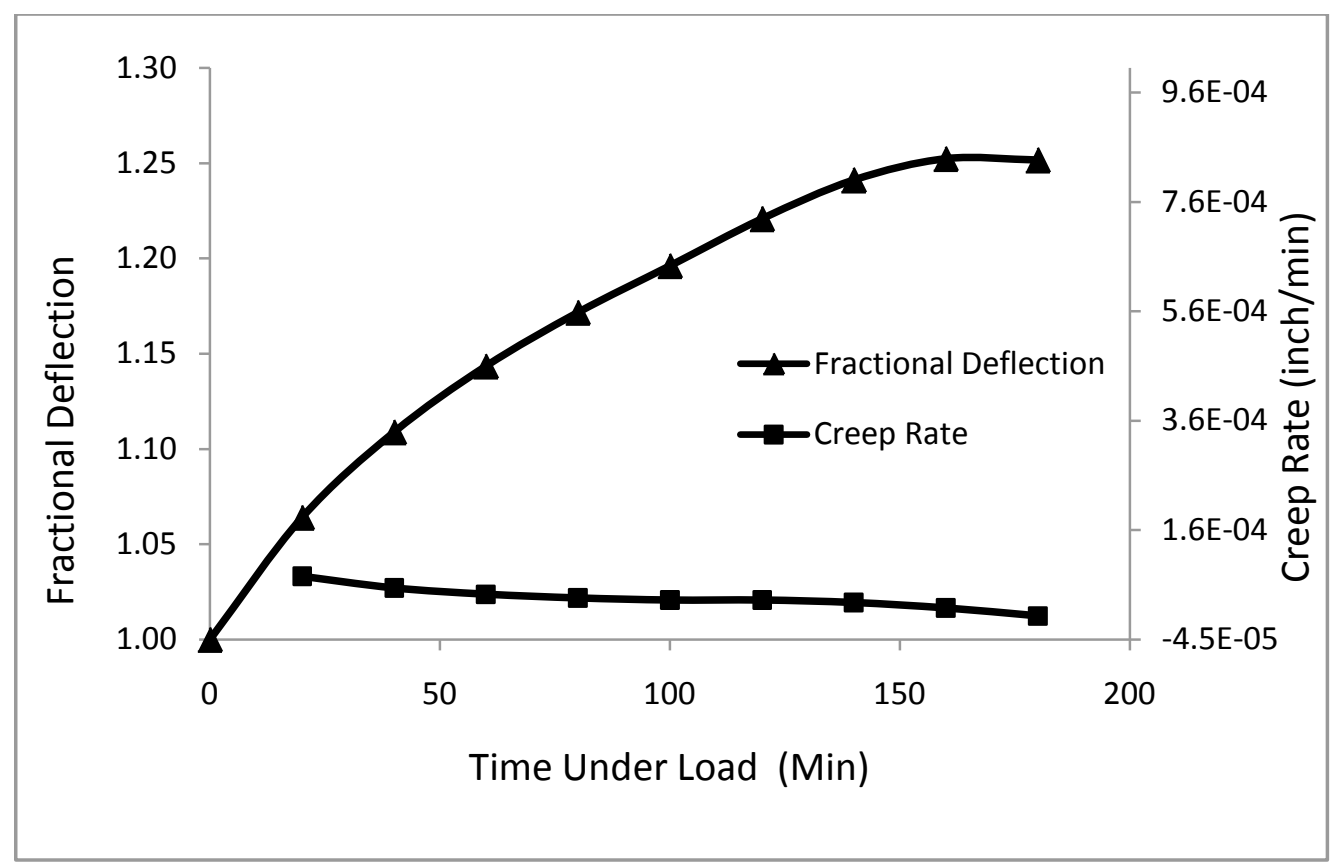

Figure 5-9 Fractional deflection and Creep rate graph for 75\% stress ratio (Test-3) for Stud to top plate connection 


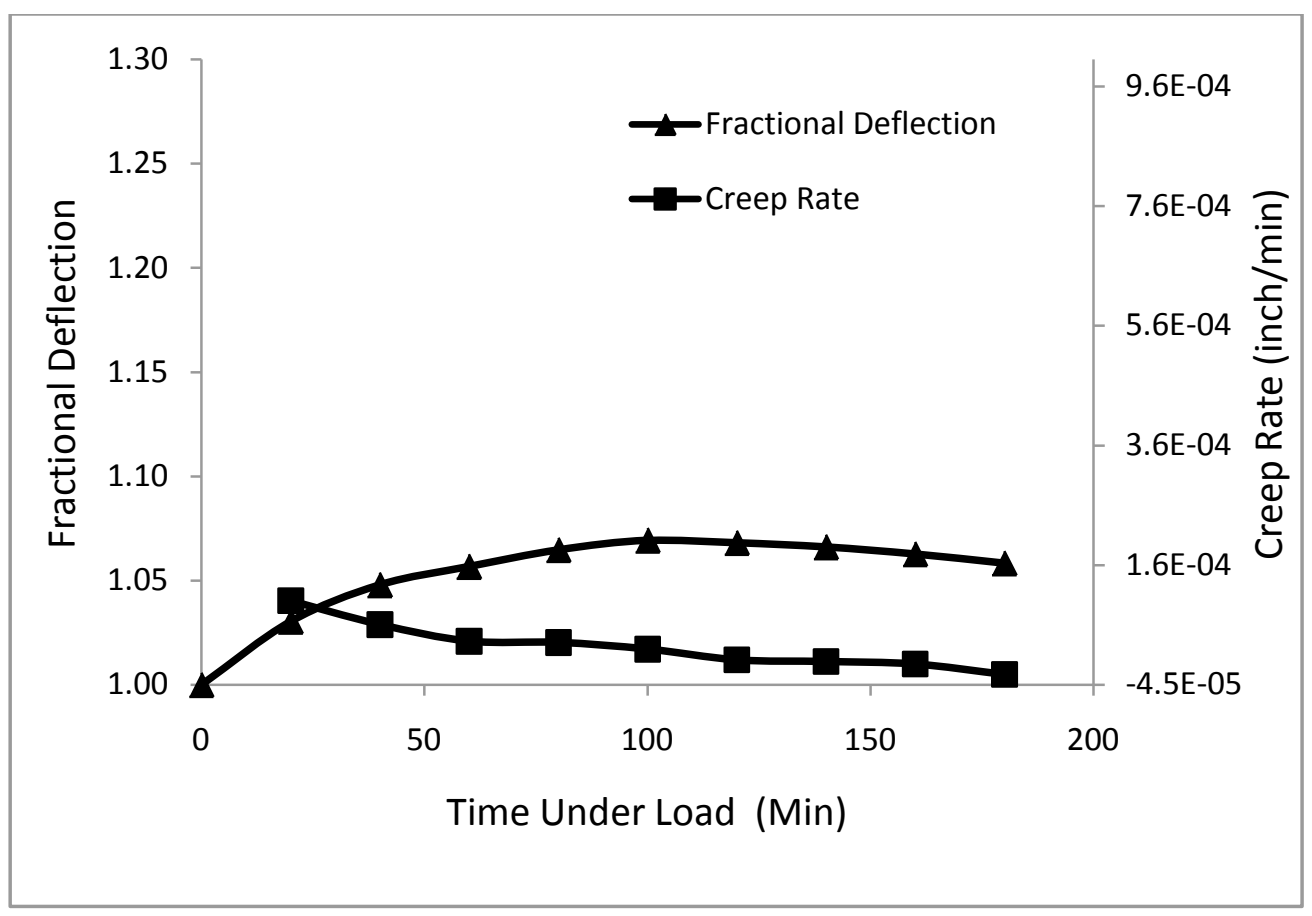

Figure 5-10 Fractional deflection and Creep rate graph for 85\% stress ratio (Test-1) for Stud to top plate connection

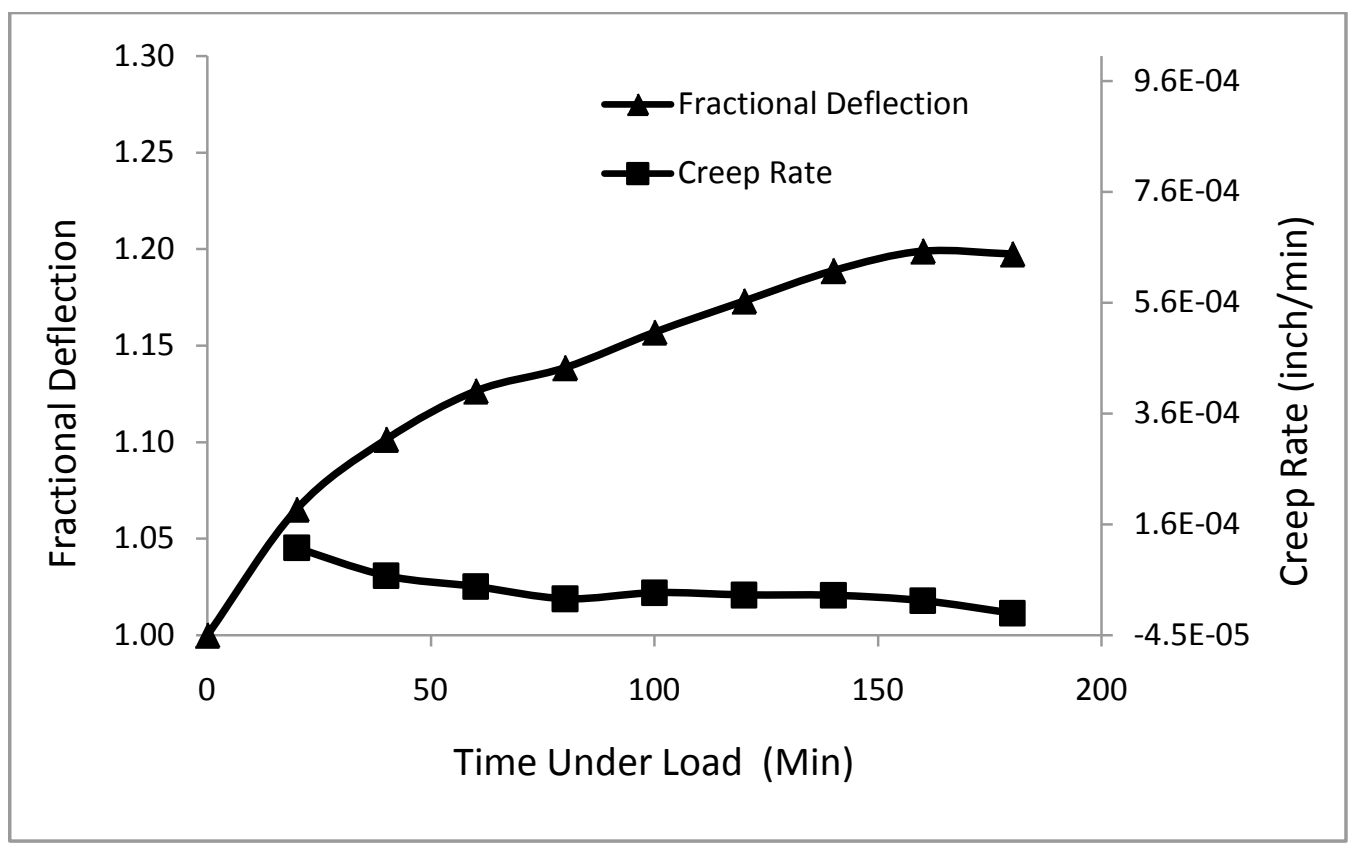

Figure 5-11 Fractional deflection and Creep rate graph for 85\% stress ratio (Test-2) for Stud to top plate connection 


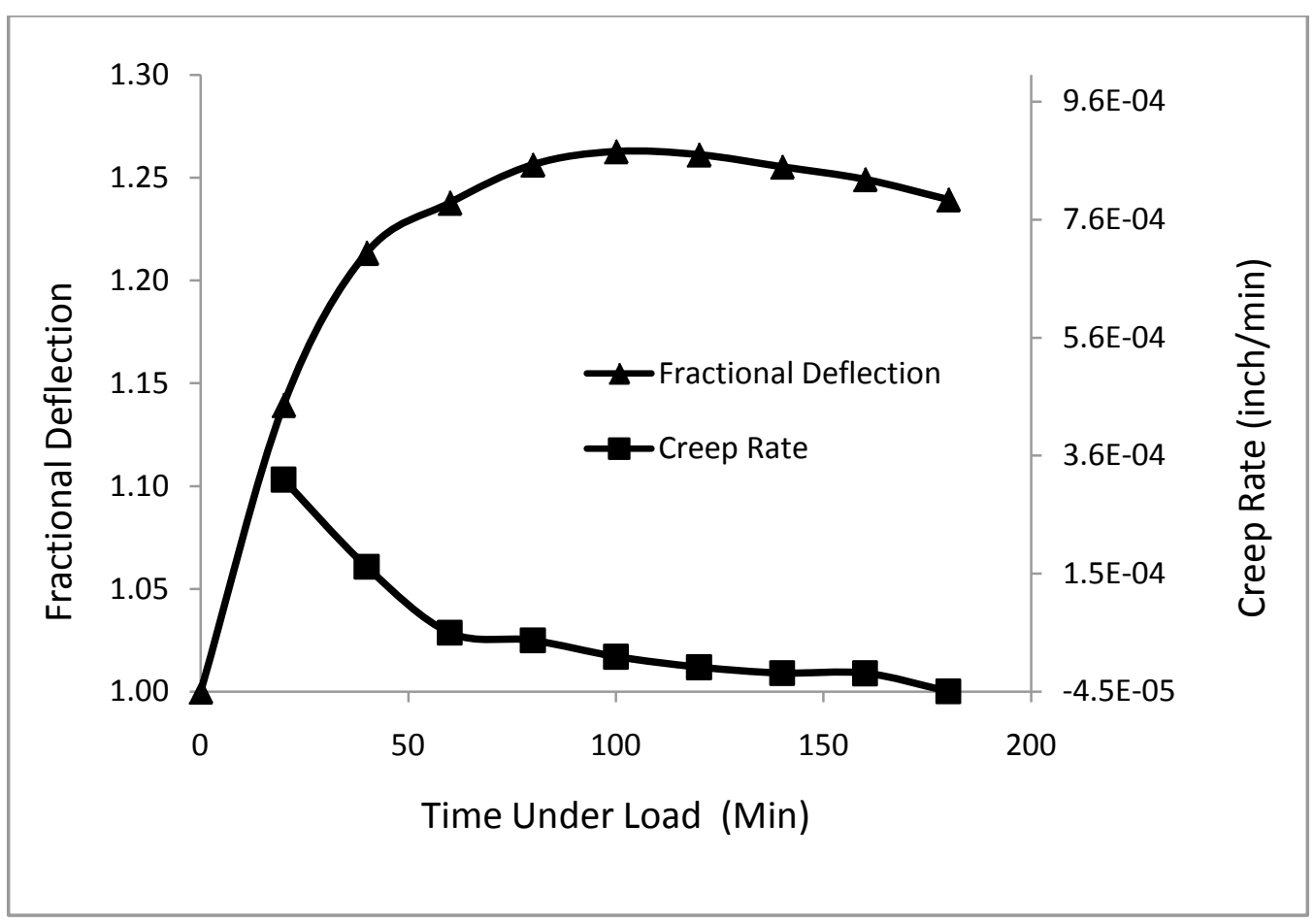

Figure 5-12 Fractional deflection and Creep rate graph for 85\% stress ratio (Test-3) for Stud to top plate connection

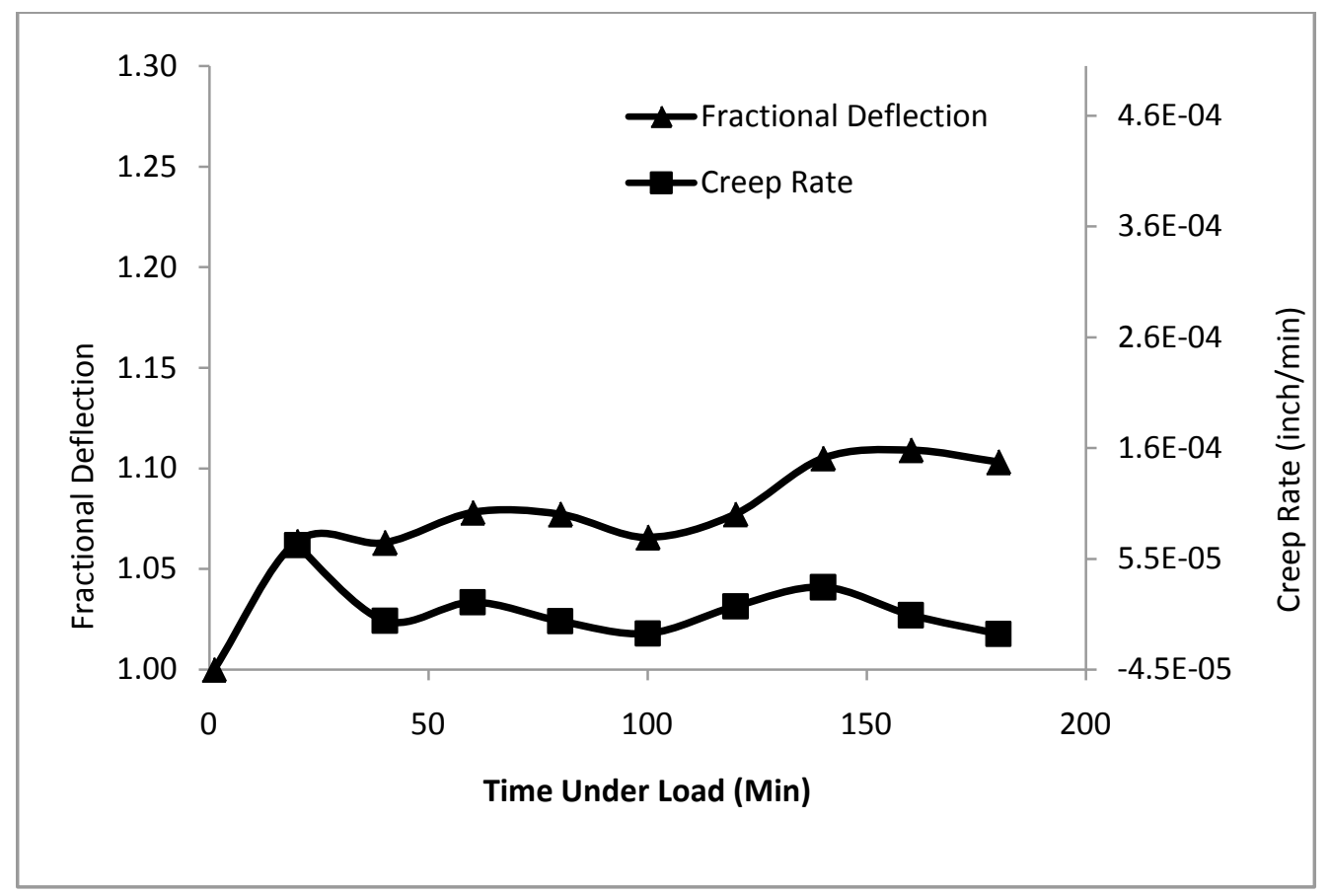

Figure 5-13 Fractional deflection and Creep rate graph for 50\% stress ratio (Test-1) for Gable end connection 


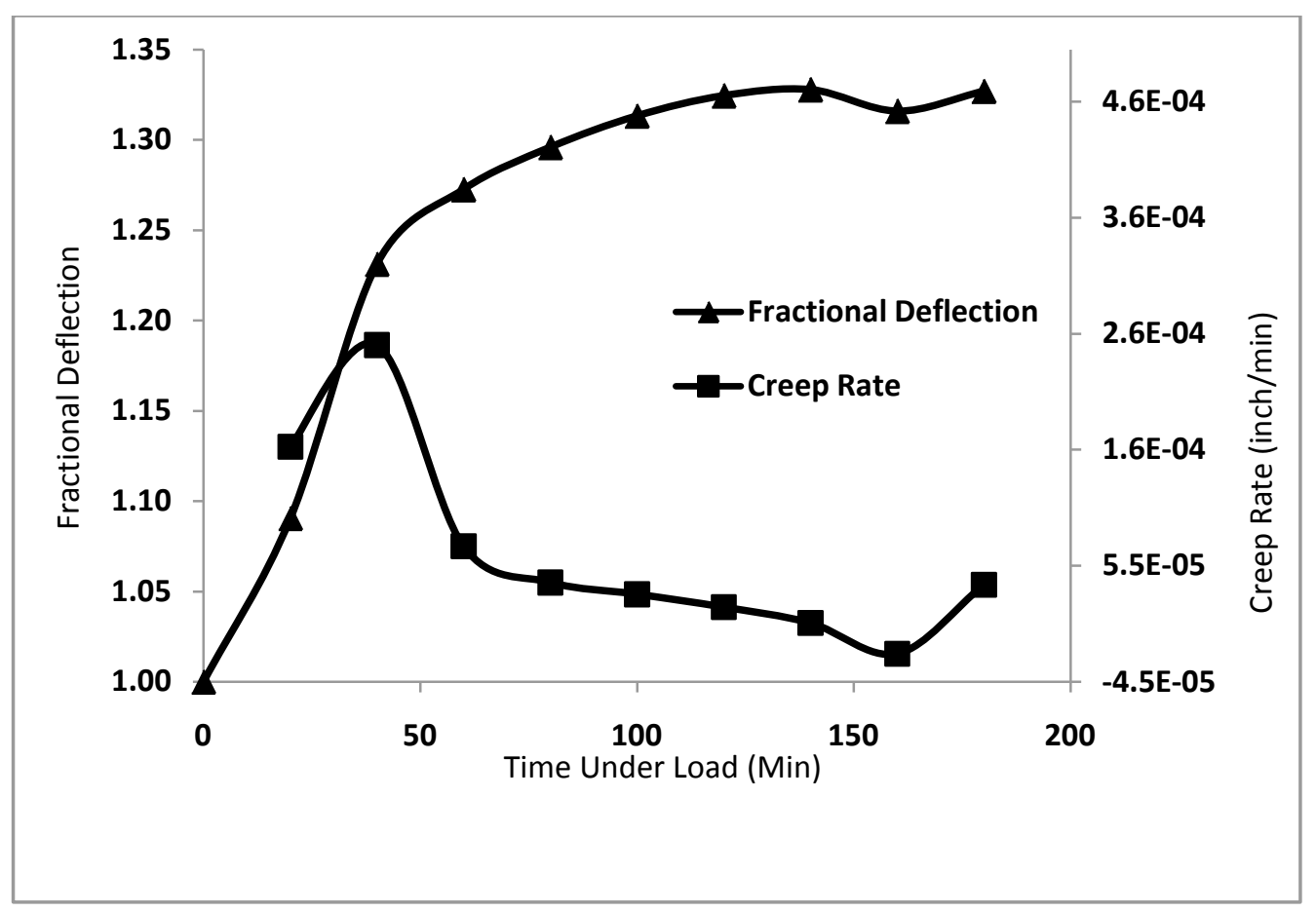

Figure 5-14 Fractional deflection and Creep rate graph for 50\% stress ratio (Test-2) for Gable end connection

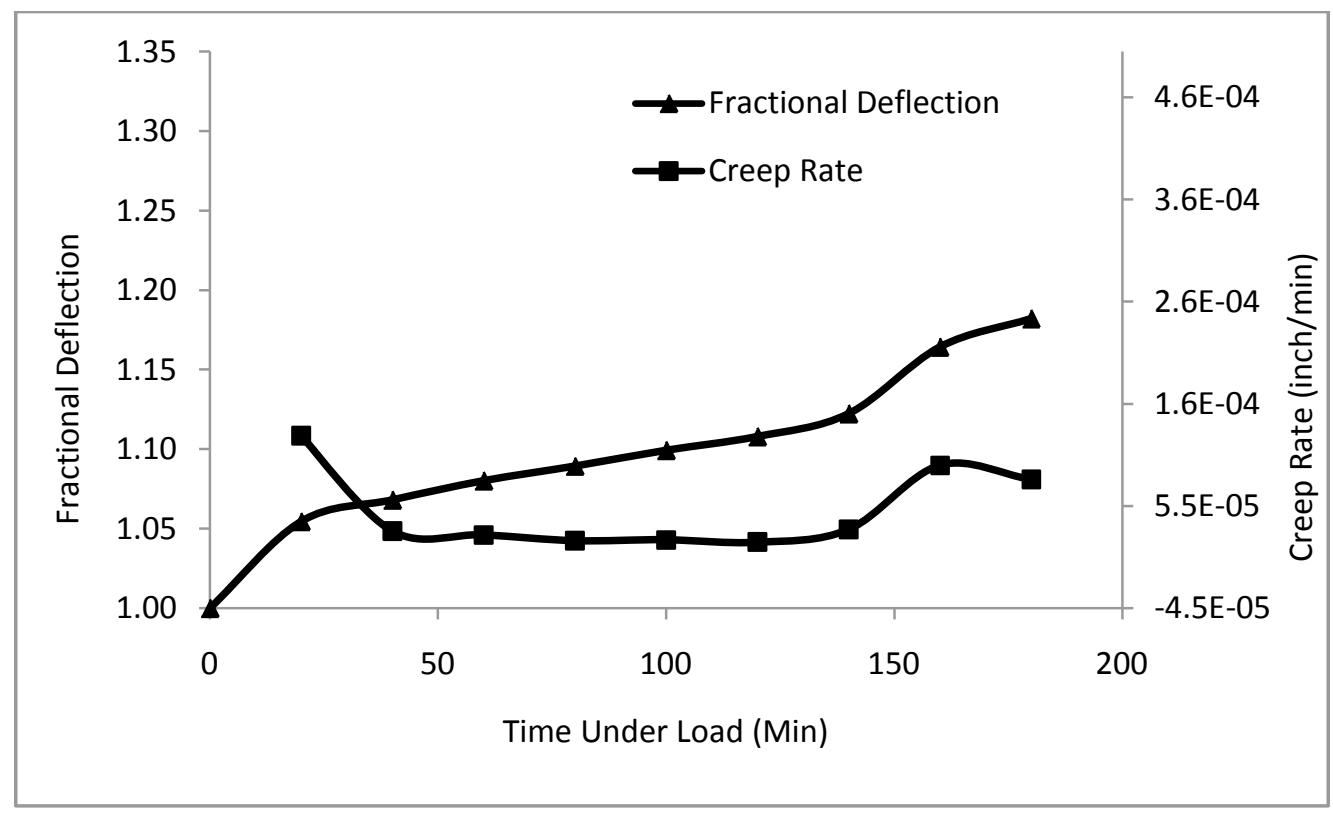

Figure 5-15 Fractional deflection and Creep rate graph for 50\% stress ratio (Test-3) for Gable end connection 


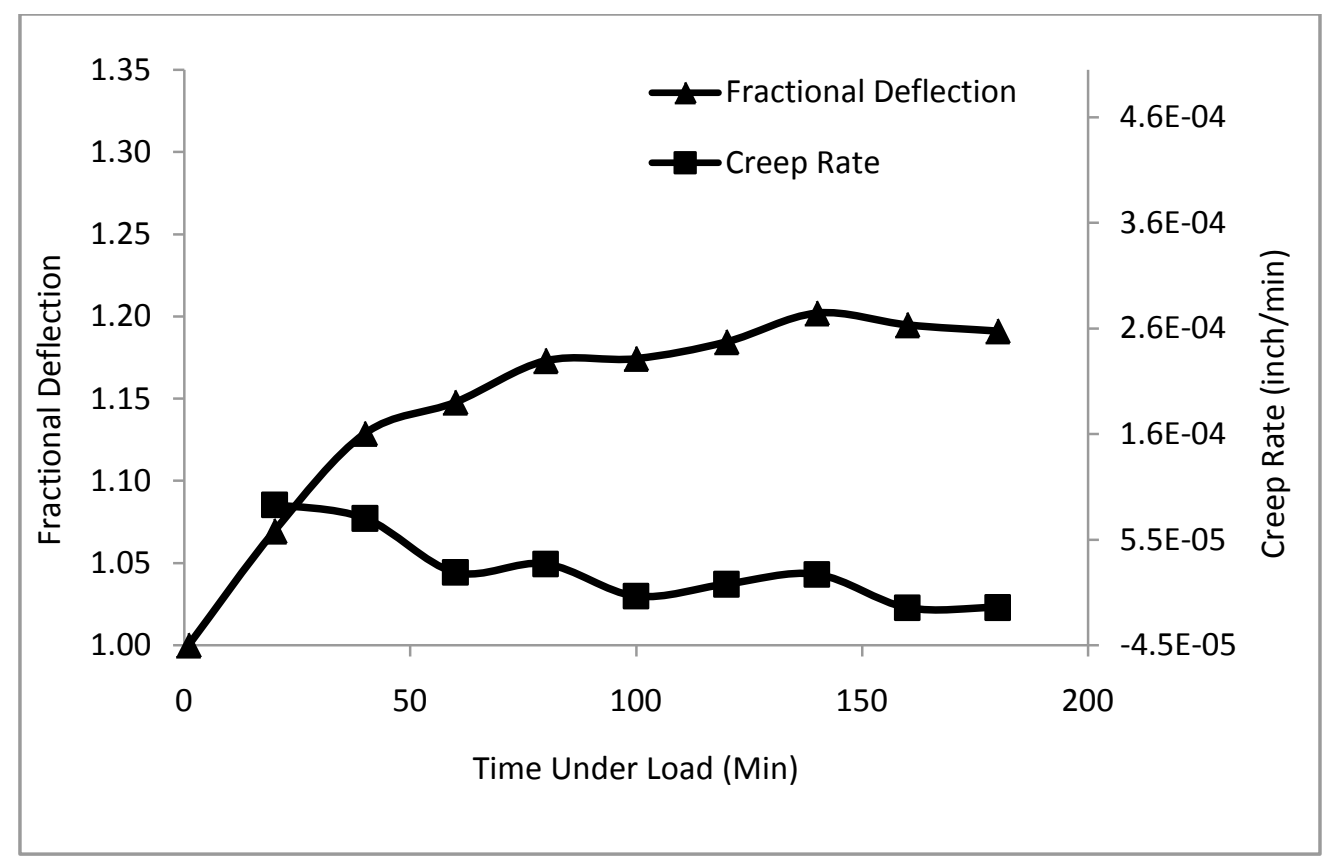

Figure 5-16 Fractional deflection and Creep rate graph for 75\% stress ratio (Test-1) for Gable end connection

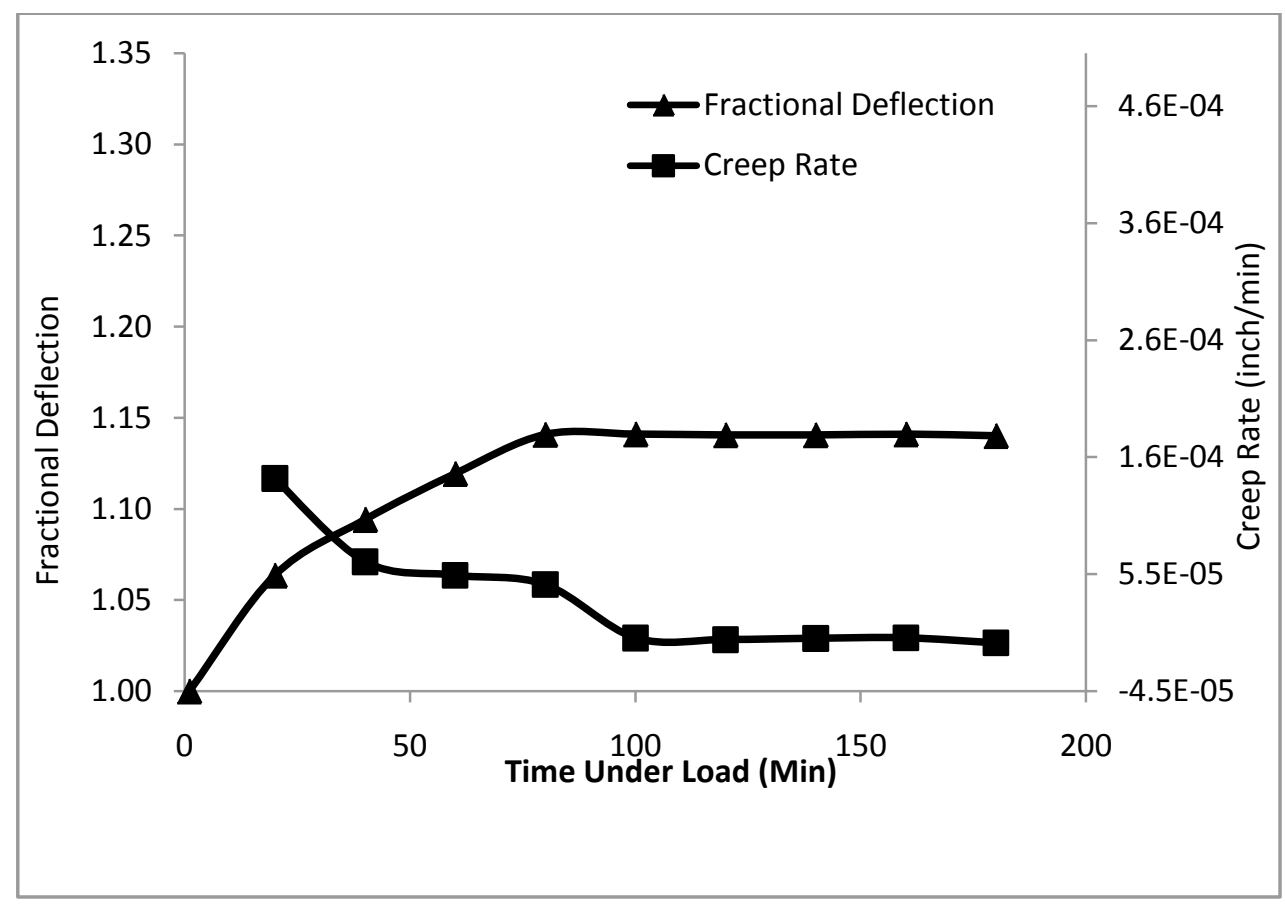

Figure 5-17 Fractional deflection and Creep rate graph for 75\% stress ratio (Test-2) for Gable end connection 


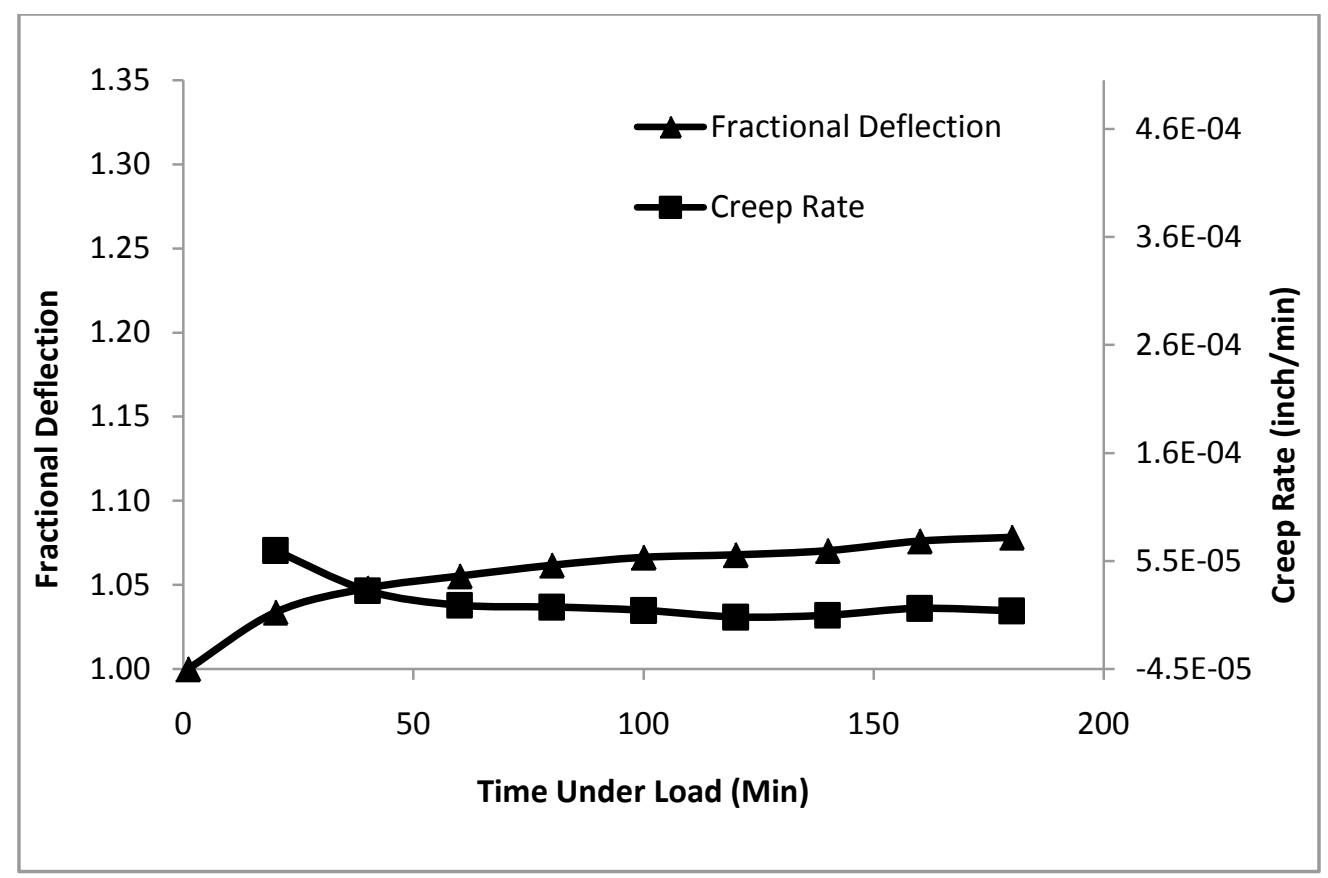

Figure 5-18 Fractional deflection and Creep rate graph for 75\% stress ratio (Test-3) for Gable end connection

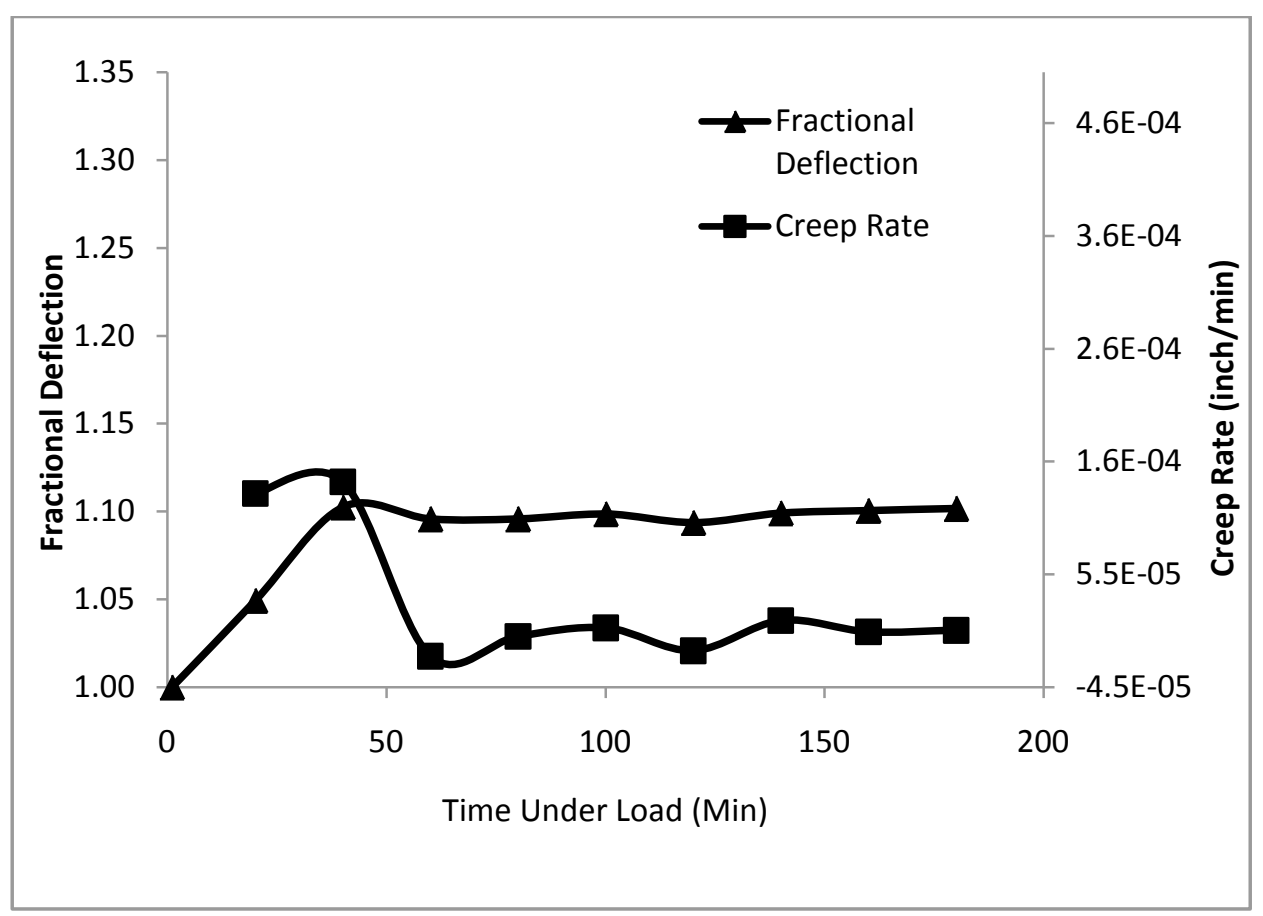

Figure 5-19 Fractional deflection and Creep rate graph for $85 \%$ stress ratio (Test-1) for Gable end connection 


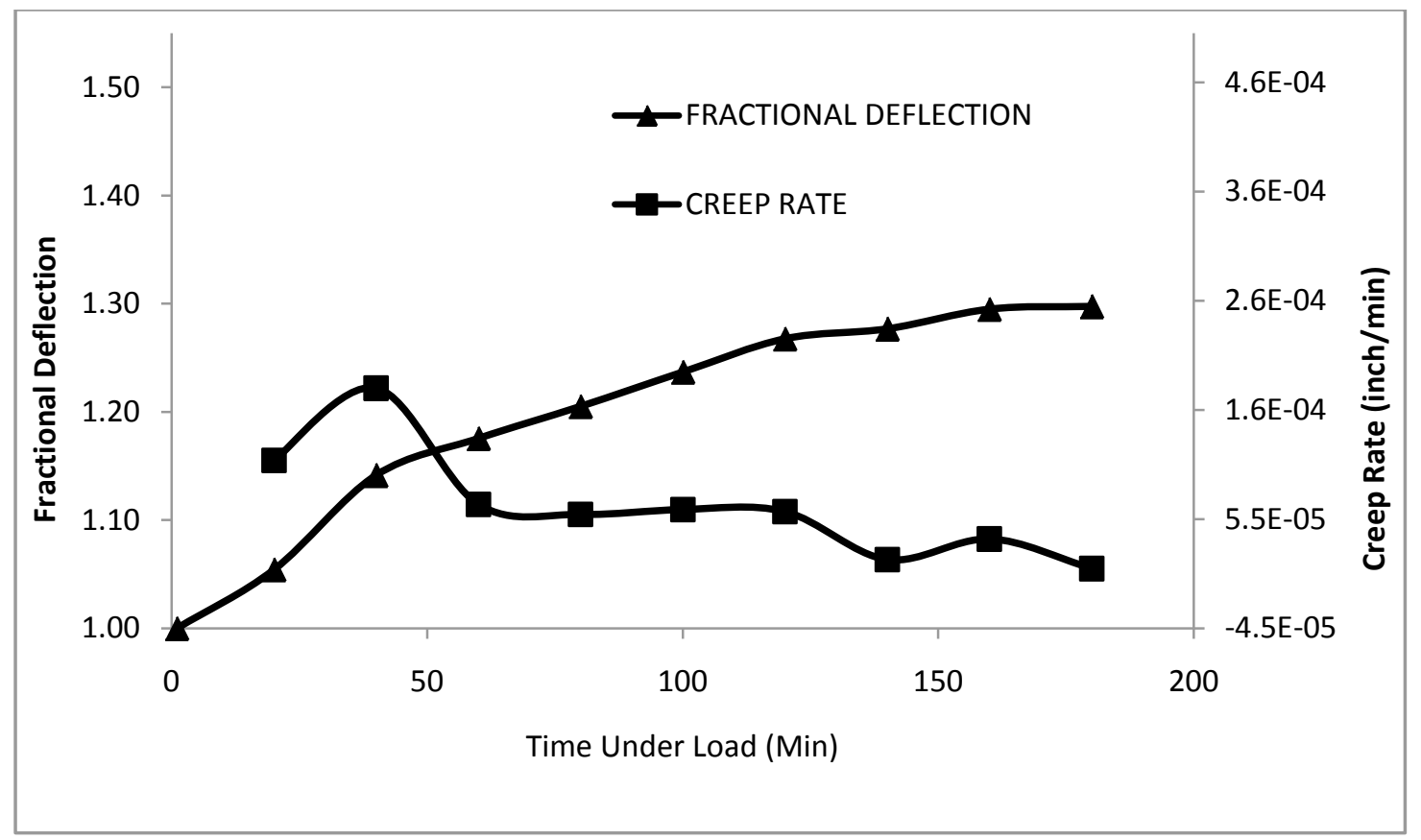

Figure 5-20 Fractional deflection and Creep rate graph for $85 \%$ stress ratio (Test-2) for Gable end connection

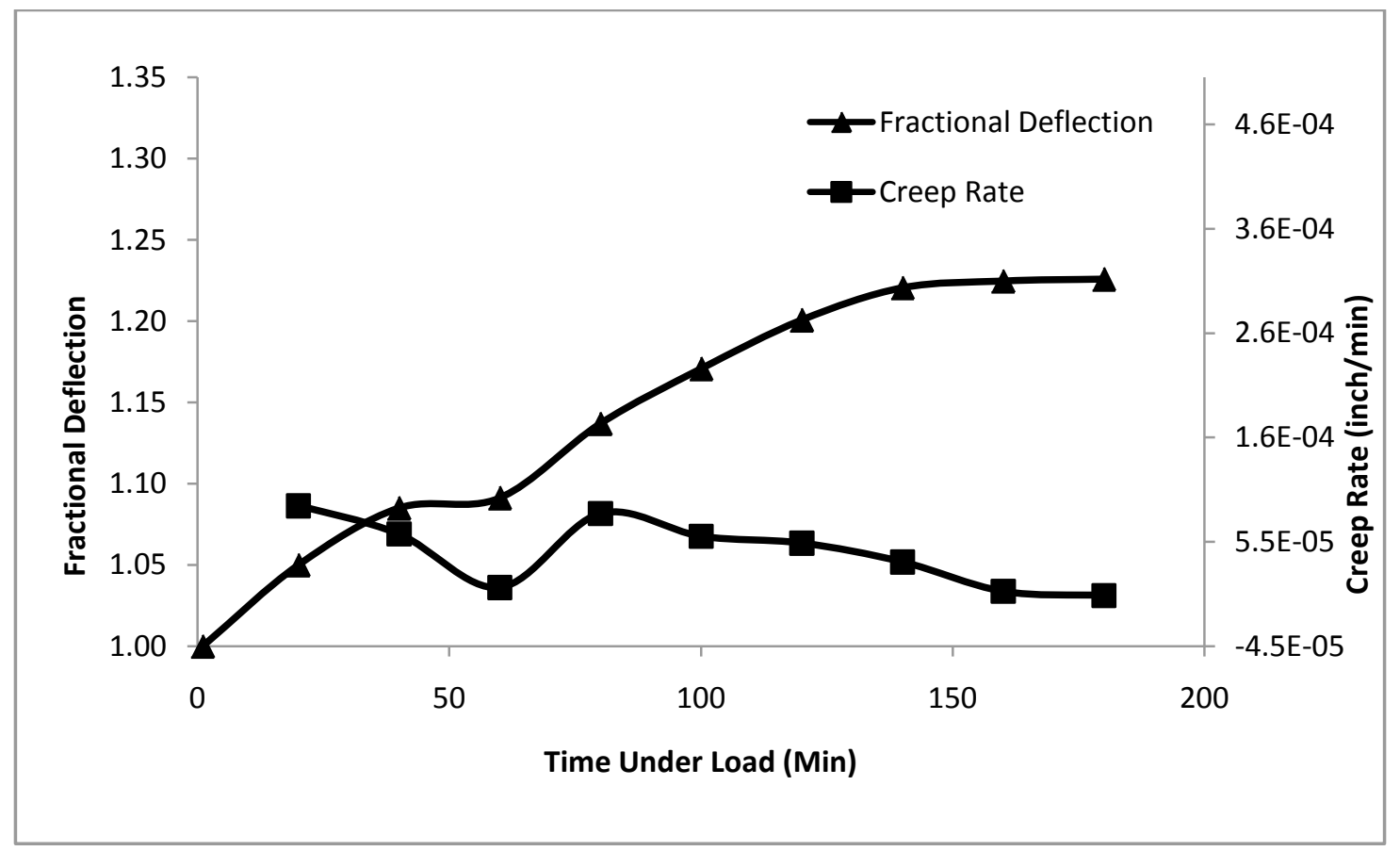

Figure 5-21 Fractional deflection and Creep rate graph for $85 \%$ stress ratio (Test-3)

for Gable end connection 


\begin{tabular}{|c|c|c|c|c|}
\hline \multicolumn{5}{|}{$\mathbf{5 0 \%}$ ULTIMATE LOAD } \\
\hline & TIME UNDER LOAD (HOURS) & TEST-1 & TEST-2 & TEST-3 \\
\hline \multirow{2}{*}{ FRACTIONAL DEFLECTION } & 1 & 1.0836 & 1.0416 & 1.0763 \\
\cline { 2 - 5 } & 3 & 1.1619 & 1.0676 & 1.0917 \\
\hline CRITERIA & DF1,DF3 $\leq 2$ & OK & OK & OK \\
\hline \multirow{2}{*}{ CREEP RATE } & D1-Di & 0.0024 & 0.0013 & 0.0018 \\
\cline { 2 - 5 } & D3-D2 & 0.0008 & 0.0003 & 0.0000 \\
\hline CRITERIA & D1-Di>D3-D2 & OK & OK & OK \\
\hline \multicolumn{2}{r|}{ CREEP EFFECT } & NO & NO & NO \\
\hline
\end{tabular}

Table 5-4 Creep analysis of 50\% ultimate load for Stud to top plate connection

\begin{tabular}{|c|c|c|c|c|}
\hline \multicolumn{5}{|c|}{$75 \%$ ULTIMATE LOAD } \\
\hline & TIME UNDER LOAD (HOURS) & TEST-1 & TEST-2 & TEST-3 \\
\hline \multirow{2}{*}{ FRACTIONAL DEFLECTION } & 1 & 1.1083 & 1.0903 & 1.1413 \\
\cline { 2 - 5 } & 3 & 1.1434 & 1.1627 & 1.2521 \\
\hline CRITERIA & DF1,DF3 $\leq 2$ & OK & OK & OK \\
\hline \multirow{2}{*}{ CREEP RATE } & D1-Di & 0.0044 & 0.0038 & 0.0031 \\
\cline { 2 - 5 } & D3-D2 & 0.0004 & 0.0015 & 0.0007 \\
\hline CRITERIA & D1-Di>D3-D2 & OK & OK & OK \\
\hline \multicolumn{2}{r|}{ CREEP EFFECT } & NO & NO & NO \\
\hline
\end{tabular}

Table 5-5 Creep analysis of 75\% ultimate load for Stud to top plate connection

\begin{tabular}{|c|c|c|c|c|}
\hline \multicolumn{5}{|c|}{$85 \%$ ULTIMATE LOAD } \\
\hline & TIME UNDER LOAD (HOURS) & TEST-1 & TEST-2 & TEST-3 \\
\hline \multirow{2}{*}{ FRACTIONAL DEFLECTION } & 1 & 1.0564 & 1.1221 & 1.2358 \\
\hline & 3 & 1.0612 & 1.1984 & 1.2459 \\
\hline CRITERIA & $\mathrm{DF} 1, \mathrm{DF} 3 \leq 2$ & OK & $\mathrm{OK}$ & OK \\
\hline \multirow{2}{*}{ CREEP RATE } & D1-Di & 0.0035 & 0.0042 & 0.0106 \\
\hline & D3-D2 & -0.0004 & 0.0009 & -0.0006 \\
\hline CRITERIA & D1-Di>D3-D2 & OK & OK & OK \\
\hline \multicolumn{2}{|c|}{ CREEP EFFECT } & $\mathrm{NO}$ & $\mathrm{NO}$ & $\mathrm{NO}$ \\
\hline
\end{tabular}

Table 5-6 Creep analysis of $85 \%$ ultimate load for Stud to top plate connection 


\begin{tabular}{|c|c|c|c|c|}
\hline \multicolumn{5}{|c|}{$.50 \%$ ULTIMATE LOAD } \\
\hline & TIME UNDER LOAD (HOURS) & TEST-1 & TEST-2 & TEST-3 \\
\hline \multirow{2}{*}{ FRACTIONAL DEFLECTION } & 1 & 1.0728 & 1.2666 & 1.0793 \\
\hline & 3 & 1.1072 & 1.3196 & 1.1702 \\
\hline CRITERIA & DF1,DF3 $\leq 2$ & $\mathrm{OK}$ & $\mathrm{OK}$ & OK \\
\hline \multirow{2}{*}{ CREEP RATE } & D1-Di & 0.0015 & 0.0093 & 0.0036 \\
\hline & D3-D2 & 0.0005 & -0.0001 & 0.0027 \\
\hline CRITERIA & D1-Di>D3-D2 & OK & OK & OK \\
\hline \multicolumn{2}{|c|}{ CREEP EFFECT } & $\mathrm{NO}$ & $\mathrm{NO}$ & $\mathrm{NO}$ \\
\hline
\end{tabular}

Table 5-7 Creep analysis of 50\% ultimate load for Gable end connection

\begin{tabular}{|c|c|c|c|c|}
\hline \multicolumn{5}{|c|}{ 75\% ULTIMATE LOAD } \\
\hline & TIME UNDER LOAD (HOURS) & TEST-1 & TEST-2 & TEST-3 \\
\hline \multirow{3}{*}{ FRACTIONAL DEFLECTION } & 1 & 1.1499 & 1.1181 & 1.0549 \\
\hline & 3 & 1.1936 & 1.1408 & 1.0768 \\
\hline & DF1,DF3 $\leq 2$ & $\mathrm{OK}$ & OK & $\mathrm{OK}$ \\
\hline \multirow{3}{*}{ CREEP RATE } & D1-Di & 0.0038 & 0.0051 & 0.0021 \\
\hline & D3-D2 & 0.0002 & 0.0000 & 0.0003 \\
\hline & D1-Di>D3-D2 & $\mathrm{OK}$ & $\mathrm{OK}$ & $\mathrm{OK}$ \\
\hline \multicolumn{2}{|c|}{ CREEP EFFECT } & NO & NO & $\mathrm{NO}$ \\
\hline
\end{tabular}

Table 5-8 Creep analysis of 75\% ultimate load for Gable end connection

\begin{tabular}{|c|c|c|c|c|}
\hline \multicolumn{3}{|c|}{$\mathbf{8 5 \%}$ ULTIMATE LOAD } \\
\hline & TIME UNDER LOAD (HOURS) & TEST-1 & TEST-2 & TEST-3 \\
\hline \multirow{2}{*}{ FRACTIONAL DEFLECTION } & 1 & 1.0979 & 1.1740 & 1.1043 \\
\cline { 2 - 5 } & 3 & 1.1009 & 1.2958 & 1.2250 \\
\hline CRITERIA & DF1,DF3 2 & OK & OK & OK \\
\hline \multirow{2}{*}{ CREEP RATE } & D1-Di & 0.0050 & 0.0070 & 0.0037 \\
\cline { 2 - 5 } & D3-D2 & 0.0002 & 0.0014 & 0.0010 \\
\hline \multicolumn{2}{|c|}{ CREEP EFFECT } & OK & OK & OK \\
\hline \multicolumn{2}{|c|}{} & NO & NO & NO \\
\hline
\end{tabular}

Table 5-9 Creep analysis of $85 \%$ ultimate load for Gable end connection

\subsection{Dynamic load testing:}

During the 6 hours test none of the connections failed. In order to analyze the data and better understand the effect of dynamic loading on the displacement and the stiffness degradation of the connection five graphs are plotted as discussed below: 
1) Displacement, using mean of means, vs. number of cycles:

Total of 5,400 cycles were recorded. Mean of each cycle was calculated by averaging 100 data points per cycle which gave 5,400 mean displacements. The data was then grouped in 54 sets, each set consisting of 100 cycles. For each set of 100 cycles a mean was taken as 'mean of means': $\overline{u_{i}}$ where $i=1,2, \ldots .54$. Each mean of means was normalized by diving with $\overline{u_{1}}$ as $\overline{u_{i}} / \overline{u_{1}}$

2) Displacement, using mean of peaks, vs. the number of cycles:

The peaks of 5,400 cycles were determined and grouped in 54 sets, each consisting of 100 peaks. The average of each set $\hat{u}_{i}$ was calculated and was divided by $\overline{u_{1}}$ for normalization.

3) Stiffness, using mean of means, vs. the number of cycles:

For the 5,400 cycles, stiffness was calculated by dividing the load, $\mathrm{P}$ by the displacement. These stiffnesses were then grouped in to 54 sets, each consisting of 100 cycles. For each set of 100 cycles a mean was taken as 'mean of means':

$\overline{k_{i}} \quad$ where $\mathrm{i}=1,2, \ldots .54$. Each mean of means was normalized by diving with $\overline{k_{1}}$ as $\overline{k_{i}} / \overline{k_{1}}$

4) Stiffness, using mean of peaks, vs. the number of cycles:

The peaks of 5,400 cycles were determined and grouped in to 54 sets, each consisting of 100 peaks. The average of each set $\hat{k}_{i}$ was calculated and was divided by $\overline{k_{1}}$ for normalization.

5) Percentage stiffness degradation vs. the number of cycles:

Percentage degradation was calculated using the formula shown below:

$$
\Delta k(\%)=\frac{\overline{k_{i}}-\overline{k_{1}}}{\overline{k_{1}}} \times 100
$$




\subsubsection{Dynamic loading results for Shear connection and Stud to top plate connection:}

As seen in Figure 5-22, 5-24, 5-26, 5-28, 5-30 and 5-32 the raw data was contaminated with noise. Digital low-pass filtering was performed using Matlab and the filtered data are shown in Figure 5-23, 5-25, 5-27, 5-29, 5-31 and 5-33. The plots for shear connection show that displacements under $75 \%$ stress ratio were higher than those under $85 \%$ stress ratio. Such results may be attributed to the variability between test specimens tested using different stress ratios and such variability could occur due to:

1) The variation in the thickness of the epoxy between the glass fibers and the wood fibers.

2) Due to the physical properties of wood which affects the ultimate capacity of the wood piece.

3) The size of the FRP which could be due to the human error.

For the displacements plots of each connection, mean of means and mean of peaks are plotted in Figures 5-34 to 5-37 for shear and stud to top plate connection. The plots for various stress ratios show similar increasing trends. For the stiffness, mean of means and mean of peaks are plotted in Figures 5-38 to 5-41. Figure 5-42 to 5-43 shows the percentage of stiffness degradation for the various stress ratios. It is observed that the percentage of stiffness degradation for each case is very low and is in the range of 0 to $0.1 \%$. This proves that there was no degradation in shear and stud to top plate connections due to cyclic loading. Thus fatigue induced stresses on such connections as could be experienced due to wind speed fluctuations during hurricanes may not have significant effects. 
Due to the complexity of dynamic load testing a suitable set up for the gable end connection could not be developed. The set up used for static and creep loading was not rigid enough for performing the fatigue test.

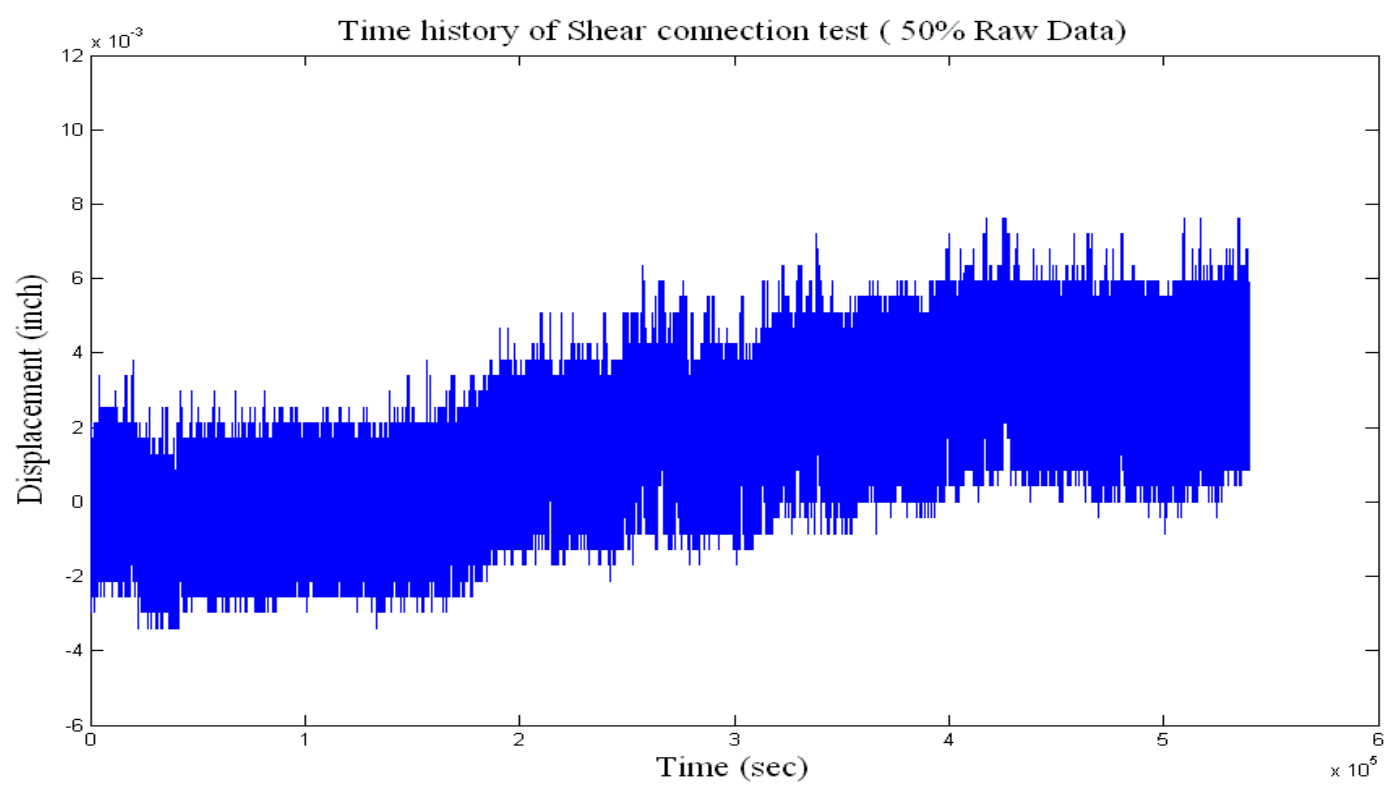

Figure 5-22 Time history of Shear connection test (50\% Raw data)

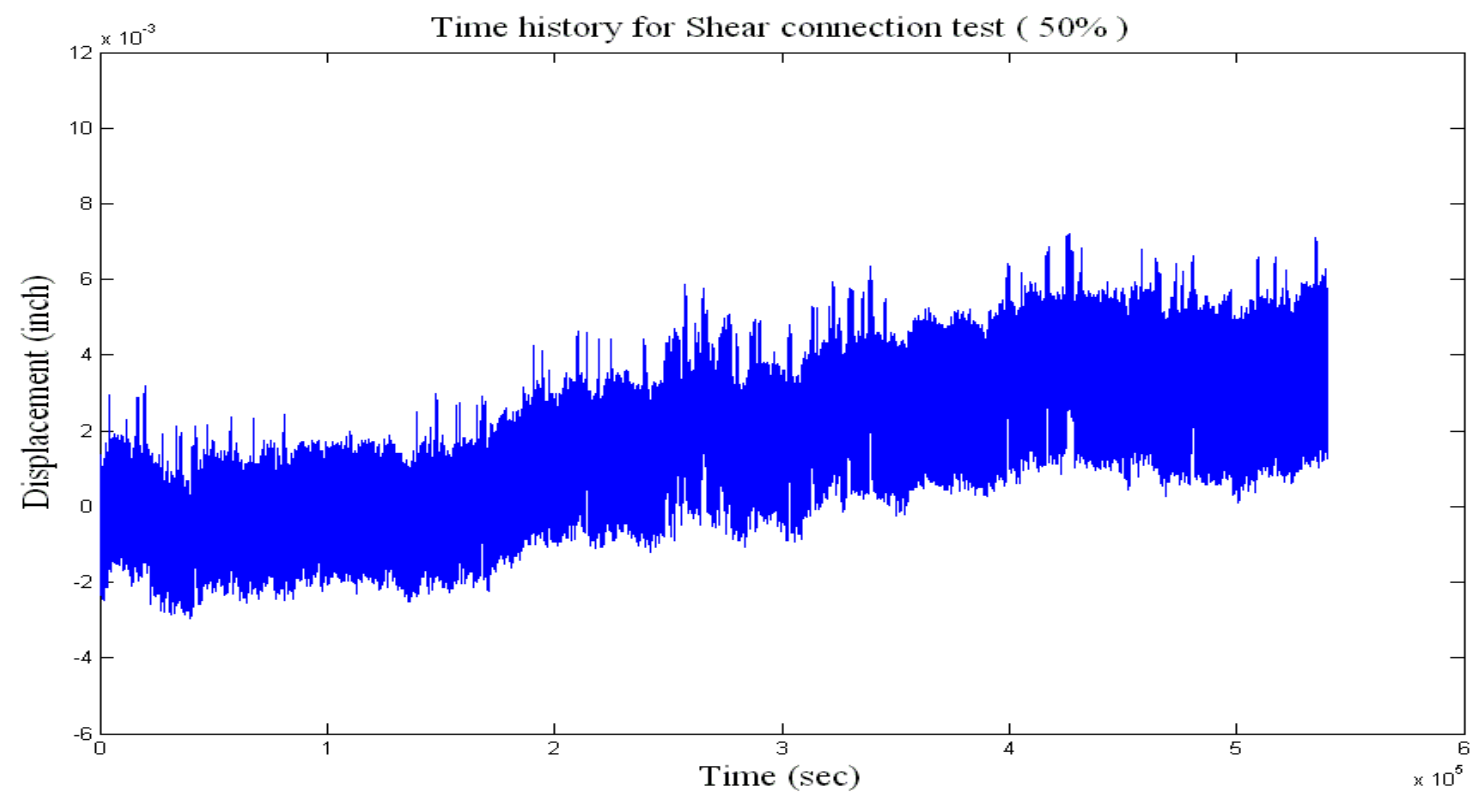

Figure 5-23 Time history of Shear connection test (50\% Filtered data) 


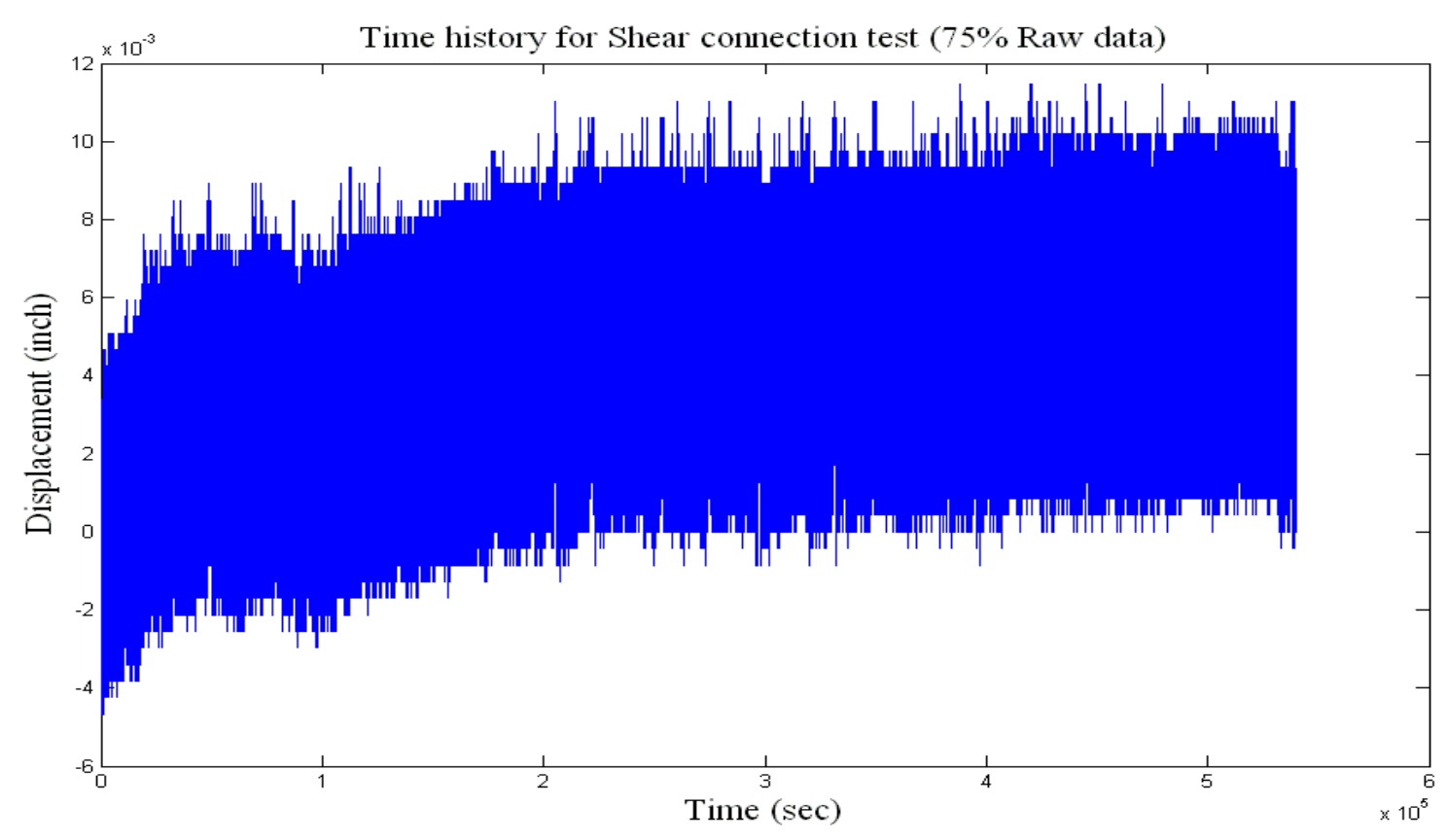

Figure 5-24 Time history of Shear connection test (75\% Raw data)

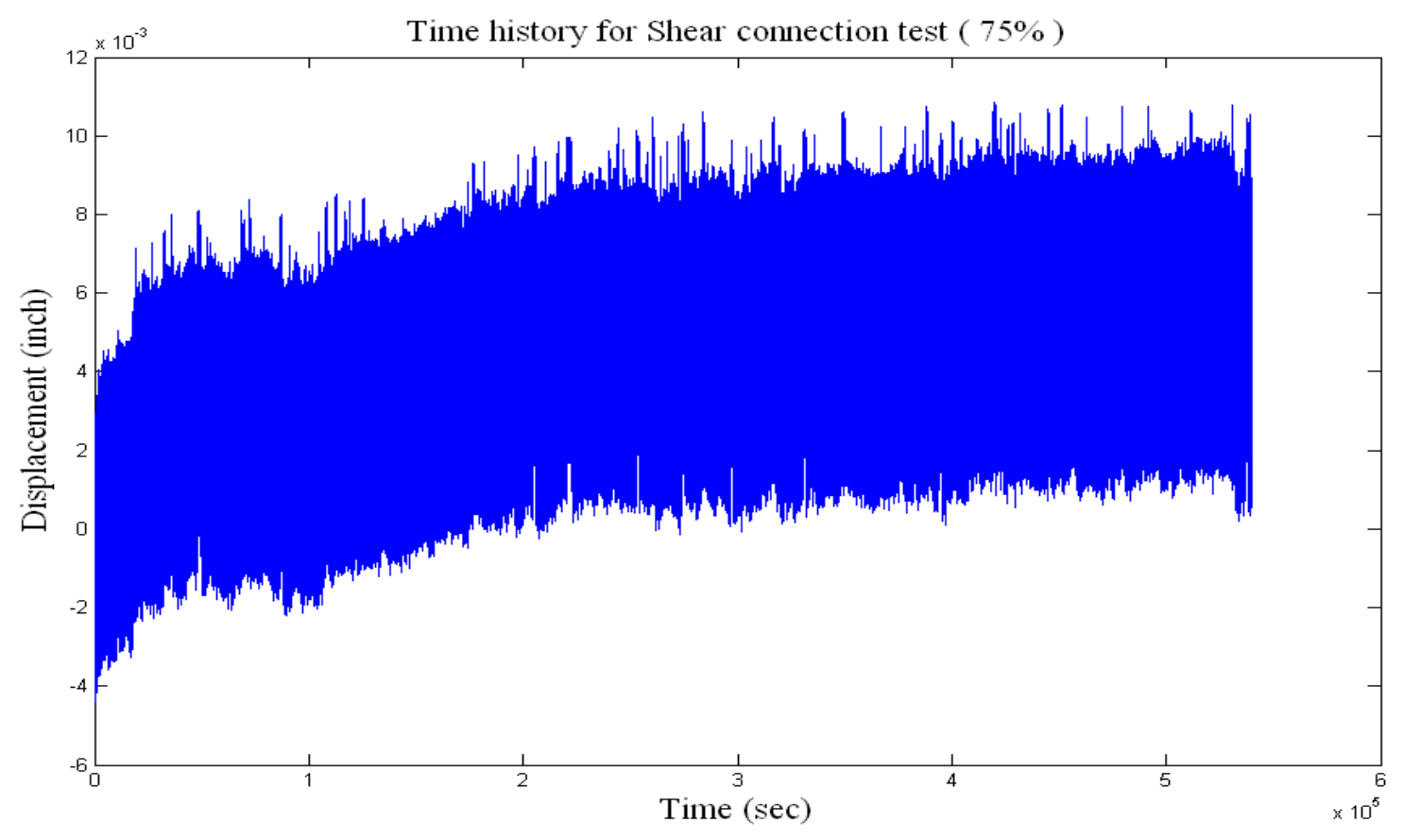

Figure 5-25 Time history of Shear connection test (75\% Filtered data) 


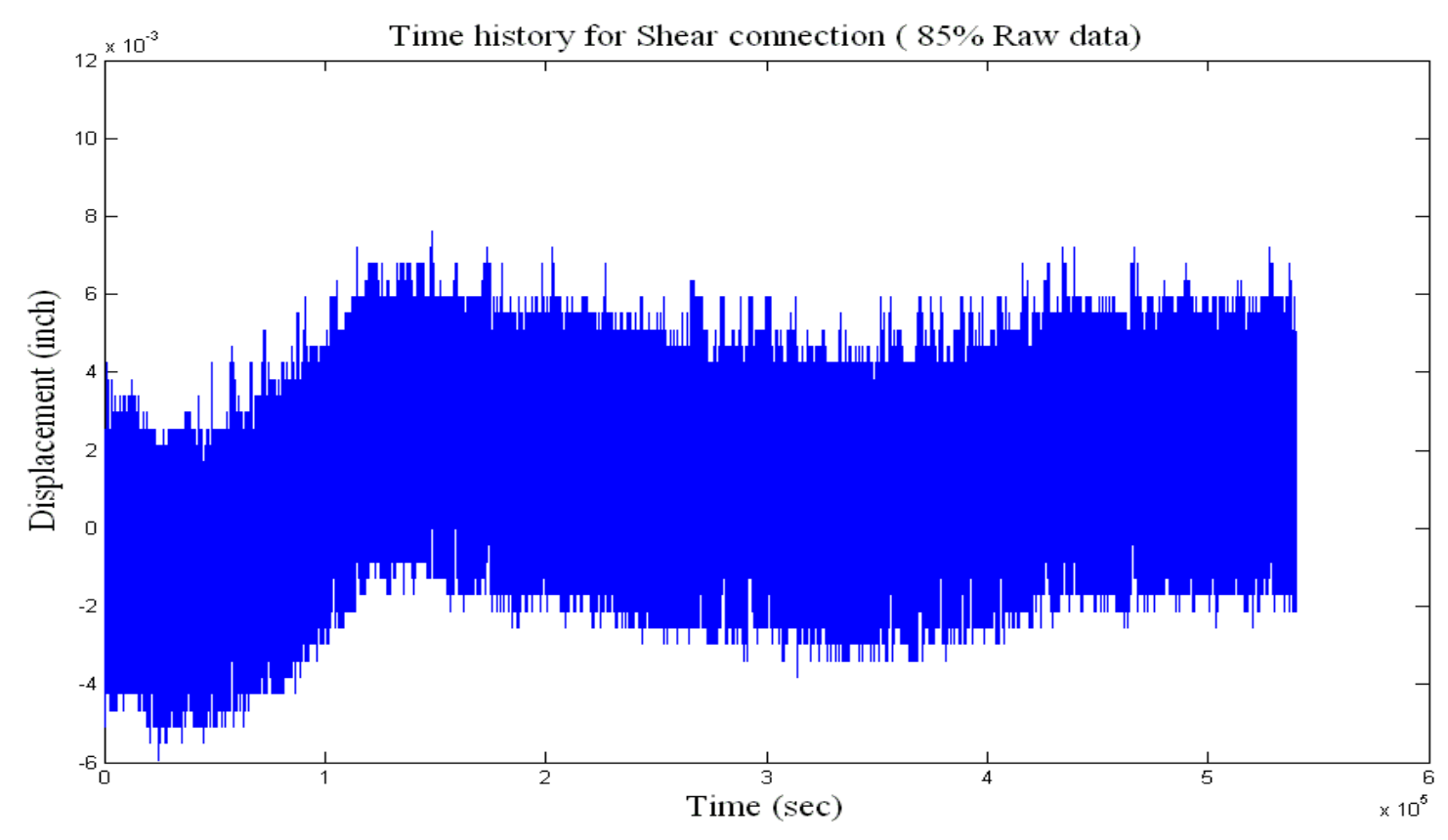

Figure 5-26 Time history of Shear connection test (85\% Raw data)

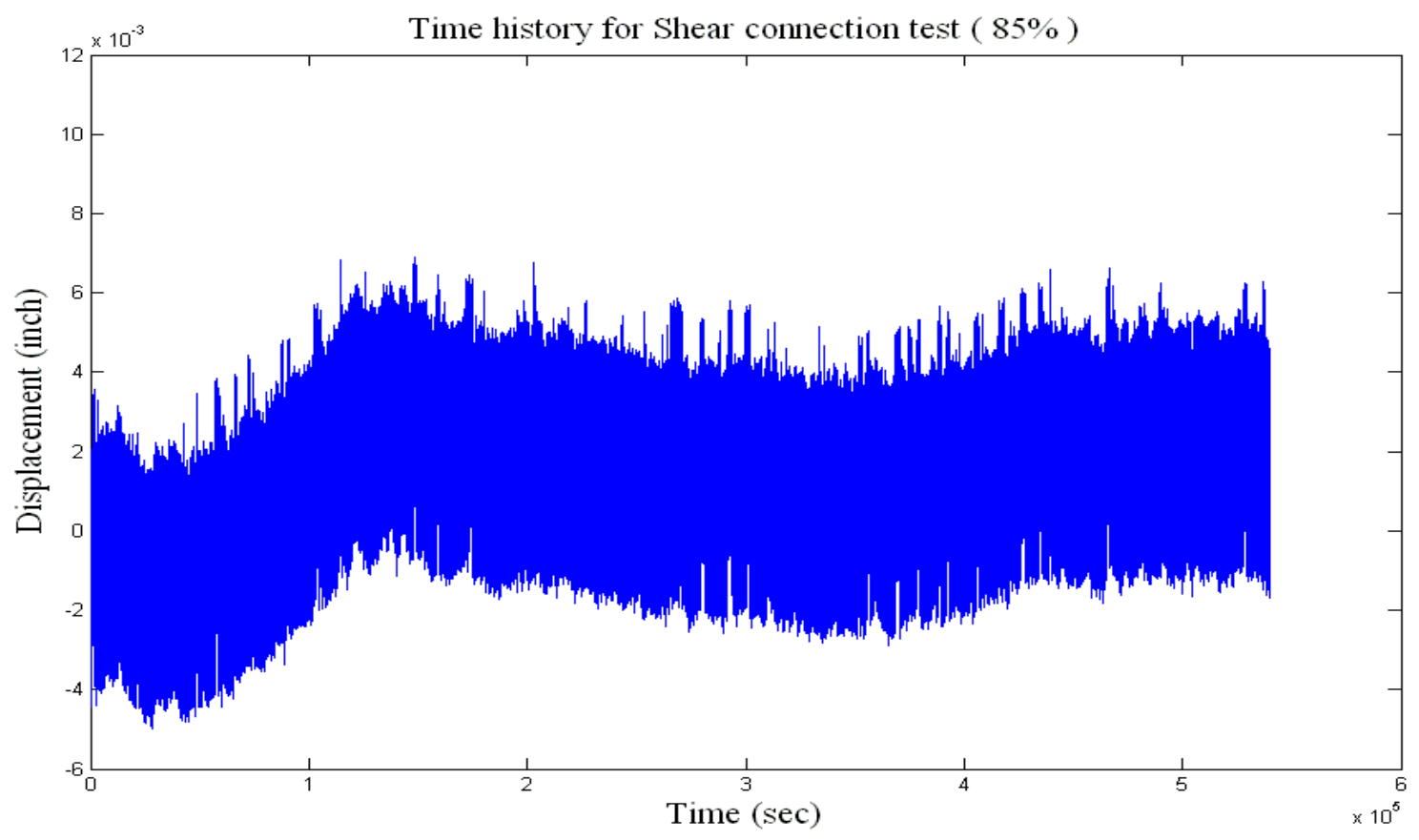

Figure 5-27 Time history of Shear connection test (85\% Filtered data) 


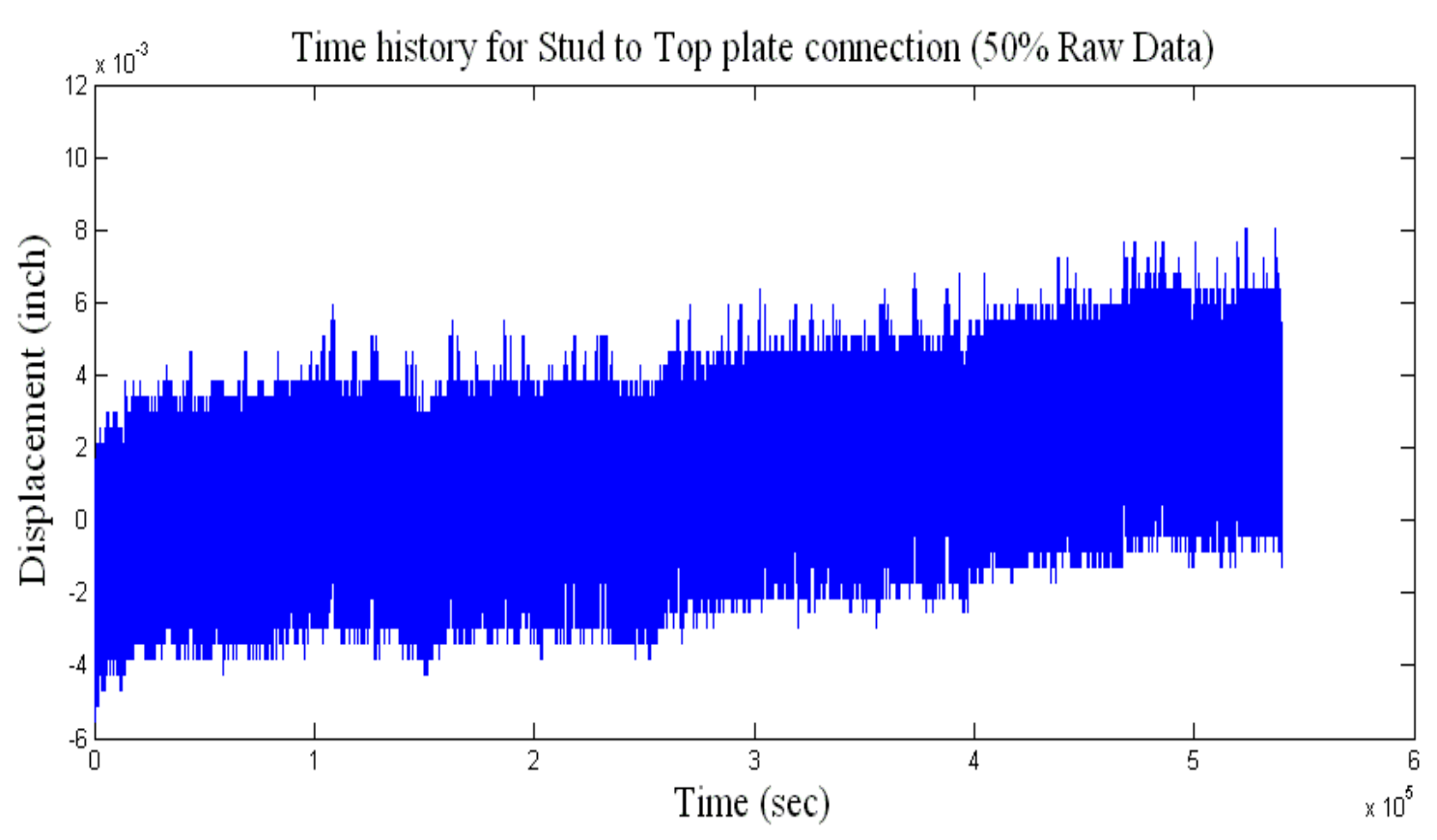

Figure 5-28 Time history of stud to top plate connection (50\% Raw Data)

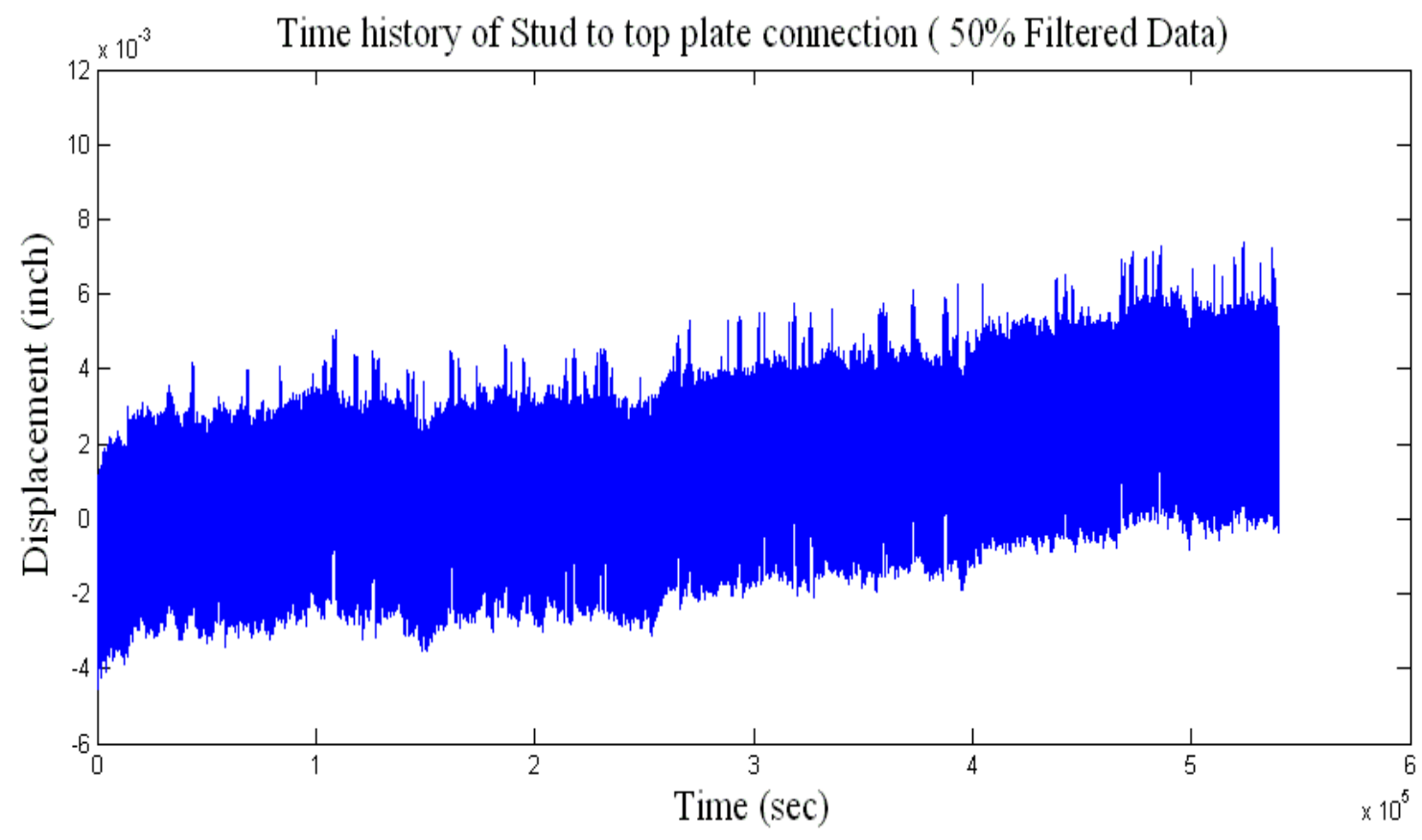

Figure 5-29 Time history of stud to top plate connection (50\% Filtered Data) 


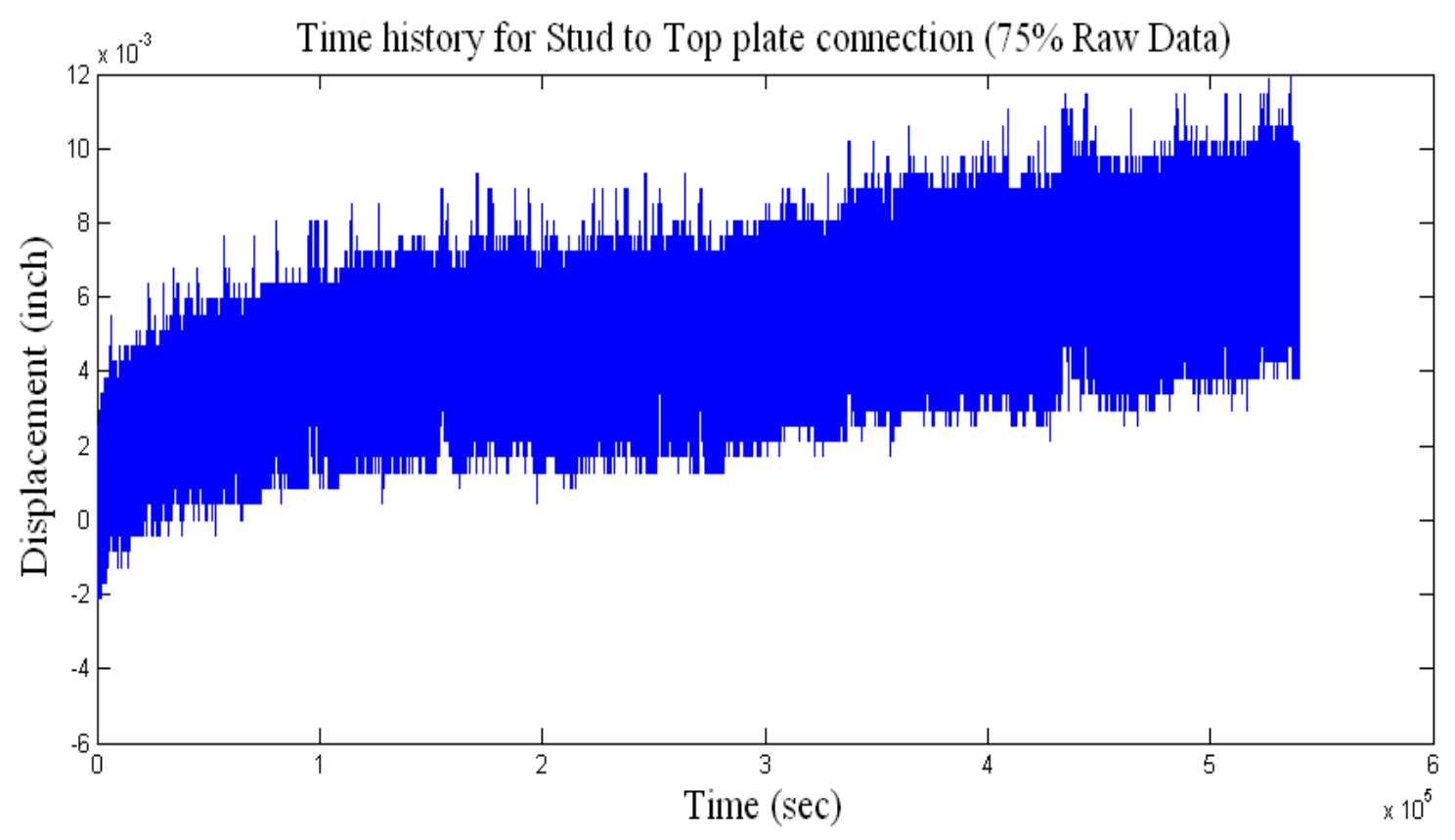

Figure 5-30 Time history of stud to top plate connection (75\% Raw Data)

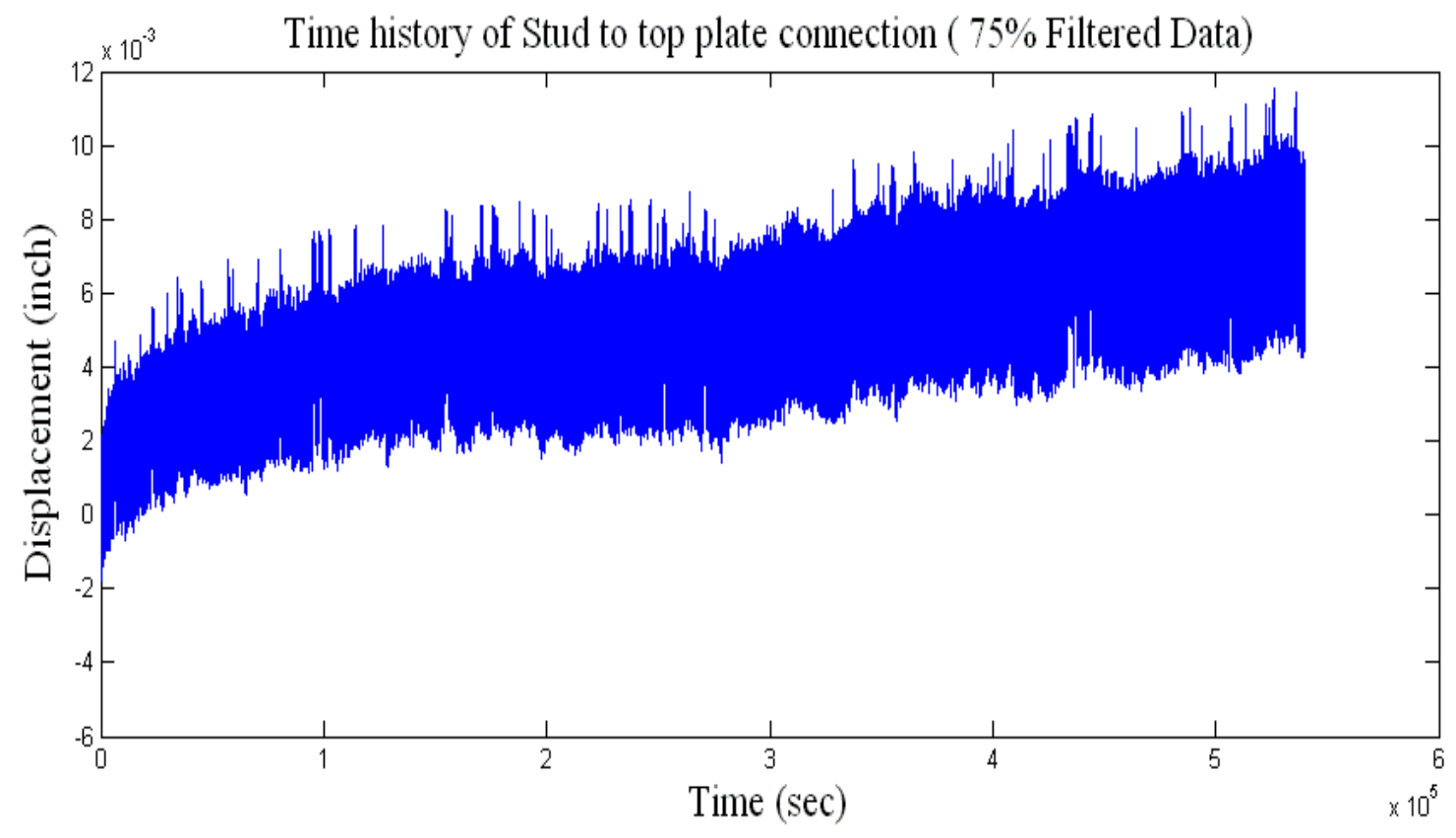

Figure 5-31 Time history of stud to top plate connection (75\% Filtered Data) 


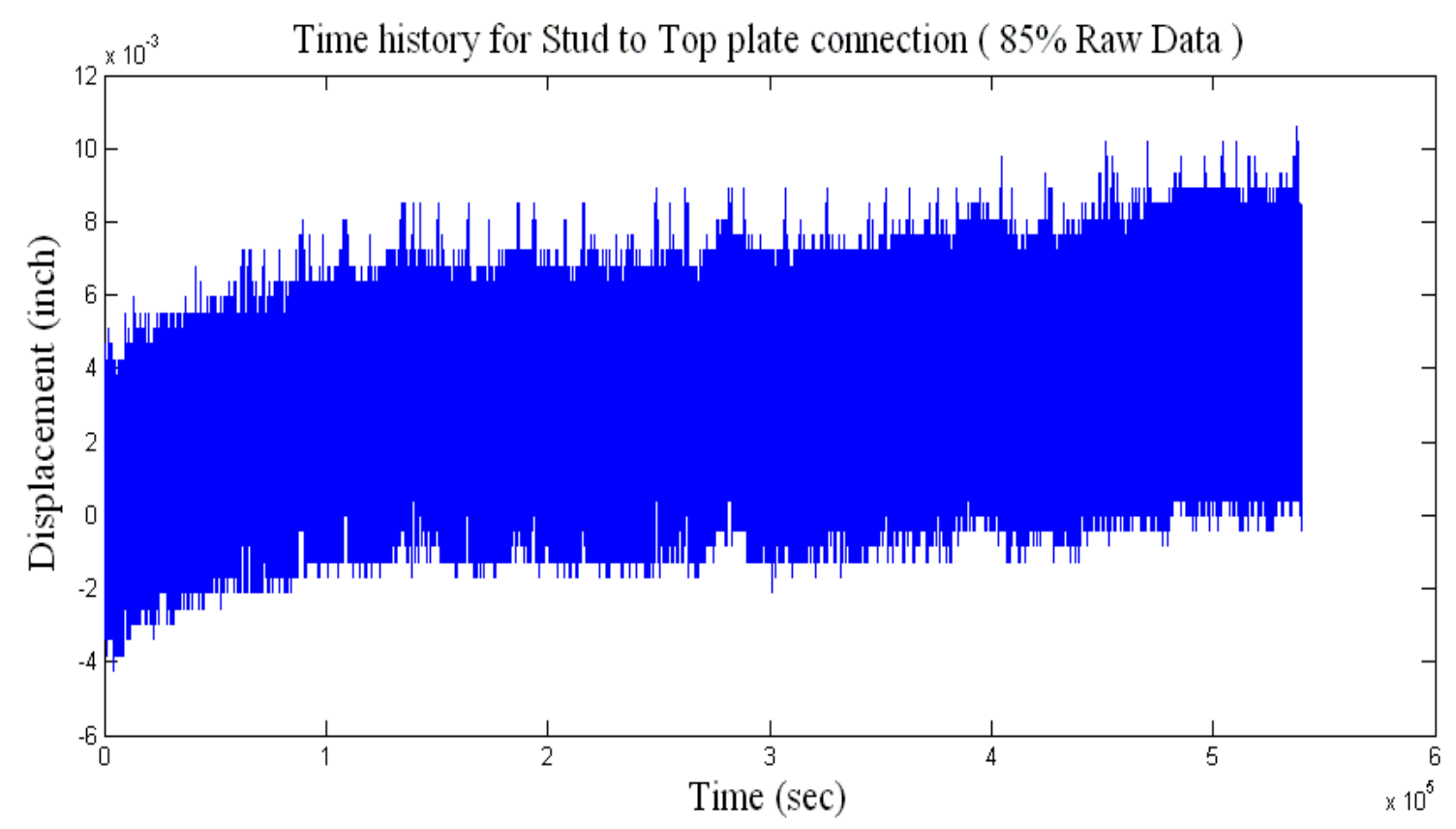

Figure 5-32 Time history of stud to top plate connection (85\% Raw Data)

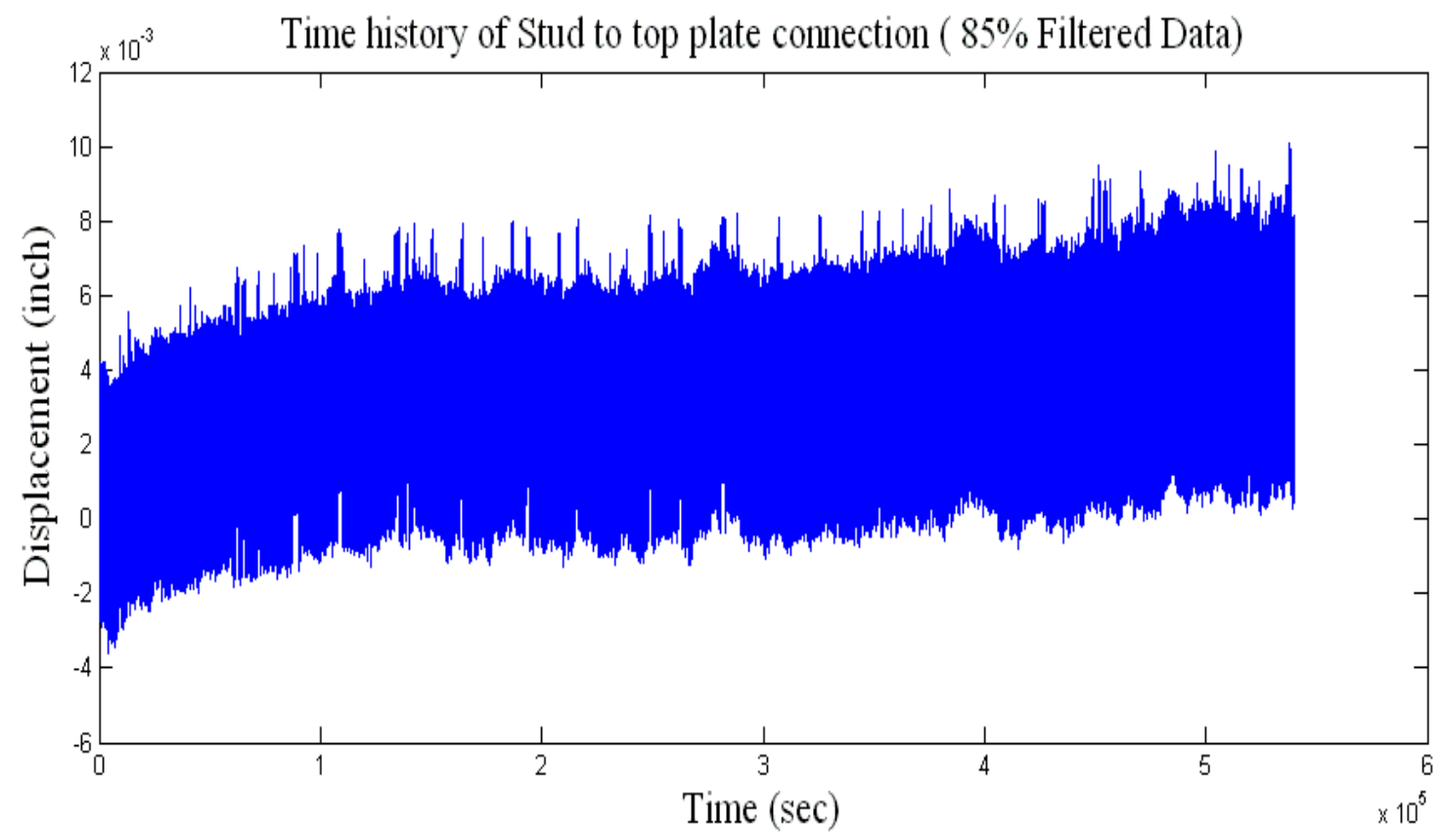

Figure 5-33 Time history of stud to top plate connection (85\% Filtered Data) 


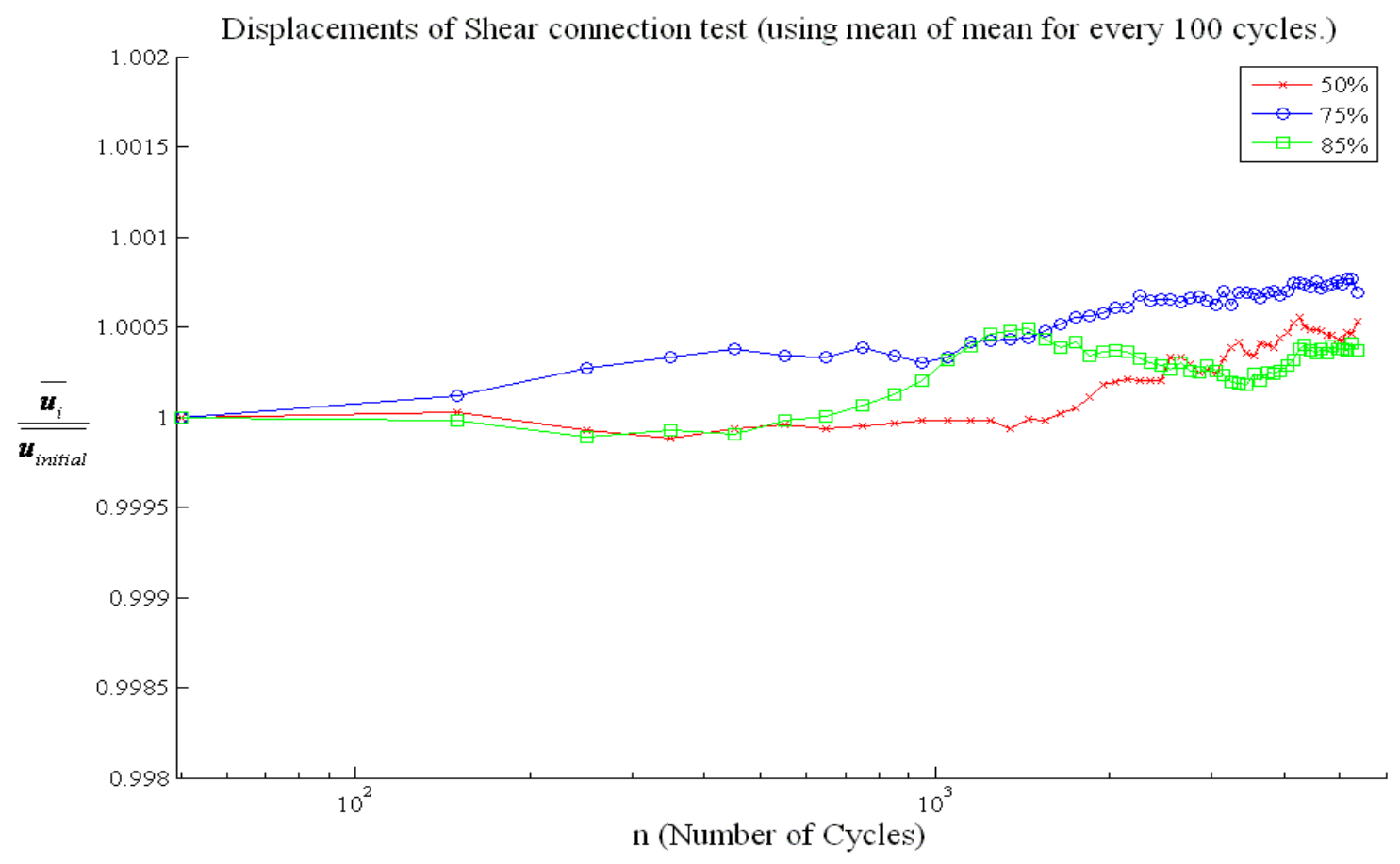

Figure 5-34 Displacement of Shear connection test using mean of means

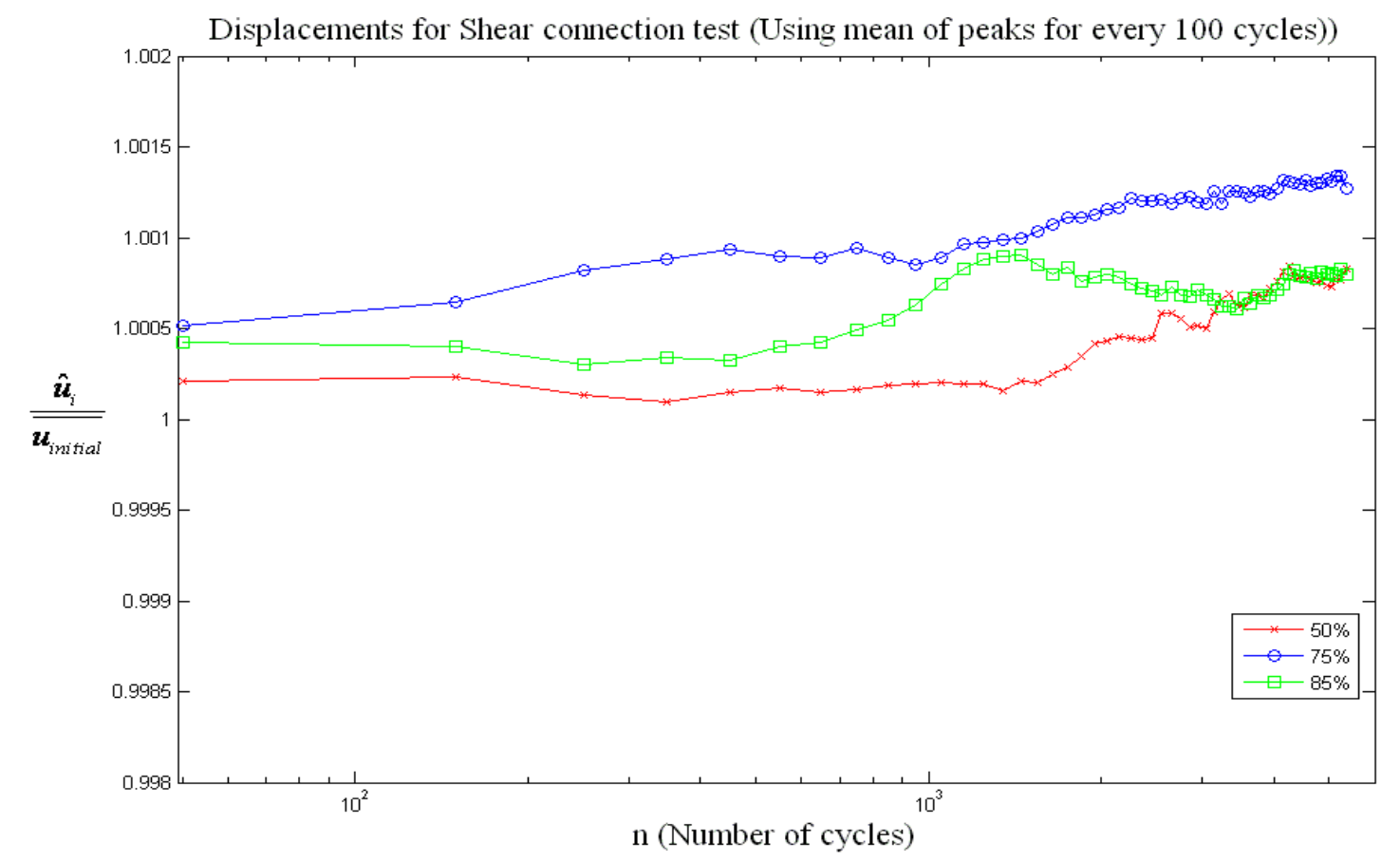

Figure 5-35 Displacement of Shear connection test using mean of peaks 
Displacements of Stud to Top plate connection (using mean of mean for every 100 cycles.)

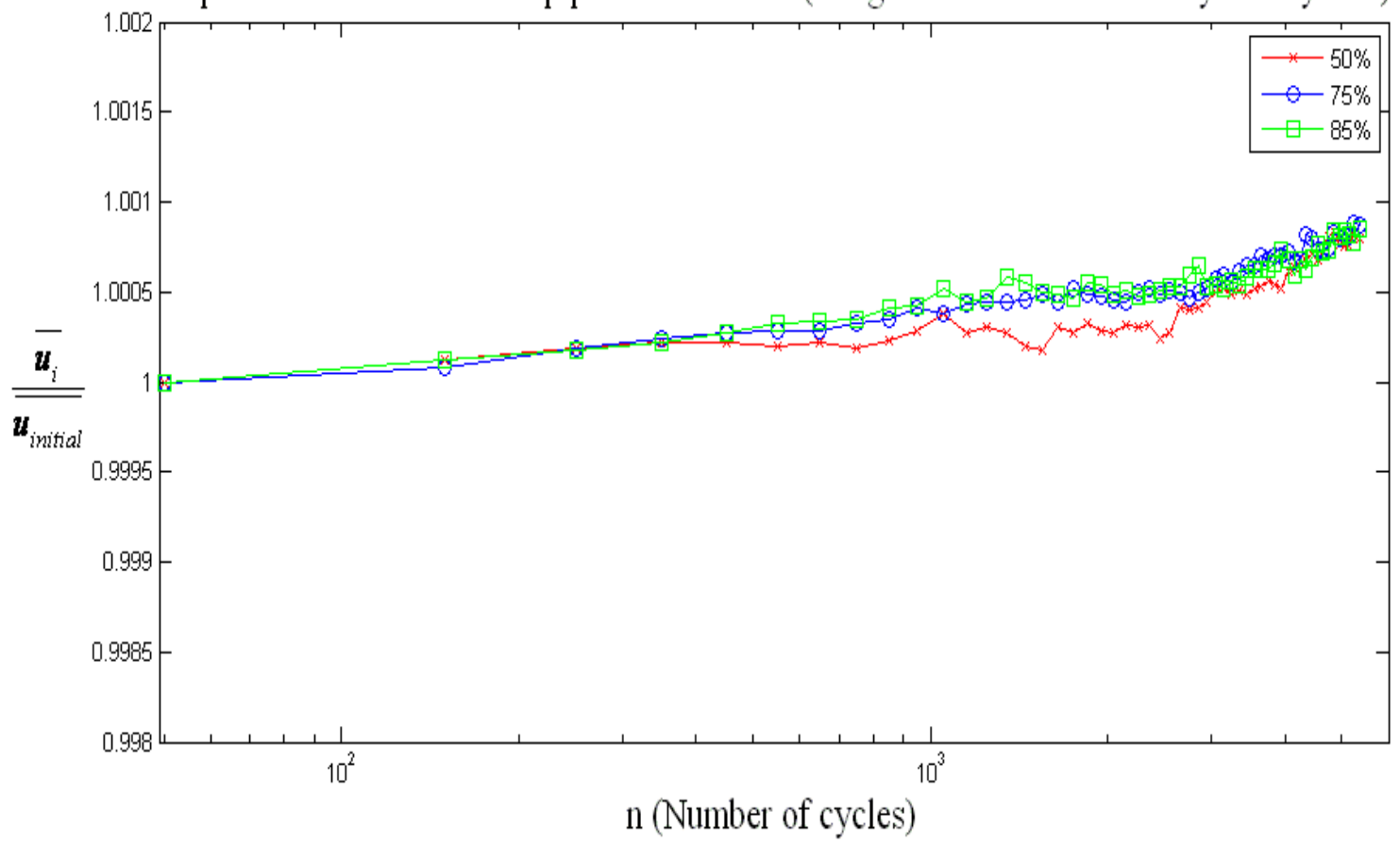

Figure 5-36 Displacement of Stud to Top plate connection using mean of means

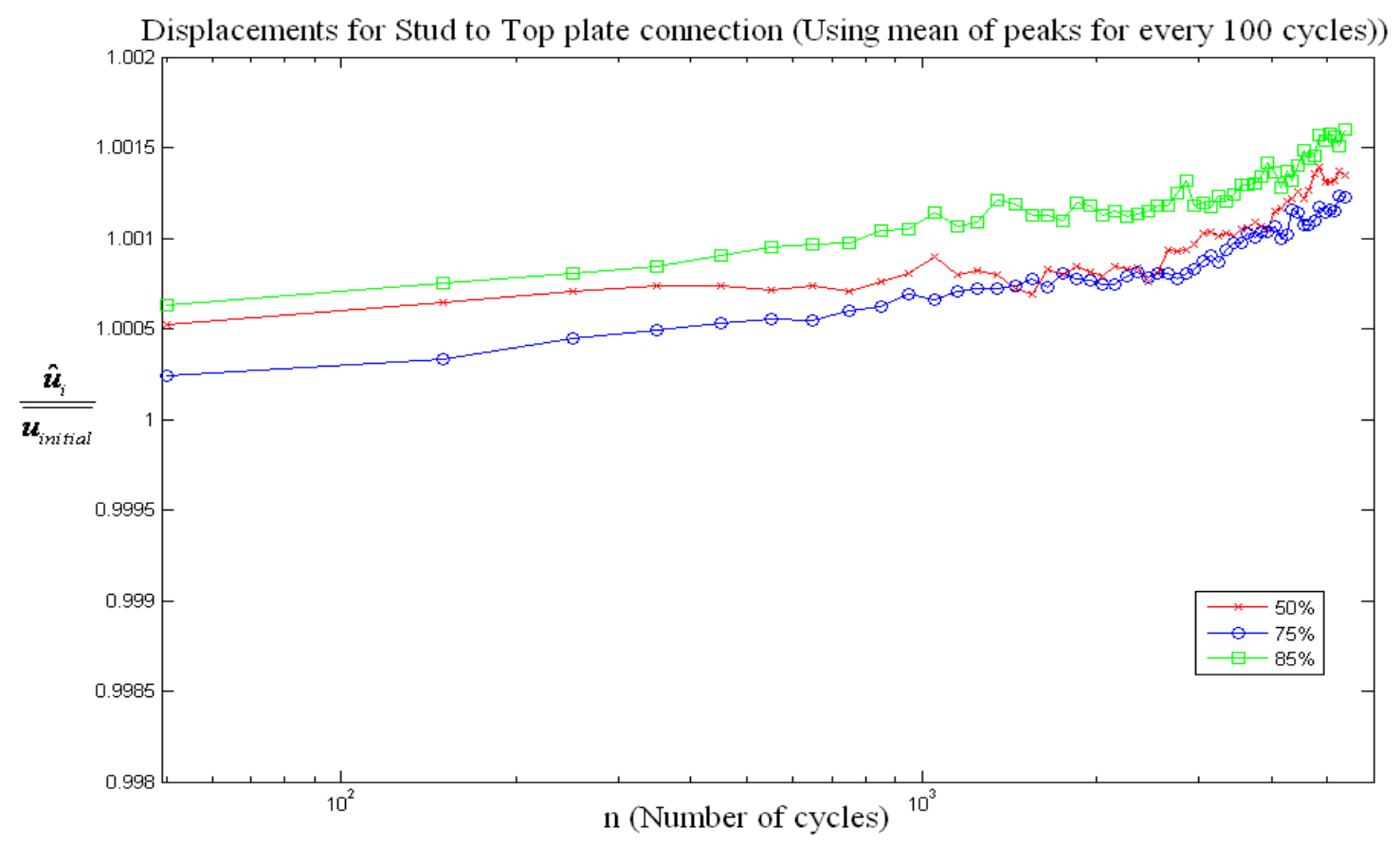

Figure 5-37 Displacement of Stud to Top plate connection using mean of peaks 


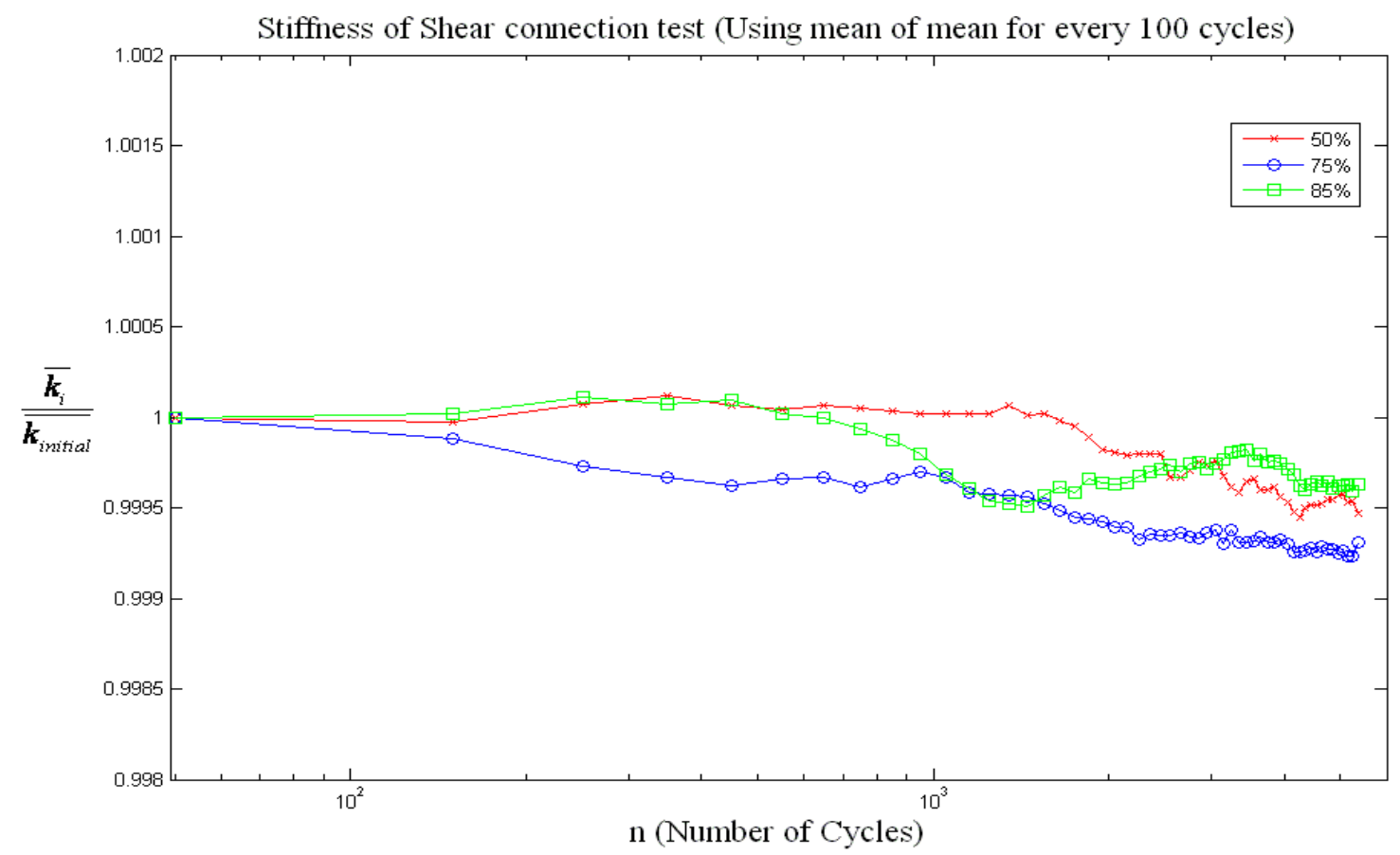

Figure 5-38 Stiffness of Shear connection test using mean of means

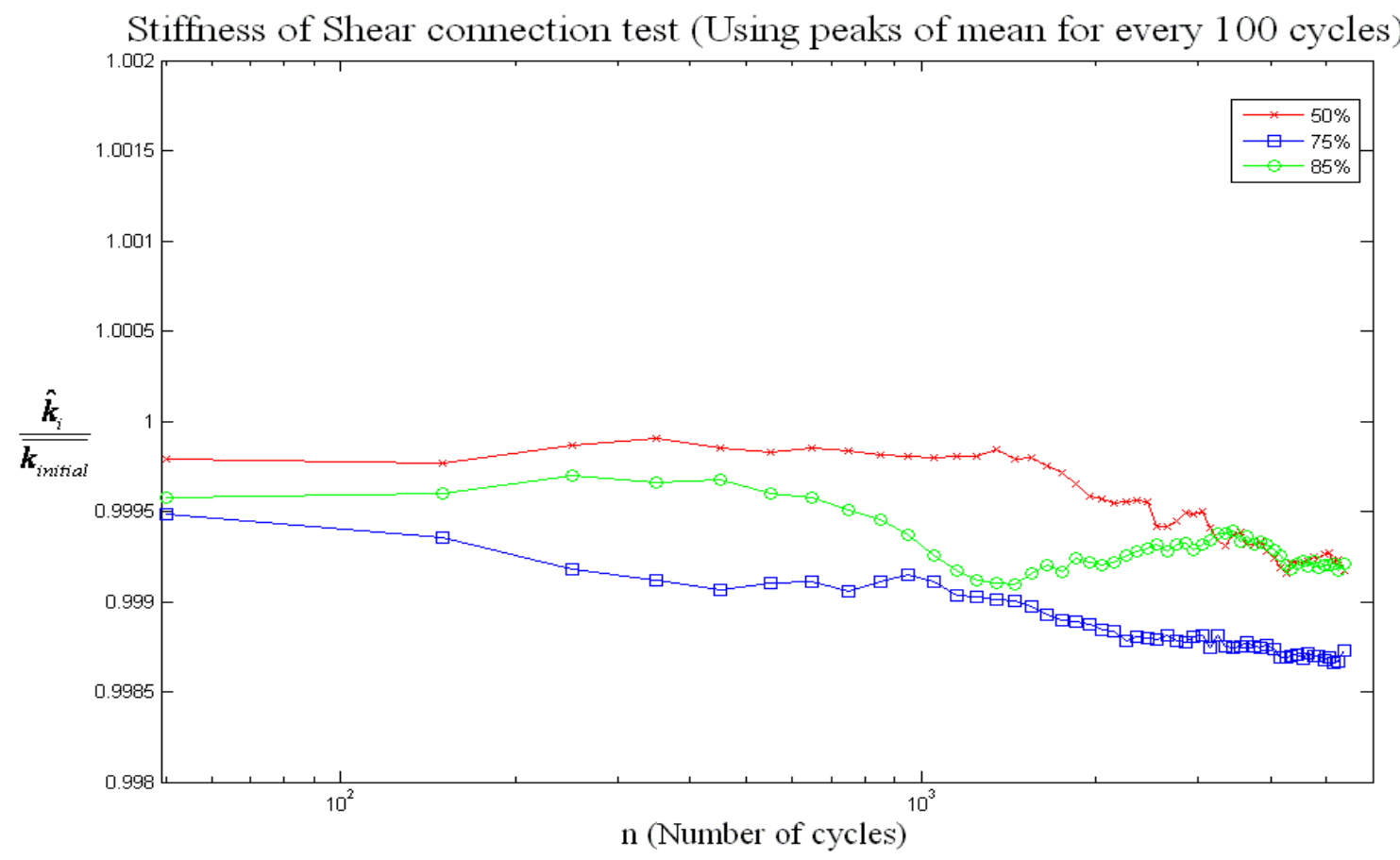

Figure 5-39 Stiffness of Shear connection test using mean of peaks 


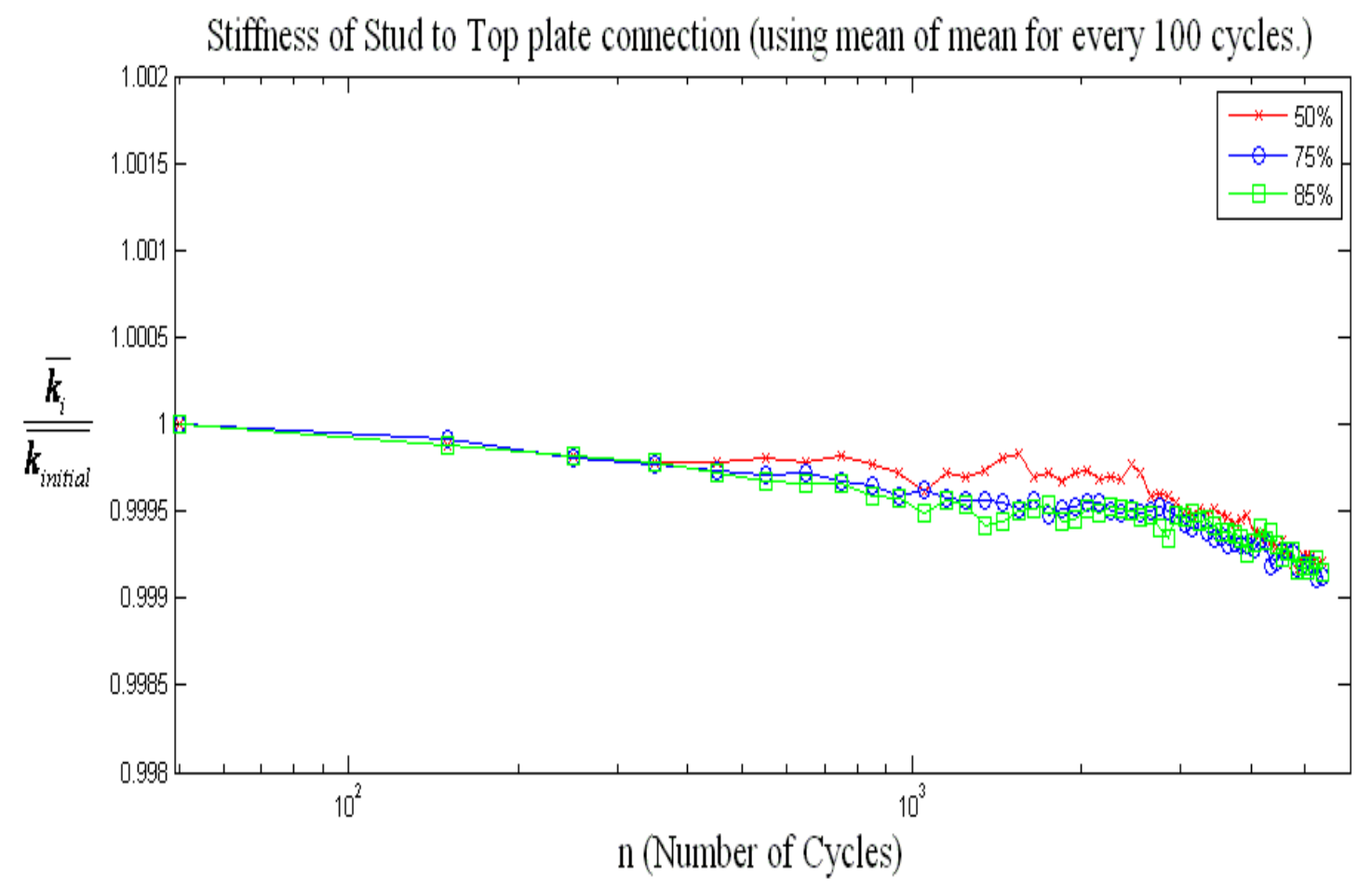

Figure 5-40 Stiffness of Stud to Top plate connection using mean of means

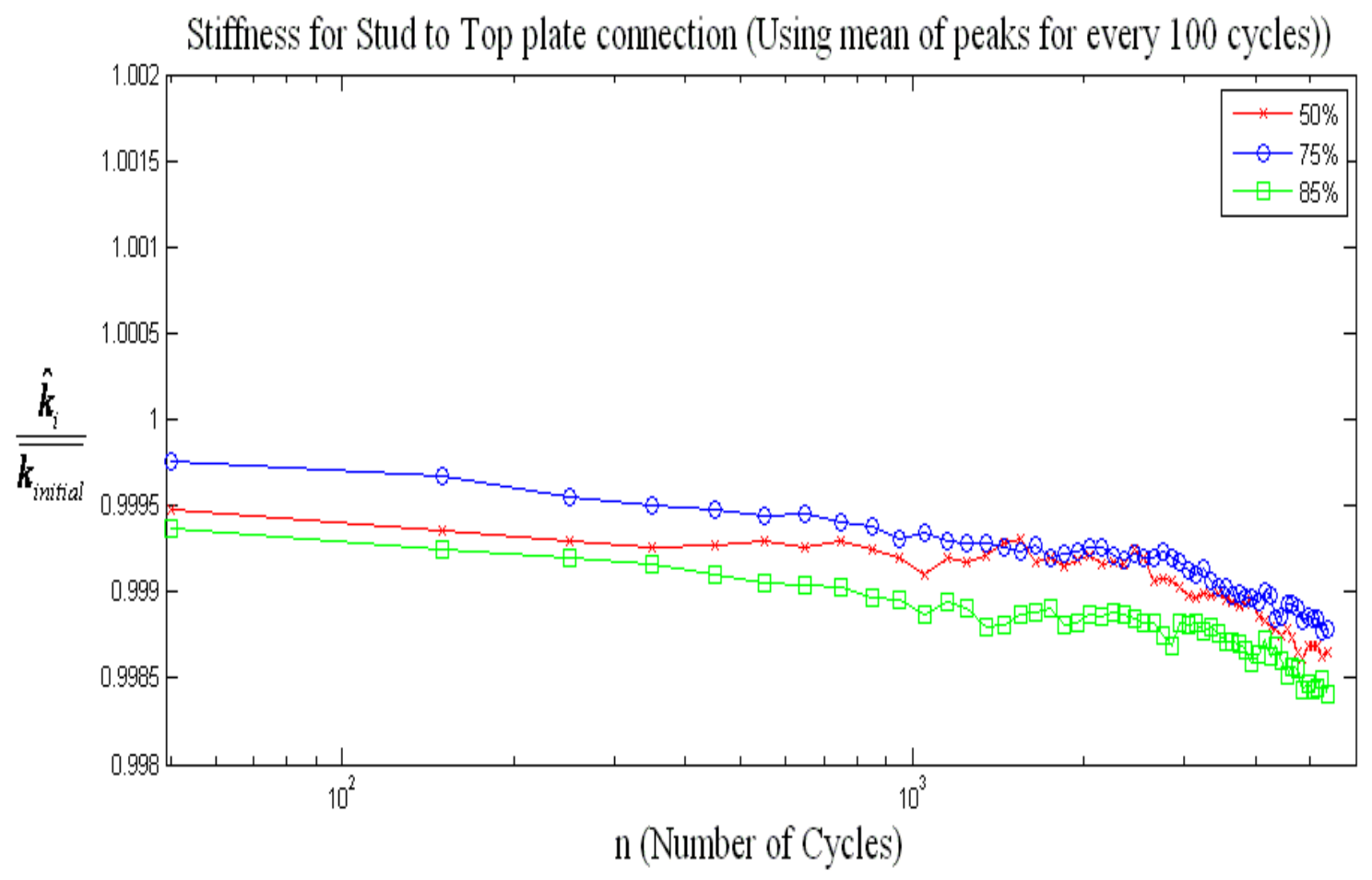

Figure 5-41 Stiffness of Stud to Top plate connection using mean of peaks 


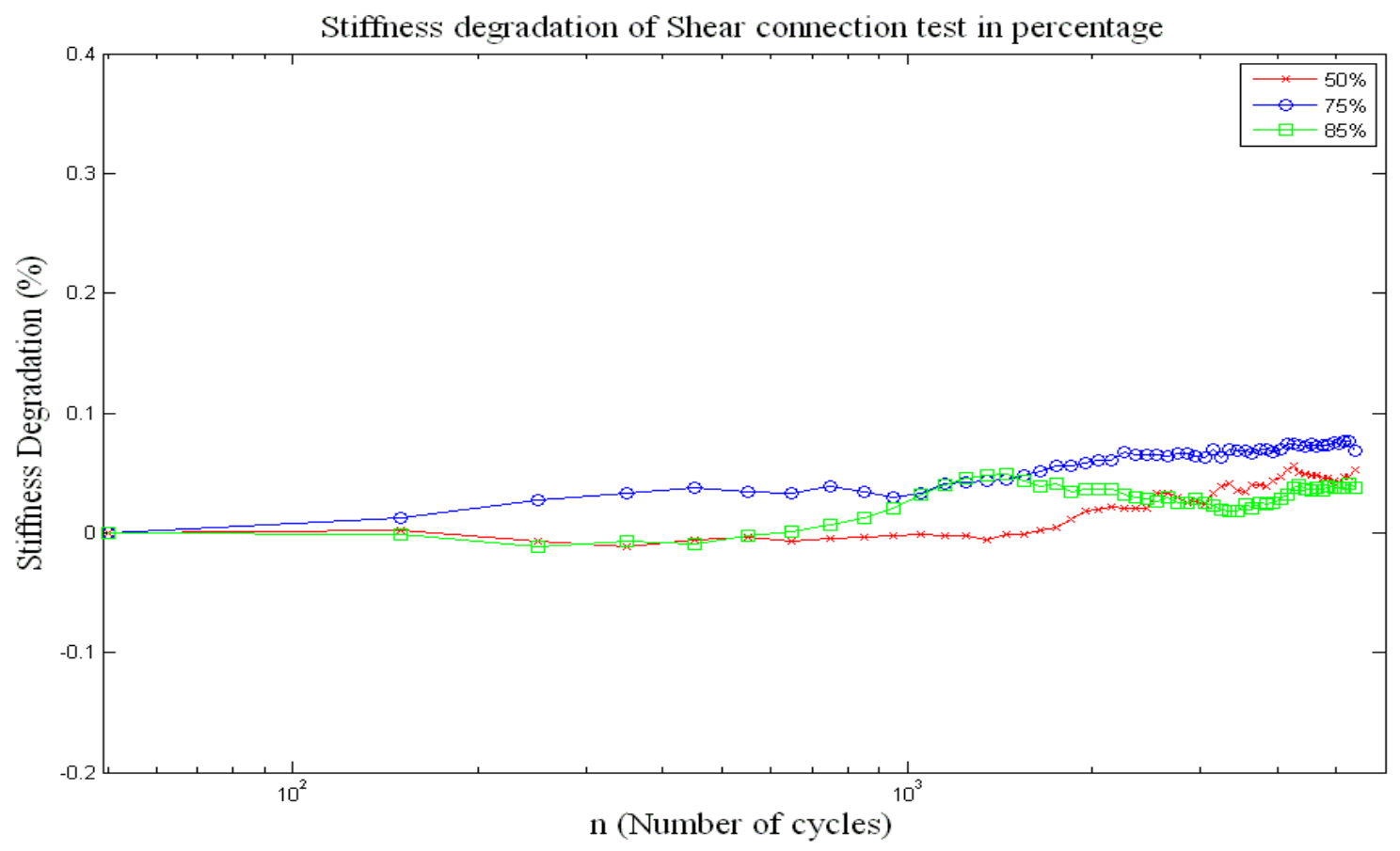

Figure 5-42 Stiffness degradation of shear connection test in percentage

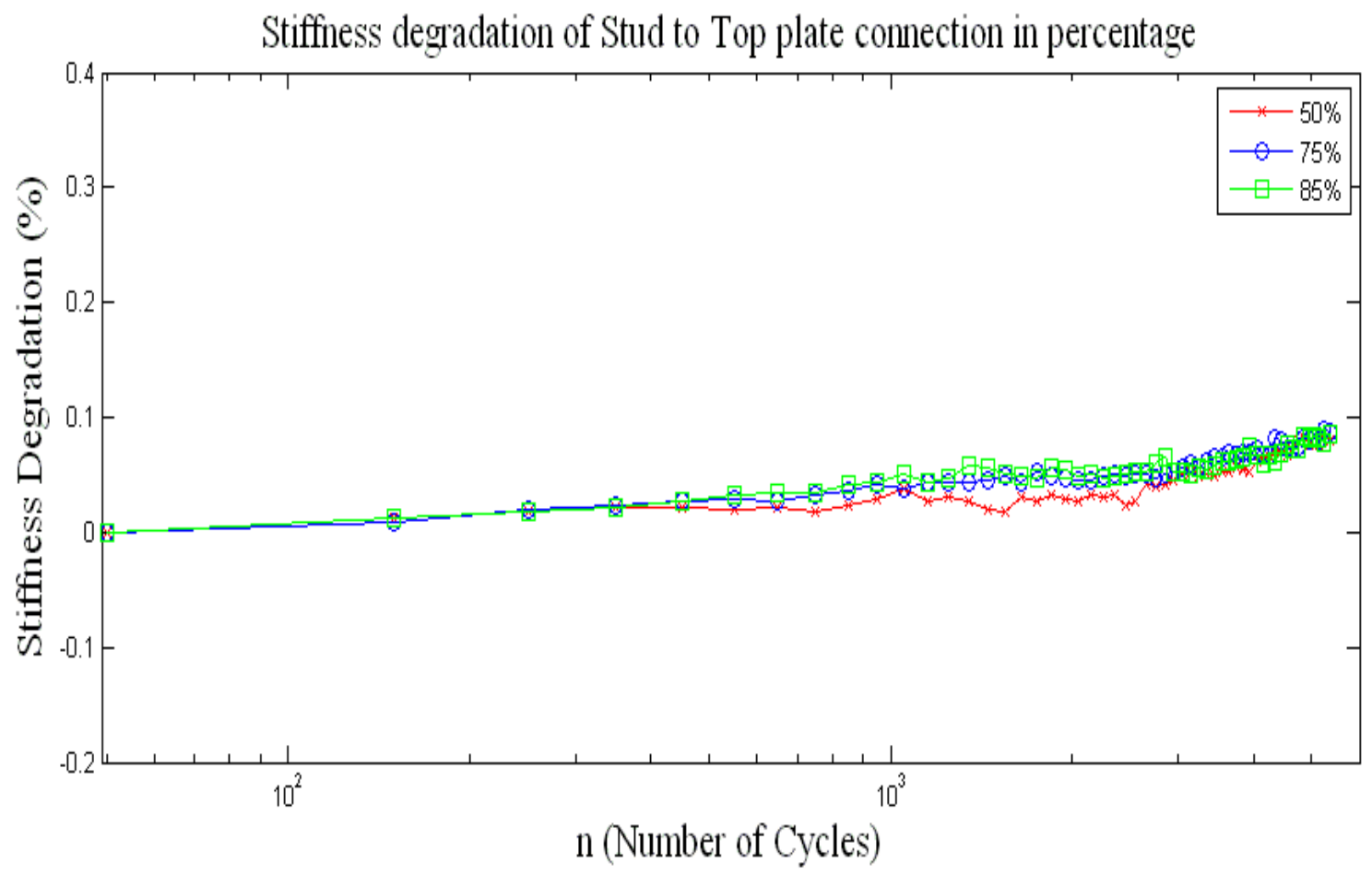

Figure 5-43 Stiffness degradation of Stud to Top plate connection in Percentage 


\section{Conclusions:}

The conclusions can be summarized as follows:

1) The current design practices may overestimate the capacity of the connections by as much as a factor of about two and can therefore be the cause of roof-towall connection failures in extreme wind events. The current research established the modified design approach and proposed a realistic relationship between the capacity of the connection joint and the number of fasteners in the joint.

2) In continuation of the research and development of FRP roof to wall connection (Canbek, 2009), two more FRP connections for stud to top plate and gable end were developed for the continuous load path. The results showed that the ultimate uplift capacity of stud to top plate connection and gable end connection were 2.1 and 1.13 times the capacity of particular metallic connections, respectively.

3) The detailed analysis of three hours sustained load-displacement data with different stress ratios proved test specimens experienced a decreasing creep rate and had a fractional deflection less than 2.0. This showed that short-term creep behavior was not manifested by such connections.

4) The detailed analysis of the dynamic load testing results proves that there was no degradation of the connections due to cyclic loading. Thus fatigue induced stresses on such connections as could be experienced due to wind speed fluctuations during hurricanes may not have significant effects. 
The above results indicated that the FRP connections are feasible alternatives to existing metal connections.

\section{Future Recommendations:}

The recommended future research consists of the followings:

1) The results of creep testing for the shear connection were non-conclusive due to the inadequacy of the shear connection test set up under sustained loading because of uncontrollable load distribution between the two FRP ties separated by a gap. A more effective test set up needs to be developed to perform such creep testing.

2) Due to the complexity of dynamic load testing a suitable set up for the gable end connection could not be developed. The set up used for static and creep loading was not rigid enough for performing the fatigue test. A new rigid test set up needs to be developed to perform fatigue testing of the gable end connection.

3) The developed FRP ties should be tested for the lateral strength as the connections are also subjected to the lateral loads.

4) Effect of moisture content of wood while applying the FRP ties should be studied as moisture content may affect the properties of epoxy adhesive.

5) Effect of temperature should also be studied as it is an important factor for the durability of the connections.

6) Effect of the species of wood should also be considered as that might influence the performance of the connections. 


\section{REFERENCES}

American Society of Testing and Materials (ASTM) (2006). Standard test methods for mechanical fasteners in wood, ASTM D 1761.

American Society of Testing and Materials (ASTM) (2006). Standard test methods for mechanical fasteners in wood, ASTM D 6815-02a.

Cetin Canbek., (2009). "Development of a hurricane-resistant roof-to-wall connection using high-performance fiber composites", Master's Thesis, Florida International University.

Classe, P., and Masse, B., (2006). "Joining timber with glass fiber and epoxy." Journal of Construction Materials (CMI), 159(14538), 11-17.

Crossett.K.M, Culliton.T.J, Wiley.P.R, Goodspeed.T.R. (2004). "Population trends along the coastal United States 1980-2008." Costal trend report series, National Oceanic and Atmospheric Administration (NOAA) project.

En1995-1-1:2004 Eurocode 5. Design of timber structures. Part 1-1 General. Common rules and rules for buildings. London: British Standards Institution.

Florida building code (FBC) (2007), Building (Chapter 23- Wood), Tallahassee, FL.

Florida Building Code (FBC) (2007). Building (Chapter 23 - Wood), Tallahassee, FL. Goldenburg, S.B., Landsea, C.W., Mestas-Nunez, A.M., and Gray, W.M. (2001). "The recent increase in Atlantic hurricane activity: causes and implications." Science, 293, 474-479.

Hacker CL, Ansell MP., (2001). "Fatigue damage and hysteresis in wood-epoxy laminates.” Journal of Material Sciences, 36(2461), 609-621.

Ivan Canino., (2009). “Aerodynamic load characteristics evaluation and multi-axial performance testing on fiber reinforced polymer connections and metal fasteners to promote hurricane damage mitigation", Dissertation, Florida International University.

Kropf, F., and Meierhofer, U. (2000). "Strengthening, retrofitting and upgrading of timber structures with high-strength fibers." Journal of the International Association for Bridge and structural Engineering (IABSE),10(3), 178-181.

Lindt. J.W.V.D, Graettinger.A.J, Gupta. R, Pryor.S.E.P, Skaggs.T.D.S, Fridley.K.J, (2005). "Damage Assessment of woodframe Residential structure in Hurricane Katrine.” Preliminary Report sponsored by National Science Foundation (NSF), Colorado State University. 
Mehta, K.C., Douglas, A.S., and Ronald, H.C. (1994). "knowledge-Based system for wind damage to buildings." In hurricanes of 1992, Ronald A.C. and Mehrdad S, Editors. New York: American Society of Civil Engineers.

Meierhofer,U.A.,(1999). "Bending and Tension jointing timber by use of High-Strength Fiber Materials", Schweizer Ingenier and Architekt, 117(43), 11-16.

Miyatake, A., Fujii, T. (1995). "Strength properties of epoxy-bonded joints for timber members with internal fiber-reinforced-plastic gusset plates." Mokuzai Gakkaishi. Japan wood research society, 41(4), 380-386

Nikolaos P and Thanasis C T, (1995). "Creep behavior of FRP-Reinforced wood member.," Journal of structural engineering (JSE), 121(2), 174-186.

P.Huang, A. Chowdhury, G. Bitsuamlak, R. Liu, Development of devices and methods for simulation of hurricane winds in a full-scale testing facility, Wind and structure, 12(2), 151-177.

Pinelli, J.P., Simiu, E., Gurley, K., Subramanian, C., Zhang, L., Cope, A., Filliben, J.J., and Hamid, S. (2004). "Hurricane damage prediction model for residential structures. "Journal of Structural Engineering ASCE., 10(1061), 1685-1691.

Prevatt.D.O. (2007) "Construction scale model roof-to-wall connections in residential construction for dissemination of hurricane mitigation techniques." South Carolina Sea Grant Consortium.

Reed, T.D., Rosowsky, D.V., and Schiff. S.D. (1997). "Uplift Capacity of light-frame Rafter to Top-plate connections," Journal of Architectural Engineering, ASCE, 3(4), 156-163.

Riley, M.A., and Sadek, F. (2003), "Experimental testing of roof-to-wall connection in wood frame houses," Technical Report NISTIR 6938, National Institute of standards and technology, Gaithersburg, MD.

Rosowsky, D.V., Reed, T.D., Tyner, K.G. (1998). "Establishing design values for uplift connections in light-frame construction." Journal of Testing and Evaluation, 26(5), 426 433.

Simpson Strong Tie, (2009) “Wood construction connectors 2009-2010, C-2009.

Simpson Strong Tie (2006). High Wind framing connection guide 2006, T-HWFCG06.

Steiger, R., (2002). "Fiber reinforced plastics (FRP) in timber structures- investigations and development." Proceedings of the Eurowood workshop 2002 on "Engineered wood products innovation and exploitation", VTT Helsinki, Finland. 
Sutherland, H.J., (1999). "On the fatigue analysis of wind turbines." SAND99-0089. Albuquerque, New Mexico: Sandia National Laboratories.

Testing report (August 1989), Uplift load capacity of Simpson Strong Tie strap anchor (SP4, SP6, SP8) prepared by Tei Consulting engineers. Work Request No 89008-48.

U.S. Departement of Housing and Urban Development (HUD), office of policy development and research. (1993). "Assessment of damage to single-family homes caused by hurricanes Andrew and Iniki.” Washington D.C., HUD. 